\title{
EFEITO DO CÁDMIO EM PLÂNTULAS E CALOS DE CANA-DE- AÇÚCAR: RESPOSTAS DO SISTEMA ANTIOXIDANTE
}

\author{
RICARDO FRANCISCO FORNAZIER
}

Biólogo

Orientador: Prof. Dr. RICARDO ANTUNES DE AZEVEDO

Dissertação apresentada à Escola Superior de Agricultura "Luiz de Queiroz", Universidade de São Paulo, para obtenção do título de Mestre em Agronomia. Área de concentração: Genética e Melhoramento de Plantas.

PIRACICABA

Estado de São Paulo - Brasil

Junho - 2000 
Dados Internacionais de Catalogação na Publicação (CIP) DIVISĀO DE BIBLIOTECA E DOCUMENTAÇĀO - Campus "Luiz de Queiroz"/USP

Fomazier, Ricardo Francisco

Efeito do cádmio em plântulas e calos de cana-de-açúcar: respostas do sistema antioxidante / Ricardo Francisco Fomazier. - - Piracicaba, 2000.

$81 \mathrm{p}$

Dissertaçāo (mestrado) - - Escola Superior de Agricultura Luiz de Queiroz, 2000.

Bibliografia.

1. Antioxidante 2. Cádmio 3. Calo 4. Cana-de-açúcar 5. Metal pesado 6. Plântula 7. Poluente 8. Poluição I. Título

CDD 633.61 


\section{OFEREÇO,}
À Deus pela luz e proteção e aos meus pais e minha esposa pelo apoio irrestrito, amor e compreensão dedicados

À minha filha Gabriela, doce, razão e alegria da nossa vida, 


\section{AGRADECIMENTOS}

À Deus.

Ao Prof. Dr. Ricardo Antunes de Azevedo, pela orientação, apoio e amizade.

À Profa. Dra. Maria Lúcia Carneiro Vieira pelo estímulo, apoio e oportunidade.

Ao Dr. William Lee Burnquist, Dr.Eugênio Cesar Ulian, Sidney Donizetti Ducatti, Daniela Pascon Vianna Braga da Copersucar pelo material biológico cedido e pela disponibilidade em me auxiliar prontamente neste trabalho.

À todos os professores com os quais um dia tive contato acadêmico e a todos os funcionários do Departamento de Genética, que de alguma forma ou outra me ajudaram.

À Dra. Salete A. Gaziola e Dra. Angela P. Vitória pela ajuda e apoio dispensados.

Aos meus amigos e companheiros do Laboratório de Genética Bioquímica de Plantas, especialmente Renato Rodrigues Ferreira, Guilherme José Gonçalves Pereira e Patrícia Felippe Cardoso.

Ao CNPq pela bolsa concedida.

À FAPESP pelo apoio financeiro ao projeto. 


\section{SUMÁRIO}

Página

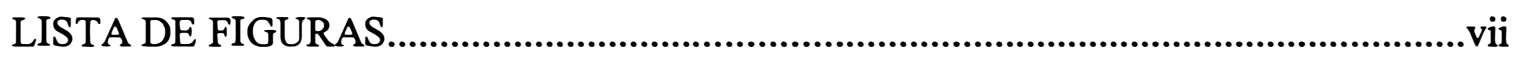

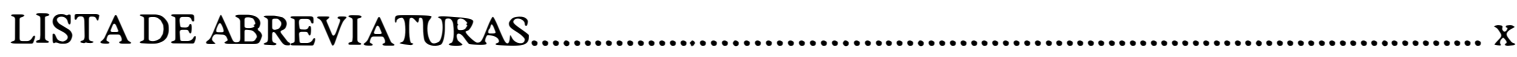

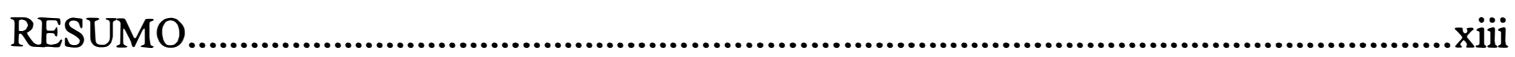

SUMMARY

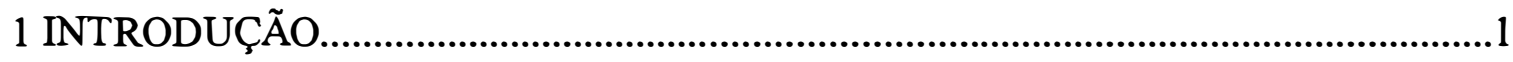

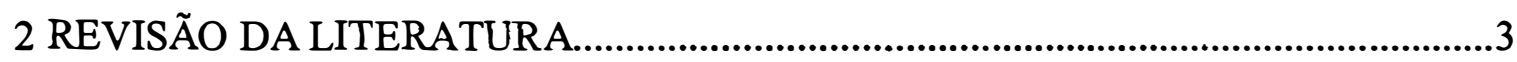

2.1 Poluentes atmosféricos e monitoramento....................................................................

2.2 Metais pesados: contexto e características................................................................

2.3 Respostas das plantas aos metais pesados.................................................................10

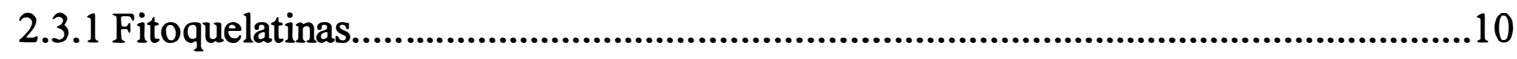

2.3.2 Compostos e enzimas antioxidantes em circunstâncias oxidativas............................15

2.3.2.1 Superóxido dismutase..................................................................................18

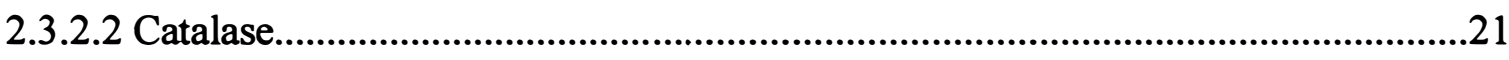

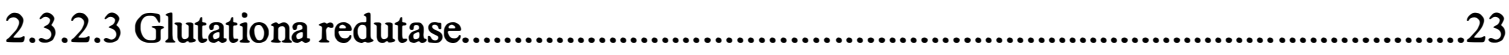

2.4 Enzimas antioxidantes como indicadores do estresse por poluição..............................26

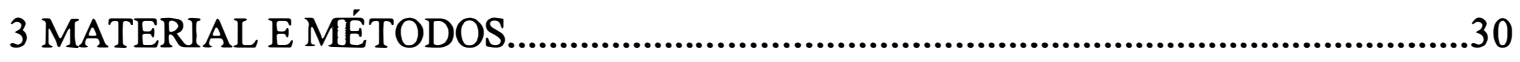

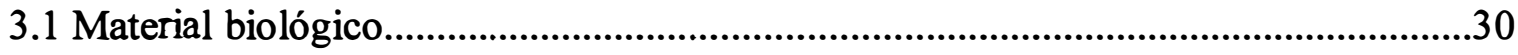




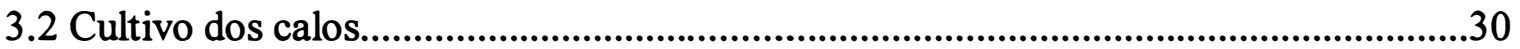

3.3 Cultivo das plântulas.................................................................................................31

3.4 Cromatografia de camada delgada para aminoácidos.......................................................31

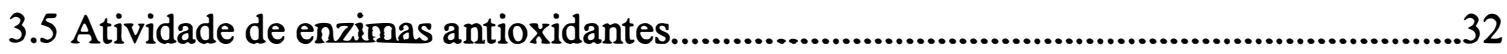

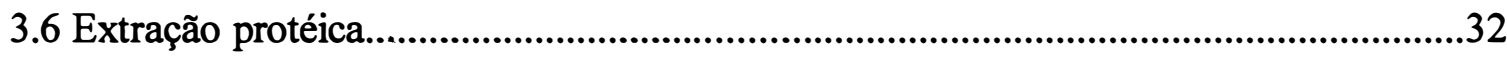

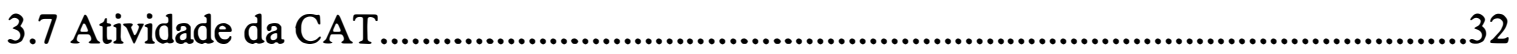

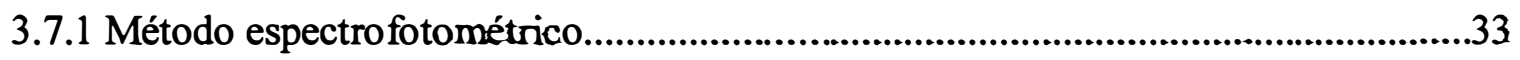

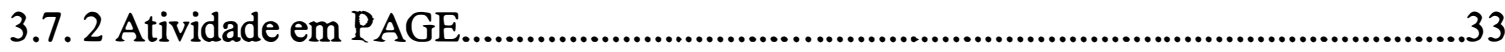

3.8 Atividade da GR

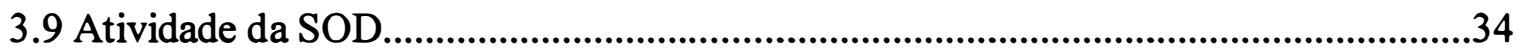

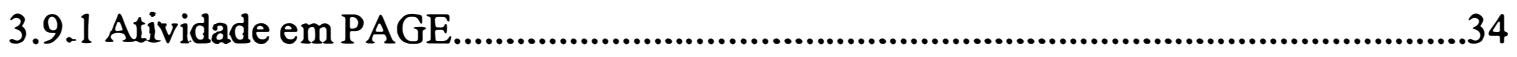

3.9.2 Determinação das isoenzimas de SOD......................................................................35

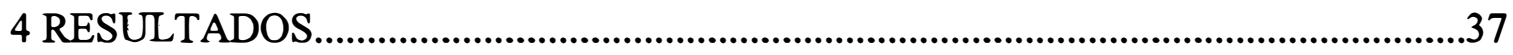

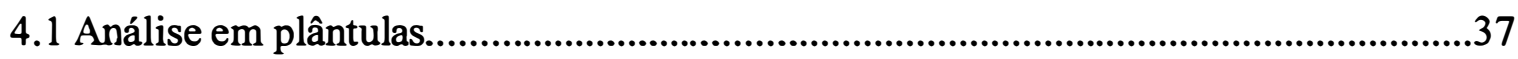

4.1.1 Determinação da concentração fitotóxica de Cd...........................................................37

4.1.2 Atividade da CAT por espectrofotometria ................................................................39

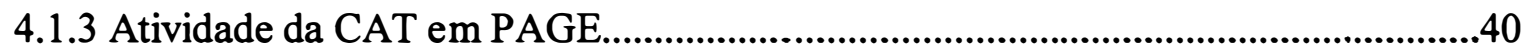

4.1.4 Atividade da SOD em PAGE.............................................................................

4.1.5 Atividade da GR por espectrofotometria..................................................................42

4.2 Resultados em calos de cana-de-açúcar........................................................................44

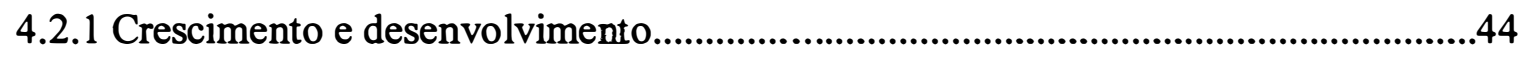

4.2.2 Experimento preliminar.....................................................................................45

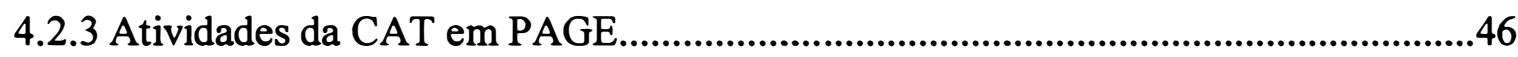




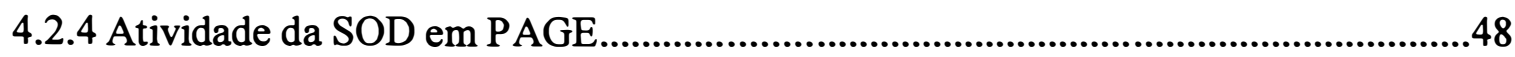

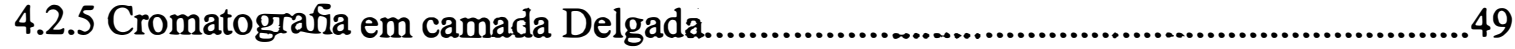

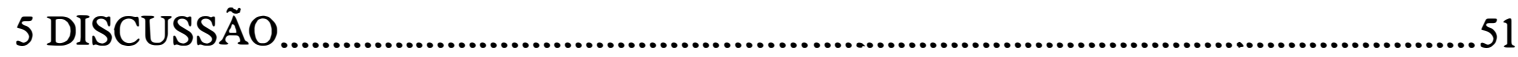

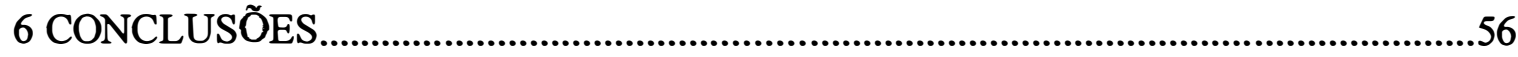

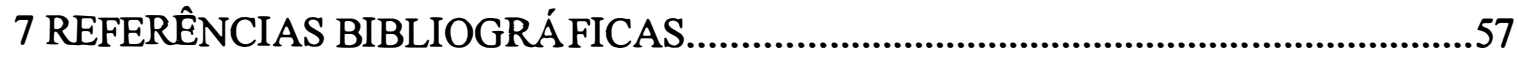




\section{LISTA DE FIGURAS}

Figura 1. Esquema da reação catalisada pela GR no ciclo da Glutationa-

Página

Ascorbato

Figura 2. Esquema da via de limpeza de EAOs.

Figura 3. Esquema do sistema de hidroponia (A) e plântulas de cana-deaçúcar em sistema de hidroponia (B)

Figura 4. Seqüência de imagens de 3 plântulas de cana-de-açúcar crescidas em sistema de hidroponia, submetidas à tratamentos com $\mathrm{CdCl}_{2}$

Figura 5. Atividade específica de CAT ( $\mu \mathrm{mol} / \mathrm{min} / \mathrm{mg}$ prot) em folhas de plântulas de cana-de-açúcar submetidas à diferentes concentrações de $\mathrm{CdCl}_{2}$

Figura 6. Atividade de $\mathrm{CAT}$ em PAGE não-desnaturante, de plântulas submetidas a tratamentos com (A) $2 \mathrm{mM}$ e (B) $5 \mathrm{mM}$ de $\mathrm{CdCl}_{2}$

Figura 7. Atividade de SOD determinada em PAGE não-desnaturante em folhas de plântulas de cana-de-açúcar, submetidas à tratamentos com (A) 0 
$\mathrm{mMe}$ (B) $2 \mathrm{mM}$ de $\mathrm{CdCl}_{2}$

Figura 8. Atividade de SOD determinada em PAGE não-desnaturante em folhas de plântulas de cana-de-açúcar, submetidas à $5 \mathrm{mM}$ de $\mathrm{CdCl}_{2}$.

Figura 9. Atividade específica de GR ( $\mu \mathrm{mol} / \mathrm{min} / \mathrm{mg}$ prot) em folhas de plântulas de cana-de-açúcar submetidas à diferentes concentrações de $\mathrm{CdCl}_{2}$

Figura 10. Efeito do $\mathrm{Cd}$ no crescimento de calos de cana-de-açúcar que foram crescidos por 15 dias em meio de cultura acrescido de (A) $0,0 \mathrm{mM}$ e (B) $1 \mathrm{mM}$ de $\mathrm{CdCl}_{2}$

Figura 11. Peso fresco de calos de cana-de-açúcar submetidos a várias concentrações de $\mathrm{CdCl}_{2}$ por 15 dias.

Figura 12. Atividade específica de CAT ( $\mu \mathrm{mol} / \mathrm{min} / \mathrm{mg}$ prot) calos de canade-açúcar submetidas à diferentes concentrações de $\mathrm{CdCl}_{2}$

Figura 13. Atividade de CAT determinada em PAGE não desnaturante em calos de cana-de-açúcar submetidos à tratamentos com $0,1 \mathrm{mM}$ e $1,0 \mathrm{mM}$ de $\mathrm{CdCl}_{2}$

Figura 14. Atividade de SOD determinada em PAGE não-desnaturante, em calos de cana-de-açúcar submetidos a tratamentos com $0,1 \mathrm{mM}$ e $1,0 \mathrm{mM}$ de $\mathrm{CdCl}_{2}$ 
Figura 15. Cromatografia de Camada Delgada para aminoácidos. solúveis de calos de cana-de-açúcar expostos à vários tratamentos com

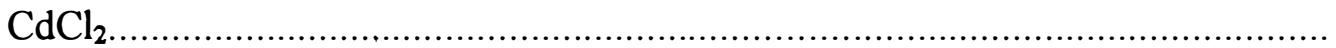

Figura 16. Caracterização das isoformas de $\mathrm{SOD}$ em calos e plântulas de cana-de-açúcar determinada em não-

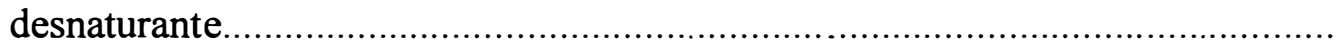




\section{LISTA DE SIGLAS, ABREVIATURAS E SÍMBOLOS}

2,4-D = ácido diclorofenoxiacético

$\gamma$-Glu-Cys = gama-glutamilcisteína

$\beta$-Ala $=$ beta-alanina

${ }^{\mathrm{I}} \mathrm{O}_{2}=$ oxigênio "singlet"

a.a. $=$ aminoácido

$\mathrm{AA}=$ ascorbato

$\mathrm{ABA}=$ ácido abcísico

$\mathrm{APX}=$ ascorbato peroxidase

$\mathrm{BSA}=$ soro albumina bovina

$\mathrm{BSO}=$ butionina sulfoximina

cad I = loco mutante para fitoquelatina

$\operatorname{cad} 2=$ loco mutante para fitoquelatina

$\mathrm{CAT}=$ catalase

Cat $l=$ gene codificante da isoforma de catalase 1

Cat $2=$ gene codificante da isoforma de catalase 2

Cat $3=$ gene codificante da isoforma de catalase 3

$\mathrm{Cd}=$ cádmio

$\mathrm{CdCl}_{2}=$ cloreto de cádmio

$\mathrm{CDNA}=$ DNA complementar

$\mathrm{CdSO}_{4}=$ sulfato de cádmio

$\mathrm{Cr}=$ crômio

CTC $=$ Centro de Tecnologia da Cana 
$\mathrm{Cu} / \mathrm{Zn}-\mathrm{SOD}=$ cobre/zinco superóxido dismutase

d.d = deionizada

$\mathrm{DHA}=$ desidroascorbato

$\mathrm{DHAR}=$ desidroascorbato redutase

$\mathrm{DTNB}=5,5$ "- ditiobis (2- ácido nitrobenzóico)

DTT $=$ ditiotreitol

EAOs = espécies ativas de oxigênio

EDTA = ácido etileno diamino tetracético

$\mathrm{FAD}=$ flavina adenina dinucleotídeo

$\mathrm{FADH}=$ flavina adenina dinucleotídeo reduzida

$\mathrm{Fe}=$ ferro

$\mathrm{FeCl}_{3}=$ cloreto férrico

$\mathrm{Fe}-\mathrm{SOD}=$ ferro superóxido dismutase

Gly = glicina

$\mathrm{GP}=$ guaiacol peroxidase

$\mathrm{GR}=$ glutationa redutase

$\mathrm{GSH}=$ glutationa reduzida

GSH2 = gene codificante da GSH

GSSG = glutationa oxidada

$\mathrm{H}_{2} \mathrm{O}=$ água

$\mathrm{H}_{2} \mathrm{O}_{2}=$ peróxido de hidrogênio

$\mathrm{Hg}=$ mercúrio

HMBPs = proteínas ligadas à metais

$\mathrm{K}_{3} \mathrm{Fe}\left(\mathrm{CN}_{6}\right)=$ ferricianeto de potássio

$\mathrm{KCN}=$ cianeto de potássio

LHC = "Light harvesting complex"

$\mathrm{MDA}=$ malonaldeído

MDHAR = monodesidroascorbato redutase

$\mathrm{Mn}=$ manganês

Mn-SOD = manganês superóxido dismutase 
$\mathrm{Mn}-\mathrm{SOD}=$ manganês superóxido dismutase

mRNA $=$ RNA mensageiro

MS = meio de cultura Murasige \& Skoog, (1962)

MT = proteína metalotioneína

MT-like = proteína análoga a metalotioneína

$\mathrm{NaCl}=$ cloreto de sódio

$\mathrm{NADPH}=$ nicotinamida adenina dinucleotídeo fosfato reduzida

$\mathrm{NBT}=$ nitro blue tetrazolium

$\mathrm{Ni}=$ níquel

$\mathrm{O}_{2}=$ oxigênio molecular

$\mathrm{O}_{2}{ }^{\circ}-=$ radical superóxido

$\mathrm{OH}^{*}=$ radical hidroxila

$\mathrm{PA}=$ persulfato de amônia

PAGE = eletroforese em gel de poliacrilamida

$\mathrm{Pb}=$ chumbo

PCs $=$ fitoquelatinas

$\mathrm{POX}=$ peroxidase

$\mathrm{PSl}=$ fotossistema $\mathrm{I}$

PSII = fotossistema II

$(\mathrm{p} / \mathrm{v})=$ proporção peso/volume

PVPP $=$ polivinil polipirrolidona

Ser $=$ serina

$\mathrm{SH}=$ grupo sulfidril

$\mathrm{SO}_{2}=$ dióxido de enxofre

$\mathrm{SOD}=$ superóxido dismutase

TEMED $=\mathrm{N}, \mathrm{N}, \mathrm{N}^{\prime}, \mathrm{N}^{\prime}$ - tetrametilenodiamina

TRIS $=$ Tris (hidroximetil)-Aminometano

$\mathrm{Zn}=$ zinco 


\title{
EFEITO DO CÁDMIO EM PLÂNTULAS E CALOS DE CANA-DE- AÇÚCAR: RESPOSTAS DO SISTEMA ANTIOXIDANTE
}

\author{
Autor: RICARDO FRANCISCO FORNAZIER \\ Orientador: Prof. DR. RICARDO ANTUNES DE AZEVEDO
}

\section{RESUMO}

Nas últimas décadas tem havido uma grande preocupação com os níveis de poluição ambiental, uma vez que esta tem causado problemas relativos a saúde humana e perdas significativas (de 5 a 30\%) na produção agrícola.

Poluentes atmosféricos como $\mathrm{CO}$ e $\mathrm{SO}_{2}$ são gerados pelas atividades humanas e industriais. A poluição por metais pesados, particularmente pelo cádmio (Cd), considerado um dos mais tóxicos é gerada principalmente pelas atividades de mineração e industriais, (manufatura de baterias, produção de fertilizantes, estabilização de plásticos), além de utilização de lodo de esgoto e fertilizantes fosfatados. Esses últimos contém o $\mathrm{Cd}$ em sua composição e sua utilização na agricultura tem aumentado a concentração desse metal no solo, plantas e reservas hídricas, o que pode aumentar a bioacumulação e biomagnificação via cadeia alimentar.

Os estudos relativos aos poluentes atmosféricos estão mais evoluídos quando comparados aqueles com metais pesados, embora estes tenham sido bastante estudados nos últimos anos. Por exemplo, um estudo realizado pelo CENA determinou que o nível 
de Cd no Rio Piracicaba é cerca de 10 vezes mais alto que o nível máximo aceitável. Existe porém a necessidade de intensificar pesquisas e determinar respostas gerais e específicas em diferentes culturas, bem como concentrações toleráveis no solo e alimentos .

Foi identificado um grupo de peptídeos denominados fitoquelatinas (PCs), capazes de se ligar aos íons de metais pesados, incluindo o $\mathrm{Cd}$ e assim desintoxicando as células pela diminuição dos íons livres no citoplasma. Entretanto, danos oxidativos freqüentemente ocorrem quando há exposição aos metais pesados, devido a intensificação na produção de espécies ativas de oxigênio (EAOs). Também uma classe de enzimas antioxidantes tem sido relatada no combate às EAOs e radicais livres decorrentes do estresse oxidativo. Plantas expostas aos metais pesados apresentam alterações nas atividades dessas enzimas. Portanto o estudo dessas alterações pode fornecer dados importantes relativos aos níveis de tolerância, especificidade da resposta em diferentes espécies e níveis de poluição no ambiente. Esses dados podem ser úteis em programas de melhoramento para obtenção de plantas mais tolerantes, além de estudos relacionados a bioacumulação e fitorremediação, uma vez que plantas tolerantes podem ajudar a diminuir a quantidade de metais nos solos contaminados.

Neste trabalho, foram observadas alterações na atividade da CAT em plântulas e calos e na atividade da GR em plântulas, onde ocorreu um aumento expressivo. A atividade da SOD não apresentou alterações significativas em nenhum dos tecidos analisados.

Estes resultados sugerem que o mecanismo principal para a defesa no estresse por Cd foi o aumento na síntese de GSH para uma conseqüente indução de fitoquelatinas, ou ação antioxidante direta da própria GSH. E ainda que a geração de radicais superóxido não foi significativamente aumentada ou que o nível basal de SOD tenha sido suficiente para combater os radicais eventualmente gerados.

Em calos é provável que o principal mecanismo antioxidante mobilizado foi a indução do aumento na atividade da CAT. 


\section{EFFECT OF CADMIUM IN SEEDLINGS AND CALLUS OF SUGAR CANE: RESPONSES OF ANTIOXIDANT SISTEM}

Author: RICARDO FRANCISCO FORNAZIER

Adviser: Prof. Dr. RICARDO ANTUNES DE AZEVEDO

\section{SUMMARY}

In the last for decades there has been a great deal of concern with environmental pollution levels, due to the suported problems to human healt and decrease (5 a 30\%) in agricultural yield.

Atmospheric pollutants such as $\mathrm{CO}$ AND $\mathrm{SO}_{2}$, are produced by human and industrial activities. Heavy metal pollution, mainly by cádmium (Cd), which is considered one of the more toxic, is generated by mining and industrial activities, and sewage sludge and phosphated fertilizers used in agriculture. the latter contains $\mathrm{Cd}$ in its composition and with continuous agricultural utilization an increase in the heavy metals levels in soils, plants and water sources, has been observed which may contribute for the bioaccumulation and biomagnification in the food chain.

The studies with atmospheric pollutants are more advanced when compared to the studies with heavy metals, although there has been a marked increase in the studies with heavy metals in the last few years. For example, a study carried out by CENA showed that the Cd level in the Piracicaba river is about ten-fold higher than the accepted level. however, research must be intensified in order to establish specific e 
general responses to the metals by different crops plants as well as a maximum acceptable concentration in the soil and food.

A group of peptides termed phytochelatins (PCs) has been identified and are capable of binding heavy metal ions, includind $\mathrm{Cd}$, detoxifying the cells by the reduction of free ions in the cytosol. However, oxidative damage often occurs due to the generation of oxygen reative species induced by heavy metals. A class of antioxidant enzymes has been reported for the scavenging of the oxigen reative species. Plants exposed to heavy metals may exhibit alteration the enzyme activity. The study of such a response may allow to evaluate levels of tolerance, specificity of response by distinct plant species and levels of pollution in the environment. These data may be useful in breeding olprograms to select tolerant plants. Moreover, tolerant plants may be used in phytorremediation, by reducing the amount of heavy metals in the contaminated soils.

In this study, it was observed alterations in CAT activity in seedlings and callus and na expressive increase in GR activity in sugar cane seedlings. SOD activity was unaltered in all tissues analysed.

The results suggest that in sugar cane the main defence system to the $\mathrm{Cd}$ stress is possibly the synthesis of GSH to be used in the synthesis of phytochelatins. 


\section{INTRODUÇÃO}

Os níveis de poluição ambiental estão crescentes e têm causado preocupação, devido ao impacto ambiental causado, além de problemas relativos a produção agrícola e saúde humana.

Dentre os poluentes, os metais pesados vêm sendo alvo de estudos, uma vez que sua emissão tem alcançado altos níveis, particularmente o cádmio, um dos mais tóxicos e que causa danos a plantas e animais. Diversas atividades humanas, principalmente industriais têm contribuído para essa emissão crescente e conseqüente contaminação de solos, corpos d'água e atmosfera. Assim, plantas crescidas nestes ambientes constituem a principal fonte de metais na dieta humana.

As plantas possuem diversos mecanismos de defesa para evitar ou aliviar os danos causados pela exposição a metais pesados, sendo que seu nível de tolerância ou susceptibilidade será função da eficiência ou especificidade desses mecanismos. Dentre estes, pode destacar-se a indução de uma classe de peptídeos denominada fitoquelatinas, que tem a capacidade de ligar-se aos íons livres no citoplasma e (ou) compartimentalizálos. Também pode ser induzida uma síntese adicional de compostos antioxidantes não enzimáticos como carotenóides, $\alpha$-tocoferol, ascorbato e glutationa e enzimáticos como superóxido dismutase, catalase e glutationa redutase entre outros.

Diversos estudos têm sido realizados relacionando as alterações na quantidade destes compostos e as diversas condições de estresse. Estes estudos são imprescindíveis para o entendimento de como funcionam estes mecanismos e para seleção de plantas tolerantes ou sensíveis para sua utilização como bioindicadores de poluição, em programas de biorremediação e até em programas de melhoramento para a 
obtenção de variedades mais tolerantes, onde o conhecimento dos mecanismos de retenção e distribuição do metal pode determinar a finalidade a ser dada a cultura.

Os estudos relacionando poluentes atmosféricos estão bastante avançados quando comparados com os relacionados a metais pesados. Portanto estudos envolvendo metais pesados para se determinar a especificidade de resposta, bem como os diferentes mecanismos mobilizados são necessários, principalmente no Brasil, onde pouco se tem feito nessa linha de pesquisa. Neste contexto, procuramos estudar os efeitos do cádmio em plantas e calos de cana-de-açúcar, uma cultura de importância sócio-econômica para o Brasil. 


\section{REVISÃO DA LITERATURA}

\subsection{Poluentes atmosféricos e monitoramento}

Nas últimas décadas os efeitos globais causados pelas atividades humanas no ambiente, bem como os efeitos a médio e longo prazo à saúde humana e produção agrícola, têm causado expressiva preocupação, principalmente em países altamente industrializados. Em culturas sensíveis ao ozônio tais como cebola e leguminosas, esta perda tem atingido níveis da ordem de 20 a 30\%. As concentrações de poluentes atmosféricos em áreas industrializadas alcançam níveis danosos às plantas (Kangasjarv, 1994). Consequentemente, o monitoramento eficiente de poluentes, bem como meios para diminuir ou eliminar seus efeitos, são hoje considerados essenciais.

Efeitos sinergísticos ocorrem entre o ozônio e outros poluentes atmosféricos, particularmente o $\mathrm{SO}_{2}$ (Willekens et al., 1994a). A presença e a complexidade dessas interações, outros fatores de estresse e estágio de desenvolvimento do organismo, levam à necessidade de monitoramento dos efeitos de poluentes atmosféricos nas plantas em seu ambiente para relacionar o efeito desse monitoramento ao seu impacto em espécies vegetais.

As pesquisas mostram que as plantas respondem por esta "agressão" induzindo um sistema antioxidante de defesa que inclui componentes de baixa massa molecular tais como glutamina, ascorbato, glutationa, carotenóides e uma variedade de enzimas que funcionam para prevenir ou limitar o dano celular por espécies ativas de oxigênio (EAOs).

Essas proteínas antioxidantes parecem ser induzidas por várias condições de 
estresse abiótico, incluindo poluentes atmosféricos,. podendo fazer parte de uma resposta geral às condições de estresse. Diferentes plantas parecem responder diferentemente a distintas condições de exposição aos poluentes atmosféricos (Willekens et al., 1994a).

Os genes que codificam estas enzimas têm sido clonados e seqüenciados, facilitando o uso de análise por Northem blot para acompanhar a expressão destes genes em resposta aos poluentes atmosféricos (Conklin \& Last, 1995; Sharma \& Davis, 1994).

Por outro lado, a análise da indução e acúmulo de compostos de defesa, proteínas antioxidantes e outras proteínas, pode fornecer um eficiente meio para monitorar o efeito dos poluentes no ambiente.

Os estudos com gases poluentes estão bastante avançados, contudo para os metais pesados os efeitos e as respostas das plantas, incluindo sistemas antioxidantes, ainda precisam ser mais estudados.

\subsection{Metais pesados: contexto e características}

A toxicidade por metais pesados em plantas tem atraído atenção de cientistas das áreas da saúde e do ambiente. Alguns aspectos relacionados à toxicidade por alumínio, cobre (Roy et al., 1988; Fernandes \& Henriques, 1991; respectivamente) e outros metais traços, têm sido revisados. A designação "metais pesados" vem do peso específico destes elementos ser maior que $5 \mathrm{~g} \mathrm{~cm}^{-3}$, sendo também conhecidos como "elementos traço", por serem naturalmente encontrados em concentrações de poucas partes por milhão (Mattiazzo-Prezotto, 1994). A origem primária dos metais pesados está relacionado à origem do solo, pois a maioria das rochas contém esses metais em sua composição (Melo et al., 1997).

O cádmio $(\mathrm{Cd})$, particularmente é toxico para animais (Hinkle, et al., 1987) e plantas (Woolhouse, 1983), e está relacionado à saúde humana pois é acumulado em muitos cereais, batatas, vegetais e frutas. Em muitos ambientes naturais e agrícolas, o nível de metais pode ser baixo e não causar fitotoxicidade significante (Wagner, 1993). 
Entretanto em função de sua concentração em tecidos de plantas, a presença desses elementos atinge níveis comercialmente inaceitáveis (Vogeli-Lange \& Wagner, 1996). Portanto, é indispensável analisar a disponibilidade, bioconcentração, toxicidade e tolerância ao $\mathrm{Cd}$ em plantas.

A poluição do ambiente por $\mathrm{Cd}$ está crescente no ambiente devido à mineração, usos industriais e atividades humanas (Brummer, 1986; Groten, 1994; Merrington, 1994; Tamaddon, 1993). O Cd é usado amplamente na fabricação de pesticidas (Page et al., 1972), formulação de pigmentos, manufatura de baterias, litografia, fotografias, cura da borracha, estabilização de plásticos, manufatura de automóveis entre outros (Prasad, 1995; Nascimento et al., 1997). Em solos agrícolas a principal fonte de contaminação por $\mathrm{Cd}$, são o uso de fertilizantes, lodo de esgoto e compostos derivados. $\mathrm{O}$ destino final do esgoto doméstico, municipal e industrial, tem levado a uma maior concentração de Cd no solo (Alloway, 1995; Lamy et al., 1993), além de outros metais pesados como $\mathrm{Cu}, \mathrm{Zn}, \mathrm{Ni}, \mathrm{Cr}, \mathrm{Mn}, \mathrm{Pb}$ e $\mathrm{Hg}$ (McBride, 1995). Em adição, alguns fertilizantes fosfatados contém altos níveis de Cd (Brummer, 1986; Campbell et al., 1988; Roberts et al., 1994; Mortvedt, 1996).

No Brasil, uma análise da presença de metais pesados em vários fertilizantes minerais e outros reparadores de solo comercializados, revelou que o $\mathrm{Cd}$ e outros metais potencialmente tóxicos, foram encontrados em baixas concentrações, porém, concentrações consideráveis de $\mathrm{Cd}$ e $\mathrm{Pb}$ foram detectadas em fontes de micronutrientes (Gabe \& Rodella, 1999).

O Cd é liberado na atmosfera como vapor em fundições e operações industriais que requerem altas temperaturas e pela queima de combustíveis fósseis, o que consequentemente, por meio da ação das chu vas, vem a contaminar também os solos e corpos d'água (Wagner, 1993), onde é bioconcentrado. Em forma solúvel e em estáveis complexos clorídricos, o Cd se liga a sedimentos de água fresca (De, 1992). Assim a contaminação das plantas com Cd se dá por meio da atmosfera, dos solos e dos corpos d'água contaminados.

De fato os solos contaminados podem ser a principal fonte de contaminação de plantas cultivadas (Dudka \& Miller, 1999). No solo os metais são fortemente retidos, 
podendo permanecer no mesmo por dezenas de anos (McGrath, 1987). O Cd é considerado mais tóxico às p’antas que crescem em solos contaminados devido à sua forte ligação a colóides orgânicos e inorgânicos (Fernandes \& Henrriques, 1991).

Produtos agrícolas contaminados facilitam a introdução do $\mathrm{Cd}$ na dieta humana. A transferência excessiva de metais pesados ao longo da cadeia alimentar é controlada por uma barreira solo-planta, entretanto no caso de alguns metais, incluindo o $\mathrm{Cd}$, essa barreira não é efetiva. Dessa maneira, alimentos originados de plantas constituem a principal fonte de Cd para a sociedade moderna (Dudka \& Miller, 1999). A importância dos efeitos tóxicos do $\mathrm{Cd}$ foi evidenciada na trágica contaminação da população da cidade de Toyama, Japão, intoxicada pela água contaminada pela mineração, que era utilizada nas culturas de arroz, onde houve grande número de vítimas com problemas neurotóxicos e descalcificação acentuada dos ossos. Sabe-se hoje que o arroz é uma planta que acumula Cd naturalmente, assim como várias outras plantas (Harrison, 1995), como o alface e o tabaco, que também são grandes acumuladores. O consumo destas faz com que o elemento se acumule no corpo humano e persista por um período de meia vida de aproximadamente dez anos. Portanto, contaminação com metais pesados vem a ser um problema mundial, levando a perdas na produtividade agrícola e apresentando perigosos efeitos para a saúde, quando estes entram para a cadeia alimentar (Nellessen \& Fletcher, 1993; Guo \& Marschner, 1995; Salt et al., 1995).

Ainda em relação ao solo, é sabido que em baixas concentrações os metais podem interferir com a diversidade e atividade das comunidades microbianas, e dessa maneira trazer sérios efeitos sobre a biomassa e fertilidade do solo (McGrath et al., 1998). Além do mais, o número de bactérias que fixam nitrogênio é muito baixo em solos contaminados (Chaudri et al., 1993).

Existem várias tecnologias para limpeza do solo, que usualmente envolvem remoção, tratamento e substituição do solo. Esses processos destróem as propriedades biológicas e estruturais do solo e podem ser extremamente caros (Black, 1995). Assim, faz-se necessário desenvolver maneiras mais baratas e menos danosas para remoção de metais tóxicos do solo, como a biorremediação, a qual utiliza organismos vivos para reduzir os riscos ambientais (McGrath, 1998). 
$\mathrm{O}$ conhecimento dos efeitos tóxicos do $\mathrm{Cd}$ sobre processos bioquímicos $\mathrm{e}$ fisiológicos é potencialmente útil para estabelecer critérios para seleção de plantas a serem utilizadas como bioindicadores, que são extremamente sensíveis à baixas concentrações de metais pesados (Kovacs \& Podani, 1986).

As plantas, de modo geral, não são capazes de regular a absorção de metais pesados, de tal forma que estando estes disponíveis e em contato com a raiz, serão absorvidos. O Cd mesmo não sendo um nutriente, é facilmente absorvido pelo sistema radicular e em plantas aquáticas, o Cd é absorvido também pela parte aérea (Ornes et al., 1993).

A absorção, distribuição e efeitos do $\mathrm{Cd}$ em diferentes processos metabólicos parecem ser controlados por diversos fatores na planta, tal como espécies e/ou variedades, água e estado nutricional (Melo et al., 1997). Espécies de plantas e também genótipos da mesma espécie, diferem amplamente em sua habilidade para absorver e transportar esses metais dentro da planta (Pettersson, 1977; Gabrielli et al., 1990; Rebafka et al., 1990; Lubben \& Sauerbeck, 1991). Outros fatores, tais como estágio de crescimento e tempo de exposição ao metal pesado, também afetam a absorção e distribuição de $\mathrm{Cd}$ entre diferentes partes da planta (Melo et al., 1997). A retenção do $\mathrm{Cd}$ na raiz varia de $34 \%$ a $97 \%$ do total de Cd na planta (Jarvis et al., 1976). Os níveis de Cd também podem ser afetados por alguns de diversos fatores fisiológicos, incluindo a absorção do Cd a partir da solução do solo, translocação raíz - parte aérea via xilema e sequestro do Cd em compartimentos subcelulares (Jonathan et al., 1998). A absorção do Cd pela superfície da raíz tem sido caracterizada em muitas espécies, como trigo (Smeyers-Verbeke et al., 1978; Jalil et al., 1994b), milho (Florijn \& Van Beusichem, 1993) e cevada (Cutler \& Rains, 1974). Demonstrou-se que o influxo de Cd através da membrana plasmática de células de raízes ocorre via um processo dependente da concentração, exibindo uma cinética de saturação em soja (Cataldo et al., 1993), Lupinus albus (Costa \& Morel, 1993), arroz (Homma \& Hirata, 1984) e milho (Mullins \& Sommers, 1986). A natureza da saturação na absorção do Cd sugere que esta é feita por algum sistema mediado por carregadores. A translocação do $\mathrm{Cd}$ da raiz para a parte aérea tem sido estudada em diversas espécies, incluindo gramíneas (Jarvis et al., 
1976),entre elas o milho (Yang et al., 1995) e outras plantas como tomate (Petit \& van de Geijn, 1978), feijão (Hardinaman \& Jacoby, 1984), e trigo (Jalil et al., 1994a). O movimento do $\mathrm{Cd}$ da raiz para a parte aérea parece ocorrer via xilema e ser dirigido pela transpiração das folhas. Evidências para isso foram obtidas por Salt et al. (1995), indicando o fechamento estomático induzido pelo ácido absísico (ABA) foi reduzido dramaticamente pelo acúmulo de $\mathrm{Cd}$ na parte aérea em mostarda Indiana.

$\mathrm{O}$ sequestro celular do $\mathrm{Cd}$ tem um grande efeito sobre os níveis de $\mathrm{Cd}$ livre no simplasto e assim pode potencialmente influenciar o movimento do $\mathrm{Cd}$ através da planta. Concentrações de $\mathrm{Cd}^{2+}$ no citosol podem ser reguladas por dois processos: $\mathrm{Cd}^{2+}$ ligado a fitoquelatinas (PCs) (Grill et al., 1985) e compartimentalização celular, particularmente no vacúolo (Rauser, 1995), embora existam evidências de que o $\mathrm{Cd}^{2+}$ ligado a PCs tem pouco efeito sobre a translocação via xilema para a parte aérea (Florijn et al., 1993a; Salt et al., 1995). A compartimentalização vacuolar do Cd pode ser um mecanismo efetivo para inibição do transporte a longas distâncias dentro da planta. A presença do $\mathrm{Cd}$ livre $\mathrm{e}$ Cd ligado a peptídeos no vacúolo de células vegetais tem sido monstrada (Vogeli-Lange \& Wagner, 1990). Existem evidências de que o Cd é transportado através do tonoplasto para dentro do vacúolo em células de raízes de aveia, tanto como um íon livre (Salt \& Wagner, 1993) como em um complexo com PCs (Salt \& Rauser, 1995).

$O$ crescimento celular e o crescimento total da planta podem ser drasticamente inibidos pela toxicidade do Cd. A inibição da expansão e crescimento celular pode ser um efeito direto ou indireto do $\mathrm{Cd}$ no metabolismo de auxinas ou carregadores de auxinas (Barcelo \& Poschenreider, 1990).

Nas plantas o Cd inibe a fotossíntese (Gregerl et al., 1994), causando mudanças estruturais nos cloroplastos (Somashekaraiah et al., 1992) e primariamente afetando os pigmentos fotossintéticos, diminuindo o conteúdo total de clorofila (Krupa,

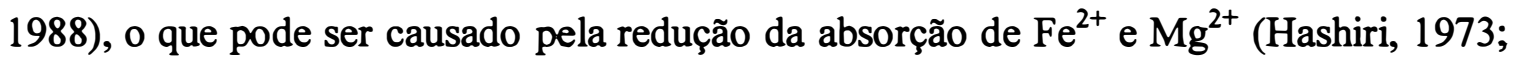
Kahn \& Frankland, 1983) e pela reação com grupos SH de enzimas específicas da fase fotoquímica (Stobart et al., 1985). Observou-se também um declínio nos níveis de ácidos graxos polinsaturados em cloroplastos (El-Shintinawy, 1999). Plântulas de aveia exibiram uma redução no conteúdo de clorofila (Gullner \& Uotila, 1998) e Helliantus 
annus (Di Cagno et al.,1999; Gallego et al., 1999). Além disso, em H. annus também foi observado uma redução na assimilação de carbono e transporte de elétron no fotossistema II (PSI) (Di Cagno et al., 1999). Em soja, El-Shintinawy (1999) observou uma inibição na fotossíntese, com redução de $85 \%$ na eficiência do PSII, associado a uma expressiva emissão de fluorescência. $\mathrm{O} \mathrm{Cd}$ também afeta a fosforilação oxidativa nas mitocôndrias,aumentando a permeabilidade passiva da membrana interna a prótons (Kesseler \& Brand, 1995). Um aumento da resistência estomática em plantas tratadas com Cd também tem sido observado (Sheoran et. al., 1990). Também o fechamento permanente dos estômatos e aumento na produção de etileno podem ser responsáveis por uma senescência estimulada pelo Cd (Fuher, 1982). Em soja, foi observado um aumento de 10 vezes na produção de etileno (El-Shintinawy, 1999). Clorose e coloração marromavermelhada nas margens e nervuras foliares também foi observada (Kabata-Pendias \& Pendias, 1992). Os sintomas de clorose observados na senescência devido à carência de Fe podem ser causados pela competição entre os dois cátions por sítios de absorção na membrana plasmática (Foy et al., 1978).

O Cd estimula a formação de EAOs (Sandman \& Boger, 1983) e aumenta o nível celular de peróxidação lipídica (Padmaja \& Prasad, 1992).

A atividade de sistemas antioxidantes é considerada inversamente proporcional aos níveis de peroxidação de lipídeos, síntese de etileno e senescência (Dhindsa et al., 1981; Lesham, 1988).

O Cd também pode aumentar a susceptibilidade de plantas ao estresse oxidativo devido à depleção de glutationa (GSH) causada pela indução da formação de PCs, que são peptídeos ricos em grupos SH (Rauser, 1995) e inibição de muitas enzimas (Van Assche \& Clijster, 1990).

Como exemplo para alguns dos efeitos citados, estudos em girassóis submetidos ao $\mathrm{Cd}$ mostraram uma diminuição significativa no conteúdo de clorofila variando del 5 à $30 \%$. O conteúdo de malondialdeído (MDA) aumentou 50\%, indicando uma peroxidação de lipídeos. Também o conteúdo de GSH diminuiu 20\% (Gallego et al., 1996). 
Dentre os metais pesados, o efeito do $\mathrm{Hg}$ no ambiente em geral e para ecossistemas brasileiros, está melhor definido dada a maior quantidade de estudos com este elemento, sendo notória a carência de pesquisas desenvolvidas com $\mathrm{Cd}$ e $\mathrm{Pb}$ (Eysink, comunicação pessoal). Portanto, há a necessidade de se diagnosticar o grau de contaminação do ambiente sujeito a esse elemento e também, o estabelecimento de índices toleráveis de poluição.

A necessidade de se estabelecer índices de contaminação, levou o Centro de Energia Nuclear da Agricultura-USP (CENA-USP) a realizar um estudo para se diagnosticar o grau de contaminação por metais pesados dos organismos bentônicos da Bacia do Rio Piracicaba e a determinação da intensidade e atual contaminação da água. Análises conduzidas pela CETESB nesta Bacia já demonstraram que o $\mathrm{Cd}$ atinge 10 vezes o nível considerado aceitável. Todavia, estes estudos não incluem análises dos efeitos bioquímicos e fisiológicos dos metais pesados em plantas cultivadas (Fostier, comunicação pessoal).

\subsection{Respostas das plantas aos metais pesados}

Os possíveis mecanismos de defesa contra metais pesados em plantas podem envolver: sequestro dos íons por PCs, compartimentalização, imobilização na parede celular, exclusão e (ou) diminuição do transporte através da membrana plasmática, síntese de proteínas e compostos relacionados ao estresse (Zangh et al., 1999; Di Toppi \& Gabrielli, 1999).

\subsubsection{Fitoquelatinas}

A grande quantidade de metais em tecidos de plantas hiperacumuladoras sugere a existência de mecanismos de defesa para evitar seus efeitos danosos (Schickler. \& Caspi, 1999). 
As plantas respondem ao estresse por metal pesado com a indução de uma família de peptídeos formados de unidades repetidas de $\gamma$-Glu-Cys seguidos por um Gly no terminal-C. Estes peptídeos foram genericamente denominados de fitoquelatinas (PCs). São encontrados em plantas superiores e também em algumas espécies de algas, leveduras e fungos (Howden et al., 1995; Satofuka et al.,1999). Alguns autores se referem a esses peptídeos como proteínas ligantes de metais (Heavy Metal Binding Proteins - HMBP) (Galli et al., 1996). Kotrba et al., (1999), cita que plantas podem ter dois grupos de proteínas: metalotioneínas de plantas (MT) e análogas à metalotioneínas de plantas (MT-like proteins). As PCs desempenham o principal papel na desintoxificação de metais em plantas (Clemens et al., 1999) e tem-se constatado a ocorrência de Cd ligado a elas (Leopold et al., 1999).

Estes peptídeos, os quais são relacionados a GSH têm uma estrutura geral ( $\gamma$-GluCys) $n-$ Gly, onde $n=2-7$ segundo Grill et al. (1985) e Rauser (1995), porém diversos autores citam n= 2-11 (Satofuka et al., 1999; Kotrba et al., 1999). A síntese destas PCs pode ser induzida rapidamente em células de cultura de tecidos e raizes subsequente a adição de Cd ou uma série de outros metais pesados (Grill et al., 1987), sendo Cd o indutor mais forte e o $\mathrm{Zn}$ o mais fraco (Steffens, 1990).

Estudos para se entender o papel das PCs no processo de desintoxicação dos metais pesados, foram inicialmente baseados no modelo das metalotioneínas, que são produzidas pelos animais na presença de metais pesados e que apesar de diferirem na estrutura e biossíntese, funcionalmente são análogas às metalotioneínas. Estes polipeptídeos, foram originalmente descritos na levedura Schizosacharomyces pombe, onde foram induzidos pelo Cd e denominados cadistinas (Steffens, 1990).

As similaridades dos PCs à GSH indicam que os mesmos não devem ser produto gênico primário, e que apresentam uma via biossintética comum. $\mathrm{O}$ primeiro passo limitante na biossíntese do GSH é catalisado pela enzima poli-glutamilcisteína sintase, que é inibida pelo butionina sulfoximina (BSO) e que também é um inibidor da biossintese das PCs.

Esta inibição por BSO forneceu a primeira evidência do papel das PCs na desintoxicação por metais pesados, pois culturas de células tratadas com BSO eram 
incapazes de sintetizar PCs e tomavam-se susceptíveis, com inibição do crescimento, a baixos níveis de metais pesados (Steffens, 1990).

A síntese de PCs requer a adição de $\gamma$-glutamilcisteína através da ação de uma enzima constitutiva em plantas, fitoquelatina sintase (PC-sintase), que transfere a $\gamma$ glutamilcisteína de uma molécula de GSH ou PC já existente, para uma outra GSH ou polímero de $\gamma$-glutamilcisteína. A PC-sintase tem atividade induzida pelo $\mathrm{Cd}$ ( Grill et al., 1989; Kotrba; Há et al., 1999; Chen et al., 1997). Em contrapartida, um estudo demosntrou a presença da PC-sintase em células de tomate crescidas na ausência de $\mathrm{Cd}$. O nível da atividade da enzima é regulado durante o ciclo de cultura, com a maior atividade ocorrendo posteriormente ao $3^{\circ}$ dia de subcultivo. Células resistentes ao $\mathrm{Cd}$ cresceram em meio contendo $6 \mathrm{mM} \mathrm{CdCl}_{2}$, apresentando $65 \%$ de aumento na atividade desta enzima, comparada a células não selecionadas. A PC-sintase foi encontrada em raízes e caules de tomate mas não em folhas e frutos. A distribuição desta enzima em tomate e a regulação da enzima em cultura de células indicam que a PC-sintase e PCs podem apresentar funções no metabolismo de plantas não relacionadas diretamente a formação de complexos com Cd (Chen et al., 1999).

Os genes que codificam a PC-sintase ainda não foram bem identificados (Clemens et al., 1999), porém foram isolados recentemente em trigo e Arabidopsis thaliana e demonstrado que são constitutivamente expressos e também induzidos por $\mathrm{Cd}$ externo (Cobbett, 1999). Clemens et al. (1999) identificou um cDNA de trigo, o qual expressando em Saccharomyces cerevisiae resultou em aumento da tolerância ao $\mathrm{Cd}$. Neste trabalho também foram identificados homólogos dessa nova família de genes em Arabdopsis thaliana, S. pombe e inesperadamente em Caenorhabditis elegans. Células de $S$. pombe com esse gene incompleto exibiram hipersensibilidade ao $\mathrm{Cd}$ e não foram hábeis em sintetizar PCs. Extratos de células de E. coli expressando um cDNA para sintese de PC-sintase de A. thaliana ou o gene de $S$. pombe, catalizando uma síntese GSH-dependente metal-induzida, in vitro, demonstrou que ambos genes codificam essa enzima. A comparação de sequências de aminoácidos (a.a.) mostra uma região Nterminal altamente conservada, a qual presumidamente seja o domínio catalítico, e uma região C-terminal variável contendo múltiplos resíduos de Cys e que provavelmente está 
envolvida na ativação da enzima pelos metais (Ha, et al., 1999). Plantas preferencialmente desviam enxofre para a síntese de PCs após a exposição ao $\mathrm{Cd}$, o que às vezes devido à baixa disponibilidade de enxofre, pode causar severa inibição no crescimento de raíz, sendo esse estado revertido por suprimento com altas concentrações de enxofre (McMahon \& Anderson, 1998). Estudos moleculares têm indicado que a síntese do mRNA que codifica as duas enzimas envolvidas na síntese de GSH - $\gamma$ glutamilcisteína sintetase e glutationa sintetase também é induzida pelo $\mathrm{Cd}$ em plantas de Arabidopsis thaliana (Xiang \& Oliver, 1998). Níveis de mRNA da ATP sulfurilase e APS redutase foram aumentados em Brassica juncea, um acumulador de metais pesados após a adição do Cd, embora o efeito tenha variado com o tempo e dose de Cd aplicado (Heiss et. al., 1999; Lee \& Leustek, 1999).

Diversas espécies apresentam ainda peptídeos relacionados a PCs. Certos legumes apresentam homo-fitoquelatinas, ou ( $\gamma$-Glu-Cys) $)_{n}-\beta$ Ala (Grill et al., 1986), enquanto algumas gramíneas produzem hidroximetil-fitoquelatinas ou ( $\gamma$-Glu-Cys) $)_{n}$-Ser (Klapheck et al.,1994). Como visto, as características e composição dos complexos ligantes de $\mathrm{Cd}$ variam consideravelmente entre espécies, concentrações de $\mathrm{Cd}$, tempo de exposição e meio nutritivo. Esses complexos podem ser de baixo e alto peso molecular (Murasugi et al, 1983; Kneer \& Zenk, 1992; Di Toppi et al., 1999).

Em estudos recentes visando uma análise genética dos mecanismos de desintoxicação dos metais pesados em plantas, foram isolados duas classes de mutantes de Arabidopsis thaliana sensíveis ao Cd. A primeira classe denominada cadl, era incapaz de acumular ou seqüestrar $\mathrm{Cd}$.

Foram analisados quatro mutantes cadl independentes, com três níveis diferentes de sensibilidade ao $\mathrm{Cd}$ e foi demonstrado que todos eram deficientes no acúmulo de PC quando expostos ao $\mathrm{Cd}$. Todos eles eram também deficientes na atividade da PCsintase, indicando que este gene é o responsável por codificar esta enzima (Howden et al., 1995a). Em outra classe isolada, mutantes para um outro loco, cad2, apresentaram níveis reduzidos de PCs devido a um decréscimo do nível endógeno de GSH, oferecendo um melhor conhecimento do papel da GSH em plantas (Howden et al., 1995a,b).

Muitos estudos têm relacionado a síntese de PCs e GSH à alterações relacionadas 
a metais (Mehra \& Winge, 1991). Grill et al., (1989) mostrou que as PCs são sintetizadas a partir de GSH. Também foi mostrado que ocorre uma depleção de GSH em culturas de suspenção celular de Datura inoxia (Jackson et al., 1992) e raízes de milho (Meuwly \& Rauser, 1992; Ruegsegger et al., 1992) expostas aos metais pesados.

A GSH é o composto tiol mais abundante em plantas, animais e microrganismos (Singhal et al., 1987), o qual é principalmente citosólico em plantas e animais (Wagner, dados não publicados).

A GSH tem uma afinidade relativamente alta para ligação ao $\mathrm{Cd}$ fazendo deste composto um quelante potencial no citosol (Perrim \& Watt, 1971). Evidências sugerem que GSH constitui uma primeira e rápida resposta de defesa contra exposição ao $\mathrm{Cd}$ e que a tolerância para sustentar a exposição depende da síntese de PCs em plantas (Singhal et al., 1987). Em adição, resultados obtidos em folhas de tabaco mostraram que PCs foram sintetizadas em uma ordem sequencial, sendo pequenos peptídeos sintetizados antes de peptídeos maiores (Vogeli-Lange \& Wagner, 1996). ElShintinawy, (1999), mostrou que a adição de GSH conteve o efeito de retardamento do crescimento induzidos pelo $\mathrm{Cd}$ em soja, pela remoção desses íons do citoplasma e do $\mathrm{H}_{2} \mathrm{O}_{2}$ gerado nos cloroplastos.

Em adição, estudos moleculares com $S$. pombe $e$. thaliana revelaram a presença de um segundo gene envolvido na síntese de GSH e glutationa sintetase (GSH2), o qual é sugerido ser o responsável por codificar uma enzima bifuncional, capaz de catalizar tanto a síntese de GSH adicionando glicina ao dipeptídeo (gamma Glu-Cys) e a síntese de PCs (Al-Lahham et al., 1999).

Esses resultados, e os dados da literatura para raízes, sugerem que diferentes tecidos de plantas podem responder diferentemente aos metais e (ou) diferentes respostas podem predominar dependendo do nível de exposição ao $\mathrm{Cd}^{2+}$ e da habilidade da planta em manter o estoque de GSH. Mecanismos para a complexação do $\mathrm{Cd}^{2+}$ no citosol com GSH, ou outros ligantes e o sequestramento para dentro do vacúolo e complexação lá dentro com ácidos orgânicos e outros ligantes (Wagner, 1993), pode ser resposta predominante sob baixos níveis de exposição. Altos níveis de exposição podem requerer mecanismos adicionais de complexação como PC-Cd, PC-Cd ${ }^{2+}-\mathrm{SH}$, e (ou)Cd ${ }^{2+}-$ 
SH (Vögeli-Lange \& Wagner, 1996).

Para uma visão global e a mais completa possível sobre esses complexos mecanismos, deve-se considerar a assimilação de nitrogênio em plantas superiores, pois esta é a principal via biossintética que leva à formação do glutamato, o qual é requerido para a síntese de metabólitos que participam de adaptações bioquímicas ao estresse por metais pesados como o Cd. Em plântulas de milho expostas ao Cd, Boussama et al., (1999), mostraram um significante decréscimo no conteúdo de nitrato relacionado à inibição das enzimas dessa via, exceto na glutamato desidrogenase, que aumentou. Embora tenha ocorrido uma diminuição no total de a.a., houve acúmulo de glutamato, prolina, lisina, metionina e glicina e paralelamente ocorreu um aumento no conteúdo de $\gamma$-glutamilcisteína e GSH. É sugerido que a indução da NADH-glutamato desidrogenase, providenciou o glutamato requerido para um aumento de prolina, $\gamma$-glutamilcisteína e GSH, comuns em condições de estresse por metais pesados.

\subsubsection{Compostos e enzimas antioxidantes em circunstâncias oxidativas}

Durante condições normais de crescimento e desenvolvimento, as plantas são invariavelmente expostas a diversas formas de estresse, tais como seca, calor, resfriamento, poluentes, radiação UV entre outros. Espécies ativas de oxigênio (EAOs) são comumente geradas sob essas condições (Rao et al., 1996).

O oxigênio na atmosfera é relativamente não reativo, mas quando em contato com sistemas metabólicos, pode ser transformado em formas reativas como superóxido $\left(\mathrm{O}_{2}{ }^{\circ}\right)$ peróxido de hidrogênio $\left(\mathrm{H}_{2} \mathrm{O}_{2}\right)$, radicais hidroxila $\left(\mathrm{OH}^{*}\right)$ e oxigênio "singlet" $\left({ }^{1} \mathrm{O}_{2}\right)$, as quais podem potencialmente causar danos ao ambiente celular (Smirnoff, 1993), ou seja, danos em lipídios de membrana afetando a sua permeabilidade (Chevrier et al., 1988), proteínas, clorofila e ácidos nucléicos (Scandalios, 1993; Foyer et al., 1994). Estas formas de oxigênio são freqüentemente chamadas de oxigênio ativo. O termo radical livre de oxigênio também é utilizado coletivamente, embora somente o superóxido e radicais hidroxilas sejam realmente radicais livres. Algumas dessas EAOs, 
podem formar radicais livres orgânicos, os quais podem interagir com um grande número de moléculas causando danos. Por esta razão as células de organismos aeróbicos possuem diversos mecanismos para remover essas EAOs antes que causem danos ou para repará-los quando ocorrem (Smimoff, 1993).

Muitos estudos examinando os efeitos do estresse por poluição têm sido conduzidos com gases poluentes, especialmente ozônio e dióxido de enxofre (Grill et al., 1979; Chiment et al., 1986; Mehlhorn et al., 1986), com chuva ácida e com metais pesados, os quais também causam estresse oxidativo em plantas (Sandmann \& Boger, 1980; Chia et al., 1984; Luna et al., 1994). O dano oxidativo é manifestado como reação do oxigênio ativo com componentes celulares, bem como sua inativação (Asada \& Takahashi, 1987; Halliwell \& Gutteridge, 1989). Os produtos gerados incluem peróxidos lipídicos (quando quebrados, originam o MDA), resultantes da oxidação dos grupos $\mathrm{SH}$ de cisteínas, e também a oxidação de resíduos de histidina, tirosina, triptofano e metionina em proteínas, prejudicando funções e levando a uma proteólise acelerada, além de alterar bases em ácidos nucléicos (Halliwell \& Gutteridge, 1989).

As plantas possuem diversos mecanismos para prevenir ou aliviar os danos causados por EAOs. Esses mecanismos incluem a limpeza por meio de antioxidantes naturais como ascorbato (AA), glutationa (GSH), $\alpha$-tocoferol e carotenóides e o uso de um sistema enzimático antioxidante o qual inclui a atividade de enzimas como superóxido dismutase (SOD), catalase (CAT) (Alscher \& Hess, 1993), ascorbato peroxidase (APX), glutationa redutase (GR), monodesidroascorbato redutase (MDHAR) e desidroascorbato redutase (DHAR), muitas das quais agem em tandem (Foyer et al., 1994; Allen, 1995; Anderson et al., 1995; Rao et al., 1996).

Os principais antioxidantes solúveis em plantas são o ascorbato e o tripeptídeo $\mathrm{GSH}$, o qual é considerado um antioxidante muito importante envolvido na proteção das membranas celulares (Alscher, 1989). Sob condições normais o estoque de GSH e AA permanece em suas formas reduzidas, sendo que $10 \%$ estão na forma oxidada (Foyer et al., 1989).

$\mathrm{O} \alpha$-tocoferol é um antioxidante lipofilico presente nas membranas que pode agir como promotor da limpeza do ${ }^{1} \mathrm{O}_{2}$, prevenindo assim a peroxidação lipídica (Halliwell 
\& Gutteridge, 1989; Winston, 1990).

Funções antioxidantes e promotoras da limpeza de radicais livres são atribuídas a um grande número de outros compostos (Larson, 1988). Muitos destes compostos aumentam sob condições de estresse, como prolina, polióis e sacarose (Hanson \& Hitz, 1982). Todos estes foram relatados como efetivos promotores da limpeza de radicais hidroxila (Smirnoff \& Cumbes, 1989).

O papel central no mecanismo antioxidativo em plantas é desempenhado pela SOD, sendo o produto de sua reação quebrado pela CAT ou outras peroxidases como APX e guaiacol peroxidase (GP). Outras enzimas como GR, DHAR e MDHAR também estão envolvidas na limpeza de EAOs (Allen, 1995). Portanto, a limpeza das EAOs envolve a interação de enzimas protetoras, antioxidantes de baixo peso molecular e seus sistemas de regeneração (Foyer et al.,1994).

Essas moléculas potencialmente danosas podem ser geradas em três principais sítios do aparato fotossintético: o complexo coletor de luz (LHC) associada ao fotossistema (PS) II, o centro de reação do PSII e o lado aceptor do PSI (Niyogi, 1999).

Os radicais superóxido produzidos pela redução do oxigênio molecular no PSI, são rapidamente convertidos a formas menos reativas (dismutados) pela SOD associada ao PSI e o $\mathrm{H}_{2} \mathrm{O}_{2}$ resultante é eliminado pela APX ligada a membrana do tilacóide. Dessa maneira, os radicais superóxido são transformados em $\mathrm{H}_{2} \mathrm{O}_{2}$ que é uma EAO menos destrutiva, além de decrescer o risco de formação do $\mathrm{OH}^{\bullet}$ (Marrs, 1996). As EAOs que escapam da destruição no tilacóide, são destruídas pela SOD localizada no estroma, além da APX. $\mathrm{O} \mathrm{H}_{2} \mathrm{O}_{2}$ produzido pela glicolato peroxidase (GP) é degradado pela CAT, principalmente nos peroxisomas. Os produtos das reações com APX, são convertidos em $\mathrm{AA}$, sendo que a redução que resulta o AA é catalisada pela enzima DHAR, via ascorbato: via metabólica da GSH. Nessa via, também a GSH é oxidada à GSSG e o nível de GSH é mantido pela GR, uma enzima dependente de NADPH. Assim o nível de ghutationa oxidada (GSSG) indica circunstâncias oxidativas (Alscher \& Hess, 1993; Asada, 1994). 


\subsubsection{Superóxido dismutase}

As SODs são enzimas que contém metais e catalisam a dismutação do radical superóxido em $\mathrm{O}_{2}$ e. $\mathrm{H}_{2} \mathrm{O}_{2}$ (Matson, 1998). Esta atividade enzimática foi primeiramente descrita por McCord e Fridovich, (1969) com uma proteína cobre/zinco de eritrócitos bovinos. Esta enzima foi encontrada em todos organismos aeróbios examinados. Em plantas existem três formas desta enzima, as quais são classificadas segundo o ín metálico em seu sítio ativo: formas cobre/zinco (Cu/Zn-SOD), manganês (Mn-SOD) e ferro (Fe-SOD) (Bowler et al., 1994; Chen \& Liu, 1996).

A remoção do $\mathrm{O}_{2}{ }^{-\bullet}$ pelas SODs é descrita como uma dismutação, reação na qual dois substratos idênticos são convertidos em dois produtos diferentes, ou seja, para duas moléculas de $\mathrm{O}_{2}{ }^{-\bullet}$ consumidas, uma molécula de $\mathrm{O}_{2}$ e $\mathrm{H}_{2} \mathrm{O}_{2}$ são geradas. Nesta reação, o ín metálico do sítio ativo oscila entre o estado oxidado e reduzido, e o $\mathrm{O}_{2}^{-\bullet}$ é envolvido em ambas reações (Matson, 1998). Essas reações estão representadas abaixo:

$$
\mathrm{Cu}^{2+}+\mathrm{O}_{2}^{-\oplus} \underset{\text { Redução do } \mathrm{Cu}^{2+}}{\stackrel{\text { SOD }}{\longrightarrow}} \mathrm{Cu}^{+}+\mathrm{O}_{2}
$$$$
\mathrm{Cu}^{+}+\mathrm{O}_{2}^{-\bullet} \underset{\text { Oxidação do } \mathrm{Cu}^{+}}{\stackrel{\text { SOD }}{\longrightarrow}} \mathrm{Cu}^{2+}+\mathrm{H}_{2} \mathrm{O}_{2}
$$$$
\mathrm{Mn}^{3+}+\mathrm{O}_{2}^{-\bullet} \underset{\text { Redução do } \mathrm{Mn}^{3+}}{\longrightarrow} \mathrm{Mn}^{2+}+\mathrm{O}_{2}
$$

$$
\mathrm{Mn}^{2+}+\mathrm{O}_{2}^{-\bullet} \underset{\text { Oxidação do } \mathrm{Mn}^{3+}}{\longrightarrow} \mathrm{Mn}^{3+}+\mathrm{H}_{2} \mathrm{O}_{2}
$$

Dismutação geral:

$$
2 \mathrm{O}_{2}^{-\bullet} \frac{\text { SOD }}{\text { Dismutação }} \longrightarrow \mathrm{O}_{2}+\mathrm{H}_{2} \mathrm{O}_{2}
$$


A Fe-SOD e Mn-SOD são essencialmente procarióticas e eucarióticas respectivamente. A $\mathrm{Cu} / \mathrm{Zn}$-SOD é de grande o corrência em procariotos e eucariotos. As duas primeiras parecem ser altamente similares na estrutura primária e tridimensional e em outras propriedades fisico-químicas. A última não apresenta tal similaridade. Assim, presume-se que a Fe-SOD e Mn-SOD podem ter um ancestral comum, tendo a $\mathrm{Cu} / \mathrm{Zn}$ SOD evoluído independentemente (Chen \& Liu, 1996). Somente em plantas as três formas coexistem, porém a Fe-SOD é mais rara e apenas recentemente é mostrada existir em plantas.

Os estudos relativos a essa enzima têm sido realizados tanto no nível subcelular como filogênico. A verificação da ocorrência em diferentes subcompartimentos de células vegetais e os estudos da evolução molecular vem sendo intensificados buscando-se entender a razão de serem mantidas três enzimas funcionalmente equivalentes, mas estruturalmente diferentes.

A avaliação de seqüências de cDNA que codificam as diferentes SODs e o uso de técnicas moleculares vem aumentando consideravelmente o conhecimento sobre este sistema enzimático e o estresse oxidativo em plantas (Bowler et al., 1994).

Como já mencionado, plantas apresentam várias isoenzimas dos tipos de SODs, em diversos subcompartimentos: mitocôndrias, cloroplastos e peroxisomos, além do citosol.

A Cu/Zn-SOD foi encontrada: no citosol de diversas espécies: arroz (Pan et al., 1999), M. crystallium (Miszalski et al., 1998), pimenta vermelha (Kim et al., 1997), espinafre (Ogawa et al., 1996) e azeitona (onde foi encontrada também junto à parede celular de grãos-de-polén) (Alche, et al., 1998); nas mitocôndrias de girassol (4 isoformas) (Corpas et al., 1998) e feijão (Corpas et al., 1991); nos cloroplastos de Arabidopsis (Kliebenstein et al., 1998), tabaco, (Kurepa, et al., 1997), feijão (Corpas et al., 1991) e aveia (ligada ao tilacóide e estroma) (Sehmer \& Dizengremel, 1998) e nos peroxissomas em abóbora, girassol e algodão (na matriz) (Corpas et al., 1998). A MnSOD foi encontrada nas mitocôndrias de aveia (Sehmer \& Dizengremel, 1998), M. crystallium (Miszalski et al., 1998), abóbora (Corpas et al., 1998), feijão (Corpas et al., 1991) e arroz (Ogawa et al., 1995); em cloroplastos de Arabidopsis (Kliebenstein et al., 
1998); em peroxisomas de abóbora (Corpas et al., 1998) e ervilha (Corpas et al., 1991). A Fe-SOD foi encontrada no citoplasma de arabidopsis (Kliebenstein et al., 1998) e Mnium affine (Christov \& Bakardjieva, 1999), em cloroplastos de M. crystallium (Miszalski et al., 1998) e tabaco (Kurepa, et al., 1997). Santos et al (1999) encontraram uma Fe-SOD em $S$. meliot que não foi inativada pelo $\mathrm{H}_{2} \mathrm{O}_{2}$. Nessa enzima constatou-se que além do $\mathrm{Fe}$, também o $\mathrm{Mn}$ age como co-fator. A comparação de $70 \mathrm{Fe}-\mathrm{SODs}$ e MnSODs indicou que essa Fe-SOD apresenta diversos resíduos atípicos em sítios específicos que podem contribuir para a ativação por $\mathrm{Mn}$ e resistência a $\mathrm{H}_{2} \mathrm{O}_{2}$. Similarmente, Kaminaka et al. (1999) encontraram uma Fe-SOD em arroz que não é inativada pelo $\mathrm{H}_{2} \mathrm{O}_{2}$. Com base nestes dados, observa-se que a Fe-SOD é mais rara e tem sua distribuição mais restrita. Ogawa et al. (1996) encontraram a presença de uma $\mathrm{Cu} / \mathrm{Zn}$-SOD no núcleo de plantas de espinafre, sendo atribuída a esta um papel protetor contra mutações fatais causadas por EAOs. Uma Mn-SOD extracelular, com grande similaridade as Mn-SODs mitocondriais de outras espécies foi encontrada em Barbula unguiculata (Yamahara et al. 1999). Streller \& Wingsle (1994) encontraram uma suposta SOD extracelular em fluídos de pinheiro escocês. Essa enzima apresenta um domínio diferente daqueles encontrados em $\mathrm{Cu} / \mathrm{Zn}$-SODs de cloroplastos e citosol em plantas.

Diversos autores têm conduzido estudos relacionando a deficiência de nutrientes como $\mathrm{Zn}, \mathrm{Cu}$, Fe e $\mathrm{Mn}$ com a atividade de SOD. Em plantas cultivadas com deficiência de $\mathrm{Zn}$ foram relatados efeitos como: decréscimo no conteúdo e atividade de $\mathrm{Cu} / \mathrm{Zn}$-SOD em arroz (Obata et al., 1999) e na atividade de Cu/Zn-SOD e Mn-SOD em Lupinus angustifolius L. (Yu \& Rengel, 1999), decréscimo da Mn-SOD com aumento simultâneo da Cu/Zn-SOD em Impatiens flanaganiae (Lall et al., 1998). Sob deficiência de Mn foram relatados: decréscimo na atividade da Mn-SOD em tabaco (Yu et al., 1999) e aumento da Cu/Zn-SOD em Lupinus angustifolius (Yu \& Rengel, 1999). No caso de deficiência de $\mathrm{Cu}$, foram relatados: decréscimo na atividade de $\mathrm{Cu} / \mathrm{Zn}$-SOD e Mn-SOD em Lupinus angustifolius (Yu \& Rengel, 1999); e decréscimo na atividade de Mn-SOD e aumento simultâneo da $\mathrm{Cu} / \mathrm{Zn}-\mathrm{SOD}$ em Impatiens flanaganiae (Lall et al., 1998). E ainda, sob deficiência de $\mathrm{Fe}$, foi observado um decréscimo da Fe-SOD em tabaco 
(Kurepa et al., 1997a). Esses dados mostram que a deficiência de nutrientes altera a atividade das três formas de SOD dependendo do tipo e severidade do estresse (Yu \& Rengel, 1999).

As isoformas de SOD apresentam grande homologia entre espécies de plantas e até considerável homologia com mamíferos. São relatadas estruturalmente como dímeros, com massas moleculares variando de aproximadamente 30 a $80 \mathrm{kDa}$, codificadas por até 3 genes em algumas espécies, sendo estes, genes nucleares de cópia única (Sakamoto et al, 1992; Miao \& Gaynor, 1993; Streller \& Wingsle, 1994; Arines et al., 1994; Thygesen et al., 1995; Murai \& Murai, 1996; VanCamp et al., 1996; Kaminaka et al., 1997; Kin et al, 1997; Kurepa et al., 1997; Miszalski et al., 1998; Ken et al., 1998; Tanaka et al., 1998; Santos et al., 1999)

\subsubsection{Catalase}

As CATs são hemeproteínas oxiredutases tetraméricas, que contém grupos de ferriprotoporfininas, com massa molecular em torno de $240 \mathrm{kDa}$. São encontradas no citoplasma, mitocôndrias e peroxisomos de células de animais, vegetais e microrganismos aeróbicos, atuando como reguladoras dos níveis de $\mathrm{H}_{2} \mathrm{O}_{2}$, os quais são decompostos em $\mathrm{H}_{2} \mathrm{O}$ e $\mathrm{O}_{2}$ (Scandalios, 1990). Na alga verde Chlamydomonas reinhardtii a CAT, que apresenta três isoformas é constituída de um dímero localizado nas mitocôndrias (Kato et al., 1997).

Essas enzimas são abundantes em glioxissomas de tecidos que armazenam lipídeos, onde decompõem o $\mathrm{H}_{2} \mathrm{O}_{2}$ formado durante a $\beta$-oxidação de ácidos graxos (Holtman et al., 1994; Voet \& Voet, 1995), e em peroxisomas de folhas verdes, onde o $\mathrm{H}_{2} \mathrm{O}_{2}$ é produzido durante a fotorrespiração pela conversão do glicolato em glioxilato (Willekens et al., 1997).

Em angiospermas, uma pequena família de genes codificam as CATs (Frugoli et al., 1998). Três isoenzimas geneticamente distintas foram caracterizadas em plantas de milho (Scandalios, 1994), enquanto duas foram identificadas em cevada (Skadsen, 
1995). Em Nicotiana plumbaginifolia também foram relatados três genes (Willekens et al., 1994b). Em Arabidopsis, uma família de multi-genes codifica subunidades individuais que se associam para formar até seis isoformas (Frugoli et al., 1996).

Uma terceira classe é localizada em tecidos vasculares e pode estar envolvida na proteção contra estresse ambiental (Willekens et al., 1994a.) As isoformas de CAT podem ser reguladas temporalmente e espacialmente e responder diferencialmente à luz (Scandalios, 1994; Skadsen et al., 1995; Willekens et al., 1994a.; Boldt \& Scandalios, 1997). Acevedo et al. (1996) sugere a existência de genes induzidos e reprimidos pela luz em cevada. Alguns trabalhos mostram que o gene Cat 3 é transcricionalmente regulado por um ritmo circadiano em milho, sendo esse um fenômeno geral nesta planta (Abler \& Scandalios, 1994; Polidoros \& Scandalios, 1998). É postulado que a regulação é independente de elementos específicos no promotor, os quais são cruciais na regulação circadiana do gene Cat 2 de arabidopsis. Em adição, os efeitos diretos de altas e baixas concentrações do próprio $\mathrm{H}_{2} \mathrm{O}_{2}$ induzindo a expressão de Cat1/Cat2 e Cat3 respectivamente, sendo que essa regulação através do $\mathrm{H}_{2} \mathrm{O}_{2}$ foi superimposta sobre a regulação circadiana de Cat3 (Polidoros \& Scandalios, 1999).

Diversas condições, algumas de estresse, estão relacionadas a alterações na atividade da CAT. Alterações sazonais foram relatadas em aveia, onde na primavera, o aumento na atividade foi relacionado a um aumento na fotorrespiração (Garcia-Plazaola et al., 1999). O resfriamento acarretou uma diminuição na atividade em Arabidopsis (Kubo et al., 1999) e milho (Leipner et al., 1999). O déficit hídrico teve o mesmo efeito em arroz (Boo \& Jung, 1999). Genótipos deficientes e tolerantes a UV-B mostraram baixa e alta atividade respectivamente (Mazza et al., 1999). Plantas tratadas com herbicida 1,10-fenantrolina apresentaram um decréscimo na atividade (Herman et al., 1998). O Cd causou um significante decréscimo na atividade em folhas de Pisum sativum (Dalurzo et al., 1997), plântulas de Helianthus annuus (Bhattacharjee, 1998), Phaseolus vulgaris (Padmaja \& Prasad, 1992), Lemna minor (Mohan \& Hossetti, 1997) e Amaranthus lividus (Bhattacharjee, 1998). Em Phaseolus vulgaris o decréscimo foi observado em raízes e folhas, mas não em caules (Chaoui et al., 1997). Um aumento na atividade foi observado em Agropiron repens (Brej, 1998), Helianthus annuus (Gallego 
et al., 1996b; 1999) e em variedades tolerantes de Solanum tuberosum (Stroinski et al., 1997). Plantas de Lycopersicon esculentum transgênico expressando CAT, mostraram uma susceptibilidade ao estresse oxidativo devido a uma supressão da atividade dessa enzima (Kerdnaimongkol \& Woodson, 1999).

\subsubsection{Glutationa redutase}

Diversos papéis metabólicos, regulatórios e antioxidativos da GSH, resultam de sua oxidação a GSSG. Para a maioria dessas funções a GSH deve estar em sua forma reduzida. Essa redução é conduzida pela flavoproteína glutationa redutase (GR) em uma reação de oxidação-redução NADPH-dependente da GSSG para GSH (Creissen et al., 1993). Este processo normalmente produz um razão de GSH:GSSG de 100:1, a qual permite a GSH funcionar como um agente redutor intracelular.

A GR contém o grupo prostético flavina adenina dinucleotídeo (FAD) para transferência de elétrons. Flavinas podem sofrer duas transferências seqüenciais de um elétron, ou transferência simultânea de dois elétrons, passando ao estado FADH ou $\mathrm{FADH}_{2}$ (Voet \& Voet, 1995).

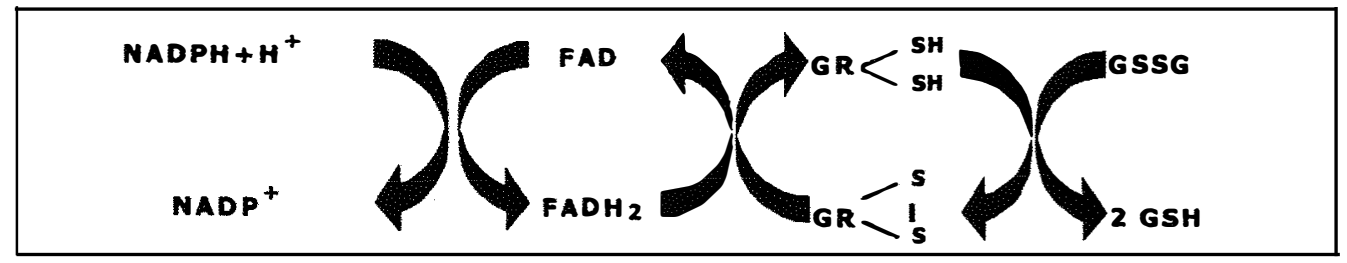

Figura 1. Esquema da reação catalizada pela GR no ciclo da Glutationa-Ascorbato

A GR é amplamente distribuída em procariotos e eucariotos e tem sido estudada em um grande número de organismos, compreendidos desde bactérias heterotróficas e fotossintéticas até plantas e animais. A seqüência de a.a. primária para GR humana é conhecida, bem como a estrutura tridimensional do homodímero, incluindo a elucidação dos sítios de ligação para FAD, NADPH e GSH. Informações estruturais detalhadas para GR em plantas ainda não são disponíveis, entretanto ela tem sido caracterizada para um amplo grupo de plantas superiores, incluindo tanto 
gimnospermas como angiospermas e parcialmente purificada em milho, ervilha, espinafre e pinho.

Em células animais, a maior atividade de GR é citosolica com uma pequena proporção localizada na matriz mitocondrial (Creissen et al., 1994). Em plantas, a maior atividade de GR é encontrada em cloroplastos. Em folhas de ervilhas os cloroplastos e mitocôndrias apresentaram $77 \%$ e $3 \%$, respectivamente, do total de atividade da GR, com o restante sendo citosólico (Edwards et.al., 1990). Essa enzima também foi encontrada na matriz de peroxisomas de ervilha (Jimenez et al., 1997).

O gene codificante para GR de E. coli foi clonado e sequenciado (Greer \& Perham, 1986) e mais recentemente clones de cDNA têm sido obtidos de GR humana, o que confirmou a seqüência de a.a. (Tutic et al., 1990). Dificuldades na purificação e sequenciamento em plantas superiores, vieram impedindo até recentemente, algumas comparações diretas entre a seqüência de a.a. de uma GR de planta e de outros organismos (Creissen et al., 1994).

Análises de cDNA de tabaco e ervilha mostraram 78\% de homologia no nível de nucleotídeos, e identidade acima de $78 \%$ e similaridade acima de $86 \%$ em seqüências de a.a. (Creiseen et al., 1992). A região de formação da ponte dissulfídica é praticamente idêntica nos casos analisados. Os resíduos de arginina requeridos para a ligação do NADPH são bastante conservados (Scruton et al., 1990). Lee et al. (1998) mostraram que uma GR de Brassica campestris apresenta 92,2 e 79,5\% de identidade com Arabdopsis e ervilha respectivamente. Em adição, constatou-se que o polipeptídeo de estrutura primária tem $50,2 \mathrm{kDa}$ em $S$. pombe (Lee et al., 1997), $54 \mathrm{kDa}$ em $B$. campestris (Lee et al., 1998), 52,7 kDa em $A$. thaliana (a GR ativa tem $110 \mathrm{kDa}$, indicando ser um homodímero) (Kubo et al., 1993), $55 \mathrm{kDa}$ em Pisum sativum (a GR ativa tem $114 \mathrm{kDa}$ sendo também neste caso um homodímero) (Madamanchi et al., 1992). A GR é codificada por genes nucleares de cópia única, sendo as isoformas resultado de modificações pós transcricionais, como processamento diferencial dos mRNAs de um mesmo gene e consequentemente levando à sua distribuição nos diversos compartimentos subcelulares, embora já tenham sido encontrados dois genes diferentes 
codificando isoformas distintas (Creisen et al., 1995, Kubo et al., 1993, Creissen \& Mullineaux, 1995).

A regulação da expressão tem sido alvo de diversas pesquisas. Badenhorst et al., (1998), sugerem uma regulação pós traducional mediada pela luz. Xiang \& Oliver (1998), mostraram níveis de $\mathrm{GSH}, \mathrm{H}_{2} \mathrm{O}_{2}$ e ácido jasmônico ativando a expressão. Elementos sensíveis ao ABA flanqueando a região 5' de um gene em arroz sugerem uma regulação mediada pelo ABA como sinal de transdução (Kaminaka et al., 1998).

Finalmente, inúmeros trabalhos vem relacionando alterações no conteúdo e atividade dessa enzima em plantas sob as mais variadas condições de estresse, como por exemplo o aumento na atividade da GR em tabaco (75\%) submetido a tratamentos com herbicidas (Lederer et al., 1999), em trigo submetido ao frio (Streb \& Feierabend, 1999), em café, submetido a alta intensidade de luz e alta disponibilidade de $\mathrm{N}$ (138\%) (Ramalho et al., 1998) e em feijão submetido ao Cd e Zn (Chaoui et al., 1997). Em contrapartida, Patra \& Panda (1998), obtiveram resultados que mostraram um decréscimo na atividade da GR em cevada submetida a $\mathrm{CdSO}_{4}$, porém o nível de PCs aumentou concomitantemente. Em plantas transgênicas uma superexpressão está relacionada à tolerância diferencial ao estresse ambiental. Tabaco expressando GR de $E$. coli, com expressão de 1 a 3 vezes superior (Aono et al., 1991) e de ervilha (Creissen et al., 1994) se mostraram pouco susceptíveis ao paraquat. Aono et al. (1991) também observou tolerância ao paraquat, mas simultaneamente as plantas não foram mais tolerantes ao ozônio. Esse resultado concorda com os resultados relatados por Creissen et al. (1994). Duas variedades de tabaco transgênicas expressando uma forma citosólica de GR bacteriana não apresentaram alterações significativas na atividade da enzima sob condições de alta intensidade luminosa, sugerindo que nesse caso a superexpressão de GR no citosol não foi suficiente para reparar os danos fotoinibitórios constatados (Tyystjarvi et al., 1999). Também foram comunicadas alterações na atividade de GR em cultura de tecidos submetidos a tratamento salino $(\mathrm{NaCl})$, onde linhagens tolerantes mostraram um aumento na atividade da enzima (Rodrigues-Rosales et al., 1999) e também em calos de soja, onde o $\mathrm{Km}$ (afinidade) da GR aumentou proporcionalmente ao aumento das concentrações salinas (El Enany, 1997). 
Em síntese, o peróxido pode então ser metabolizado diretamente por peroxidases, particularmente na parede celular e pela CAT nos peroxissomas (Azevedo et al., 1998; Polidoros \& Scandalios, 1999). No cloroplasto, o $\mathrm{O}_{2}^{-\bullet}$ é convertido pela SOD a $\mathrm{H}_{2} \mathrm{O}_{2} \mathrm{O}$ qual é então decomposto em água e oxigênio pela via do ciclo ascorbato-glutationa (Foyer et al., 1997; Noctor \& Foyer, 1998).

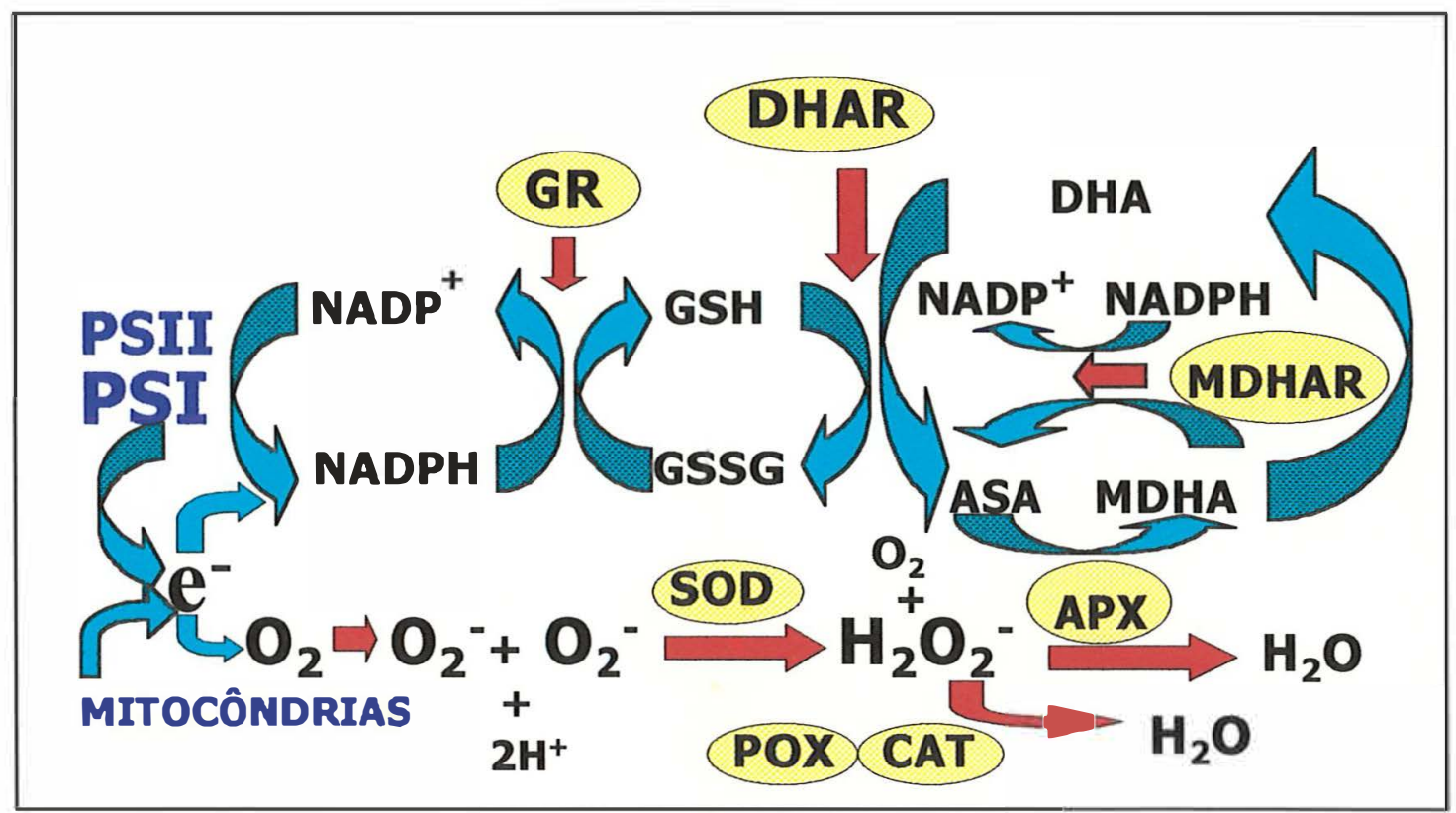

Figura 2. Esquema da via de limpeza de EAOs

\subsection{Enzimas antioxidantes como indicadores do estresse por poluentes}

Diversas isoenzimas de SOD, CAT, POX, APX e GR são encontradas em plantas e seus conteúdos relativos mudam durante exposição ao estresse. A atividade de diferentes enzimas antioxidantes parece ocorrer simultaneamente. Em tabaco e milho submetidos a tratamentos com paraquat, o aumento na atividade da SOD é acompanhado por um aumento na atividade da GR (Malan et al., 1990). Uma diminuição da atividade da CAT em raízes e folhas, mas não no caule ocorreu em Phaseolus vulgaris submetidos ao $\mathrm{Cd}$, além de um estímulo na atividade de guaiacol peroxidase no caule e aumento das 
atividades de APX e GR nas folhas (Chaoui et al., 1997). Em girassol, baixas concentrações de $\mathrm{Cd}$ acarretaram um aumento na atividade de enzimas antioxidantes com exceção da SOD. Em concentrações mais altas, a atividade permaneceu inalterada para SOD enquanto para CAT, APX, DHAR, GR e GPX diminuiram (Gallego et al., 1999). Em folhas de ervilha a atividade de CAT foi significativamente diminuída, enquanto que as atividades da SOD e da GPX aumentaram (Dalurzo et al., 1997). Em Alyssum argenteum e Alyssum maritimum a atividade de SOD aumentou em altas concentrações de Cd, enquanto que a da APX permaneceu inalterada e a da GR diminuiu (Schickler \& Caspi, 1999). Em Lupinus luteus, o Cd em baixas concentrações induziu um aumento na atividade de enzimas antioxidantes, mas em altas concentrações, a atividade de SOD não aumentou e até caiu no caso da CAT e da APX em relação ao controle. Isto implica em uma resposta antioxidante dependente da dose, estimulada por baixas concentrações e que em altas concentrações a capacidade das enzimas antioxidantes é diminuída, o que pode contribuir neste caso para uma redução do crescimento radicular (Gwozdz et al., 1997).

Está claro que oxigênio ativo é um fator comum na resposta de plantas aos principais extremos ambientais. Estes fatores podem estar atuando de três formas distintas: (1) produtos químicos tóxicos podem gerar oxigênios ativos e radicais livres diretamente, quando absorvidos pela planta (poluentes do ar, herbicidas, metais); (2) fatores ambientais físicos podem influenciar o metabolismo de tal modo que a produção de oxigênio ativo é aumentada (temperatura, radiação); (3) de modo distinto do primeiro e segundo, algum fator ambiental pode romper o metabolismo e assim o dano oxidativo aparecer como um efeito secundário (Smirnoff, 1993).

Embora a formação destas EAOs citotóxicas geralmente seja considerada o principal processo prejudicial em plantas sob condições de estresse, estas moléculas também são formadas no metabolismo normal da célula e a sua produção e destruição são um fenômeno celular regular (Kangasjarvi et al., 1994).

As células fotossintéticas são propensas aos danos oxidativos, desde que elas são sítios de alta concentração de oxigênio (Robinson, 1988) e que, através de seus 
pigmentos fotossintéticos, podem absorver luz e provocar com essa forma de energia a formação das EAOs (Asada \& Takahashi, 1987).

A fotoinibição como já citado, pode ter um componente causado por danos oxidativos, os quais podem resultar na peroxidação de lipídios na membrana do tilacóide. Existe uma relação positiva entre a peroxidação e capacidade de transporte de elétrons em cloroplastos isolados (Mishra \& Singhal, 1992). Além disto, a limitação da fixação do dióxido de carbono, aumenta a taxa de fotorredução do oxigênio, como por exemplo, pela inibição do ciclo de Calvin (Robinson, 1988).

Existem evidências de que o oxigênio age como um aceptor de elétrons e pode também proteger contra fotoinibição. Isto sugere que processos similares ocorrem em segmentos de folhas ativamente fotossintetizantes e que o PSII é provavelmente sítio de fotorredução do oxigênio, o qual pode ser visto então como um mecanismo para minimizar a fotoinibição. Em contrapartida, danos oxidativos resultam da geração de oxigênio ativo (Ireland et al., 1985). Assim, o oxigênio pode ter um duplo papel, agindo como fotoprotetor, dissipando a energia via fotorredução e como um fator de inativação e queda do PSI sob condições mais severas (Krause et al., 1985).

Danos oxidativos em cloroplastos são minimizados sob condições "normais" pela atividade de superóxidos dismutases (SODs) e enzimas do ciclo GSH-AA (também conhecido com via metabólica de Halliwell-Asada). Apesar de a maior parte da discussão desta via metabólica estar voltada a esse papel central na proteção contra danos oxidativos em cloroplastos, a presença das enzimas desse ciclo e seus substratos em tecidos não fotossintéticos demonstram claramente que esta via também funciona em outros compartimentos celulares (Creissen et al., 1994).

$\mathrm{O}$ aumento na atividade dessas enzimas antioxidantes é usado freqüentemente como indicador do estresse por poluição (Chen et al., 1991;1994). Entretanto, existem algumas limitações no uso de respostas antioxidantes e peroxidases como marcadores bioquímicos de estresse por poluição em plantas. Primeiramente, mudanças nos níveis de atividade de antioxidantes e peroxidases constituem uma resposta inespecífica para estresse oxidativo e pode ser causada por vários fatores (Bowler et al., 1992; Willekens et al., 1994). Além disso, muitos experimentos mostram o aumento dos níveis desses 
antioxidantes e atividade de peroxidases durante um pequeno período, envolvendo desde poucos minutos a diversos dias de duração em plantas expostas aos agentes poluentes (Malan et al., 1990). Portanto, muitos estudos são necessários para mostrar que esses níveis são realmente indicadores, quando o ambiente poluído continuamente por diversas semanas ou meses. Finalmente, tecidos vegetais fotossintéticos e heterotróficos, freqüentemente diferem na atividade de enzimas e conteúdo de antioxidantes (Rauser, 1987). As folhas e raízes usualmente apresentam diferentes isoenzimas com propriedades variantes, incluindo a sensibilidade aos poluentes (Bielawski \& Joy, 1986a; Bowler et al., 1992; Willekens et al., 1994). Em contrapartida, muitos estudos atuais tem sido especialmente designados para comparar enzimas de folhas e raízes, como indicadores do estresse por poluição (Roy \& Hanninem, 1994). 


\section{MATERIAL E MÉTODOS}

O trabalho foi desenvolvido no Laboratório de Genética Bioquímica de Plantas do Departamento de Genética da Escola Superior de Agricultura Luiz de Queiroz da Universidade de São Paulo (ESALQ-USP).

\subsection{Material biológico}

Plantas de cana-de-açúcar da variedade Copersucar SP80-3280 foram utilizadas para obtenção de calos e segmentos de colmos para germinação e obtenção de plântulas. Os calos foram obtidos à partir de meristemas e fornecidos gentilmente pelo CTC (Centro de Tecnologia de Cana) da Copersucar em Piracicaba. Os colmos foram cortados de plantas adultas do campo experimental do CTC .

\subsection{Cultivo dos calos}

Os calos foram cultivados em placas de petri com $20 \mathrm{ml}$ de meio de cultura MS (Murashige e Skoog, 1962), acrescidos de $2 \mathrm{mg} / \mathrm{L}$ de 2,4-D e $250 \mathrm{mg} / \mathrm{L}$ do antibiótico comercial CLAVULIN. Os subcultivos foram realizados periodicamente a cada 3 ou 4 semanas. As placas foram mantidas em sala de crescimento sob temperatura de $28 \pm 2^{\circ} \mathrm{C}$ e no escuro. Os tratamentos foram realizados acrescentando-se o cloreto de cádmio $\left(\mathrm{CdCl}_{2}\right)$ ao meio de cultura nas concentrações pré-determinadas. 


\subsection{Cultivo das plântulas}

Segmentos de colmos de 3 a $5 \mathrm{~cm}$ contendo uma gema, foram tratados, procedendo-se uma imersão em solução de água e fungicida comercial BENLAT $(0,3 \mathrm{~g} / \mathrm{L})$ por 15 minutos e colocados em seguida para germinar em placas de espuma fenólica de $2 \mathrm{~cm}$ de espessura, acondicionadas em bandejas plásticas. Os colmos germinaram em uma casa de vegetação sob condições controladas de temperatura (30 $\pm 2^{\circ} \mathrm{C}$ ) e umidade (as placas foram mantidas úmidas constantemente). Após 4 a 5 semanas do início da germinação as plântulas foram selecionadas e cultivadas em sistema de hidroponia, sendo transferidas para vasos com solução nutritiva (Hoagland e Arnon, 1938). Um compressor de ar isento de óleo foi utilizado para promover a aeração das plantas (Fig. 3). Os colmos foram sustentados por uma placa de isopor encaixada no vaso (Fig.3 ). Nessa fase foram iniciados os tratamentos onde o $\mathrm{CdCl}_{2}$ foi acrescido à solução nutritiva nas concentrações pré-determinadas.

\subsection{Cromatografia em camada delgada (TLC) para aminoácidos}

Foram utilizadas placas de sílica gel sobre poliéster de 20 × $20 \mathrm{~cm}$ (SigmaAldrich). Os a.a. livres de calos foram extraídos com água deionizada (d.d.) utilizandose de 50 a $100 \mathrm{mg}$ de tecido/50 $\mu \mathrm{L}$ de água. A extração foi feita em tubos "eppendorf", macerando-se os tecidos com um bastão de vidro. Em seguida os extratos foram centrifugados à $15.000 \mathrm{rpm}$ em uma microcentrifuga por 8 minutos. O sobrenadante foi utilizado para a aplicação de alíquotas de $10 \mu \mathrm{L}$ nas placas para a cromatografia. Antes da aplicação das amostras, as placas foram ativadas à $60^{\circ} \mathrm{C}$ pôr 120 minutos em estufa. Os cromatogramas foram desenvolvidos em cuba de vidro contendo solvente constituído de uma mistura de álcool butílico, acetona, hidróxido de amônio e água d.d. nas proporções de 50:50:25:10 mL respectivamente. Após aproximadamente 4 horas de corrida as placas foram secas em estufa ventilada por 72 horas à temperatura ambiente. 
Os cromatogramas foram revelados com uma solução de $0,2 \%$ de ninidrina em acetona $(\mathrm{p} / \mathrm{v})$. Padrões foram incluídos para a identificação dos aminoácidos.

\subsection{Atividade de enzimas antioxidantes}

Para estes ensaios, plântulas foram expostas à $0,2.0$ e $5.00 \mathrm{mM}$ de $\mathrm{CdCl}_{2}$ por 12, 24, 36, 60, 84 e 96 horas. Os calos foram expostos à 0, 0.01, 0.02, 0.05, 0.1, 0.2, 0.5 e $1.00 \mathrm{mM}$ de $\mathrm{CdCl}_{2}$. As folhas e calos coletados foram congelados em nitrogênio líquido e mantidos em Freezer à $-80^{\circ} \mathrm{C}$ para posterior extração.

\subsection{Extração proteica}

O material vegetal (congelado) foi colocado em almofariz e mantido em nitrogênio líquido para evitar o descongelamento. Foi feita uma maceração até a formação de uma farinha homogênea. Em seguida, foi adicionado Tampão Fosfato de Potássio $100 \mathrm{mM}, \mathrm{pH}$ 7,5 acrescido de $1 \mathrm{mM}$ de EDTA, $3 \mathrm{mM}$ de DTT e $5 \%(\mathrm{p} / \mathrm{v})$ de PVPP. O extrato foi centrifugado à $4^{\circ} \mathrm{C}$ e $10.000 \mathrm{rpm}$ por 32 minutos. Após este

período, o sobrenadante separado foi aliquotado, congelado em nitrogênio líquido e mantidos em Freezer à $-80^{\circ} \mathrm{C}$ para análises posteriores.

A concentração de proteína foi determinada espectrofotometricamente a $595 \mathrm{~nm}$ como descrito por Bradford, (1976). Para a curva padrão foi utilizado o BSA.

\subsection{Atividade de catalase}

A atividade da CAT foi determinada por dois métodos: por espectrofotometria e em PAGE. 


\subsubsection{Método espectrofotométrico}

CAT foi determinada segundo o método de KRAUS et al. (1995), com algumas modificações. $O$ ensaio enzimático foi constituído por Tampão Fosfato de Potássio $100 \mathrm{mM}$, pH 7,5 e 0,25\% (v/v) de $\mathrm{H}_{2} \mathrm{O}_{2} 30 \%$ em solução, com adição de $25 \mu \mathrm{L}$ de extrato vegetal (início da reação) em cubeta de quartzo diretamente no espectrofotômetro, ajustado para $240 \mathrm{~nm}$ (pico de absorção do $\mathrm{H}_{2} \mathrm{O}_{2}$ ). A reação foi monitorada pôr 1 minuto com leituras em intervalos de 1 segundo. A atividade da enzima foi determinada seguindo-se a queda na absorbância a $240 \mathrm{~nm}$. Os resultados foram expressos em $\mu \mathrm{mol} / \mathrm{minuto} / \mathrm{mg}$ de proteína.

\subsubsection{Atividade em PAGE}

Os extratos vegetais tiveram suas proteínas separadas por PAGE (8\%). Para a confecção do gel (com espessura de $3,0 \mathrm{~mm}, 17 \mathrm{~cm}$ de altura e $16 \mathrm{~cm}$ de largura), $18 \mathrm{~mL}$ de uma solução $40 \%$ de acrilamida/bis-acrilamida foi adicionada a $22,5 \mathrm{ml}$ de Tampão TRIS 2,9 M, pH 8,9 e 49,5 ml de água d.d.. Como catalisadores foram utilizados $171 \mu \mathrm{L}$ de TEMED e $225 \mu \mathrm{L}$ de persulfato de amônia (P.A.) (1\%). Uma camada de $100 \mu \mathrm{L}$ de isopropanol foi colocado para a formação de uma superfície uniforme e impedir o contato com o $\mathrm{O}_{2}$ atmosférico, facilitando a polimerização. Após a polimerização, o isopropanol foi eliminado e $40 \mathrm{~mL}$ de gel de empilhamento foram adicionados. Para confeccionar este gel foram utilizados $4.5 \mathrm{~mL}$ da solução $40 \%$ de acrilamida/bis-acrilamida, $11,25 \mathrm{~mL}$ de Tampão TRIS $500 \mathrm{mM}, \mathrm{pH}$ 6,8 e 24,75 mL de água d.d.. Para a polimerização foram utilizados $90 \mu \mathrm{L}$ de TEMED e $450 \mu \mathrm{L}$ de P.A. (1\%). A eletroforese foi feita a $4^{\circ} \mathrm{C}$, com voltagem variável e uma corrente constante de $30 \mathrm{~mA}$ por gel. $\mathrm{O}$ tempo de corrida foi em média $20 \mathrm{~h}$. O tampão de eletrodo foi TRIS $250 \mathrm{mM}, \mathrm{pH} 8,3$ acrescido de 1,92 $\mathrm{M}$ de glicina.

Nos géis foram aplicadas amostras de padrão de CAT de figado de boi (1 
unid.) e $60 \mu \mathrm{g}$ de proteína dos extratos. A revelação foi feita após a lavagem do gel com água d.d. por 45 minutos ( $3 x$ de 15 minutos) e incubação do mesmo por 10 minutos em solução de água d.d. e $\mathrm{H}_{2} \mathrm{O}_{2}$ à $0,003 \%$, temperatura ambiente e com agitação suave e constante. $\mathrm{O}$ gel foi então rapidamente lavado em água d.d e colocado por 10 minutos em uma solução de $\mathrm{FeCl}_{3} 1 \%(\mathrm{p} / \mathrm{v})$ e $\mathrm{K}_{2} \mathrm{Fe}\left(\mathrm{CN}_{6}\right) \quad 1 \%(\mathrm{p} / \mathrm{v})$ também sob agitação. Em seguida, a solução foi retirada e o gel lavado com água. A fixação foi feita com a imersão em uma solução de água d.d. e ác. acético à $7 \%$.

\subsection{Atividade de GR}

A atividade de GR foi determinada como descrito por SMITH et al. (1988), com algumas modificações. A atividade "enzimática foi determinada colorimetricamente a $30^{\circ} \mathrm{C}$ em uma mistura de $1 \mathrm{~mL}$ de Tampão Fosfato de Potássio $100 \mathrm{mM}, \mathrm{pH}$ 7,5 contendo $1 \mathrm{mM}$ de DTNB, $1 \mathrm{mM}$ de GSSG e $0,1 \mathrm{mM}$ de NADPH. A reação foi iniciada com a adição de $50 \mu \mathrm{l}$ de extrato vegetal. $\mathrm{O}$ tempo de amostragem foi de 1 minuto com dosagens feitas em intervalos de 1 segundo. A taxa de redução da glutationa oxidada foi seguida por monitoramento das alterações na absorbância a 412 $\mathrm{nm}$. Os valores de atividade foram expressos em $\mu \mathrm{mol} / \mathrm{min} . / \mathrm{mg}$ de proteína.

\subsection{Atividade de SOD}

A atividade de SOD foi determinada em PAGE. Foram determinadas também se e quais as isoformas de SOD ocorreram para calos e folhas.

\subsubsection{Atividade em PAGE}

Foi feita uma eletroforese em PAGE (7\%) nas mesmas condições como 
descrito para CAT. Foi utilizado como padrão, 2 unidades de SOD de figado de boi (Sigma). A concentração de proteínas das amostras, foi de $100 \mu \mathrm{g}$. Após o término da eletroforese, o gel foi lavado rapidamente em água destilada e incubado no escuro em uma solução composta por $30 \mathrm{~mL}$ de uma solução à $0,005 \%$ de riboflavina em água d.d. e $70 \mathrm{~mL}$ de Tampão Fosfato de Potássio $100 \mathrm{mM}, \mathrm{pH}$ 7,8, acrescida de 0,02 g de NBT, $0,02 \mathrm{~g}$ de EDTA e $300 \mu \mathrm{L}$ de TEMED. Ambas as soluções foram preparadas imediatamente antes do uso e em recipientes cobertos com papel alumímio. O gel permaneceu por 30 minutos na solução de reação, sob agitação e no escuro. Após esse período a solução de reação foi retirada, o gel imerso em água destilada e levado a luz. Nestas condições ocorre a fotoxidação do gel, propiciando a formação de uma coloração púrpura e as bandas correspondentes a atividade de SOD permanecem sem se fotoxidar, promovendo uma revelação negativa, assim como para CAT. A fotoxidação foi interrompida mergulhando-se o gel em uma solução de água d.d. e ácido acético à $7 \%$.

\subsubsection{Determinação das isoenzimas de SOD}

A $\mathrm{Cu} / \mathrm{Zn}$-SOD, é inativada por $\mathrm{KCN}$ e $\mathrm{H}_{2} \mathrm{O}_{2}$ e em geral ocorre no citoplasma e no cloroplasto. Fe-SOD é inativada por $\mathrm{H}_{2} \mathrm{O}_{2}$ e resistente a $\mathrm{KCN}$, ocorrendo no cloroplasto. A forma Mn-SOD é resistente a ambos $\left(\mathrm{KCN} \mathrm{e} \mathrm{H}_{2} \mathrm{O}_{2}\right)$ e está presente nas mitocôndrias (Azevedo et al., 1998).

Para a determinação das isoformas de SOD presentes nos calos e folhas de plântulas, foi feita uma eletroforese com $200 \mu \mathrm{g}$ de proteína de apenas uma amostra (em um único poço grande), nas condições anteriormente descritas para SOD. A amostra utilizada foi a que apresentou maior intensidade de coloração e maior número de bandas nos testes anteriores. Em seguida, o gel foi dividido verticalmente em três partes. Uma delas foi mantida à $4^{\circ} \mathrm{C}$ em Tampão Fosfato de Potássio $100 \mathrm{mM}, \mathrm{pH} 7,8$. Outra foi imersa em $100 \mathrm{~mL}$ do mesmo tampão contendo 0,0292 g de EDTA e 0,0130 g de $\mathrm{KCN}$ (esta solução inibe a isoforma $\mathrm{Cu} / \mathrm{Zn}$-SOD); e finalmente a última, imersa em $100 \mathrm{~mL}$ do tampão acrescido de $0,0292 \mathrm{~g}$ de EDTA e $70 \mu \mathrm{l}$ de $\mathrm{H}_{2} \mathrm{O}_{2}$ (provocando a inibição das 
inibição das isoformas $\mathrm{Cu} / \mathrm{Zn}$-SOD e Fe-SOD). Todos os passos descritos foram realizadas no escuro. Após 20 minutos nestas soluções, os géis foram submetidos a revelação com NBT e riboflavina, como citado anteriormente. Ao final da revelação, foi analisada a presença ou ausência de bandas no controle e nos tratamentos com $\mathrm{KCN}$ e $\mathrm{H}_{2} \mathrm{O}_{2}$. As bandas foram então classificadas como Cu/Zn-SOD, Fe-SOD ou Mn-SOD.

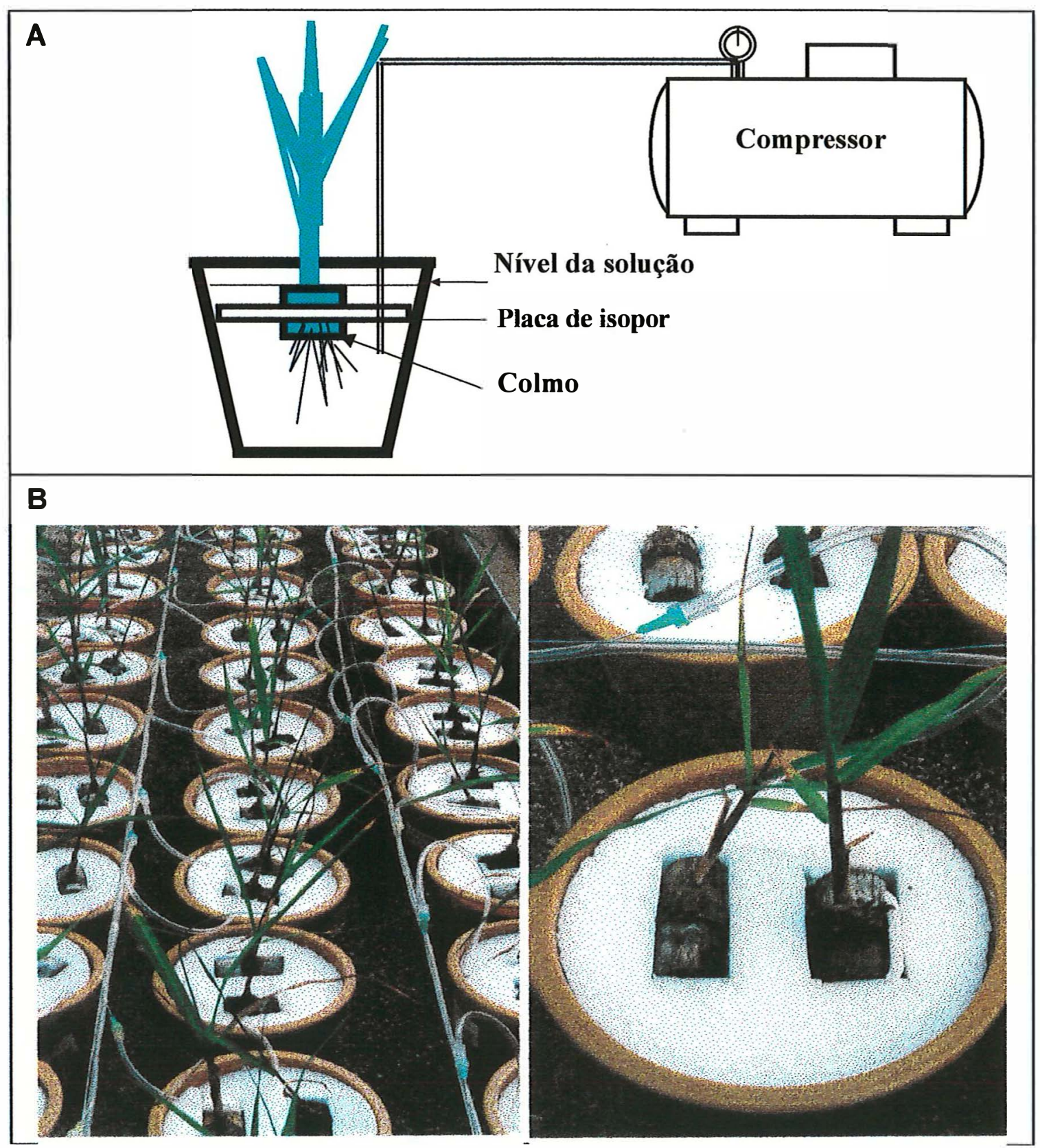

Figura 3. Esquema do sistema de hidroponia (A); Plântulas de cana-de açúcar mantidas em sistema de hidroponia em casa de vegetação (B). 


\section{RESULTADOS}

\subsection{Análises em plântulas}

\subsubsection{Determinação da concentração fitotóxica de $\mathrm{Cd}$}

Colmos de cana-de-açúcar foram germinados, transferidas em solução nutritiva e submetidas a um período de crescimento de 15 dias sob diferentes concentrações de $\mathrm{Cd}$. Como pode ser observado na Fig. 4, a adição de 1,0 mM resultou em uma inibição do crescimento da parte aérea já em plantas com 9 dias de exposição, enquanto que na concentração de $0,1 \mathrm{mM}$ o crescimento não foi afetado. A coloração das plantas começou a se alterar no período de 3 a 9 dias, sendo observado uma coloração amarelada na extremidasde das folhas de plântulas submetidas ao tratamento com 1,0 mM. Concentrações maiores foram aplicadas $(2 \mathrm{mM}$ e $5 \mathrm{mM})$ e análises enzimáticas foram realizadas. 

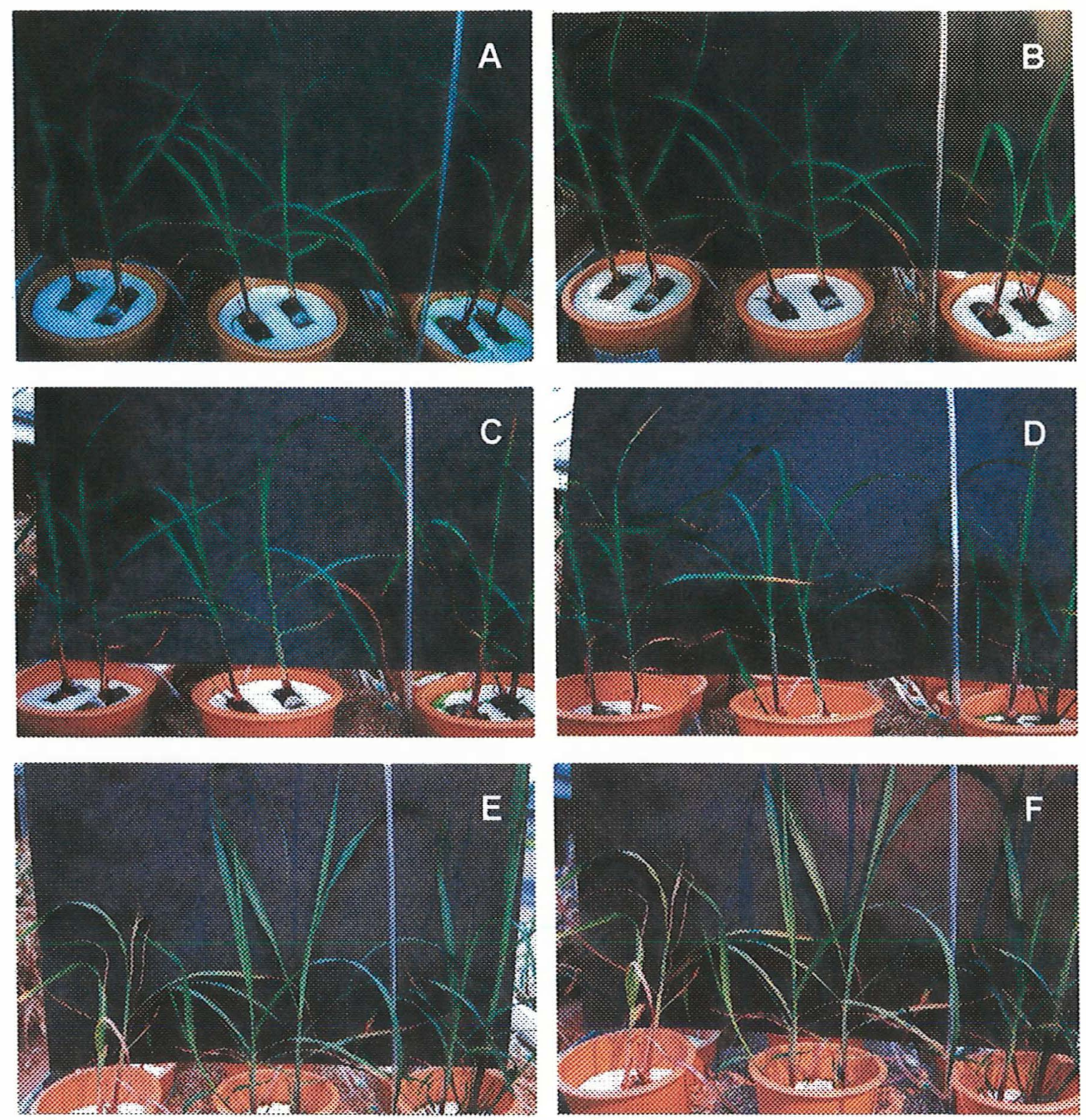

Figura 4. Seqüência de imagens de 3 plântulas de cana-de-açúcar crescidas em sistema de hidroponia, submetidas à tratamentos com $\mathrm{CdCl}_{2}$; Da esquerda para a direita os tratamentos foram 1,0mM,0,1mM e 0,0mM; Antes da aplicação (A) e 12 h (B), $24 \mathrm{~h}$ (C), 3 dias (D), 9 dias (E), 15 dias (F). 


\subsubsection{Atividade da CAT por espectrofotometria}

As atividades de enzimas antioxidantes foram determinadas em folhas de plantas de cana-de-açúcar submetidas à crescimento em presença de $\mathrm{CdCl}_{2}$.

A atividade da CAT de folhas apresentou variações significativas durante o período de tratamento em relação ao controle, na concentração de $5 \mathrm{mM}$, onde ocorreu uma diminuição de atividade à partir de $12 \mathrm{~h}$ e a manutenção de um padrão mais baixo até $72 \mathrm{~h}$. Após esse período houve um aumento progressivo até $96 \mathrm{~h}$, mas que não foi significativo em relação ao controle. Na concentração de $2 \mathrm{mM}$ não houve variação significativa, em relação ao controle, exceto uma queda nas primeiras 12 horas, seguida de um restabelecimento, sendo mantido o mesmo padrão até 96 h, considerando-se que os controles também apresentaram variações entre os períodos de tratamento (Fig. 5).

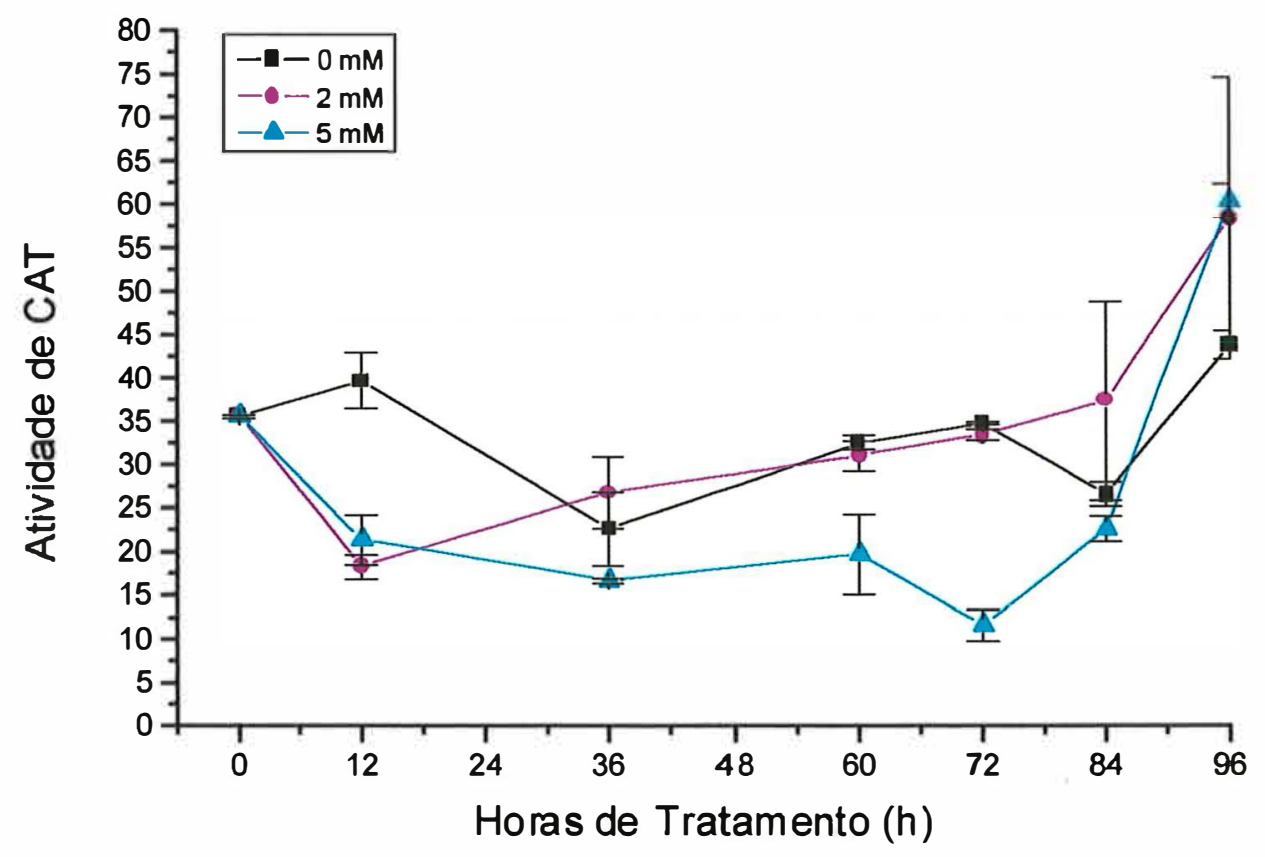

Figura 5. Atividade específica de CAT ( $\mu \mathrm{mol} / \mathrm{min} / \mathrm{mg}$ prot) em folhas de plântulas de cana-de-açúcar submetidas à diferentes concentrações de $\mathrm{CdCl}_{2}$. 


\subsubsection{Atividade da CAT em PAGE}

A atividade da CAT em PAGE apresentou um aumento na atividade na concentração de $2 \mathrm{mM}$ (Fig. 6), porém a variação não foi significativa em relação ao controle, considerando que este também apresentou um aumento, como pode-se observar nos dados espectofotométricos (Fig. 5), enquanto que na concentração de 5 mM, houve uma diminuição a partir de 36 h em relação ao controle (Fig. 6).

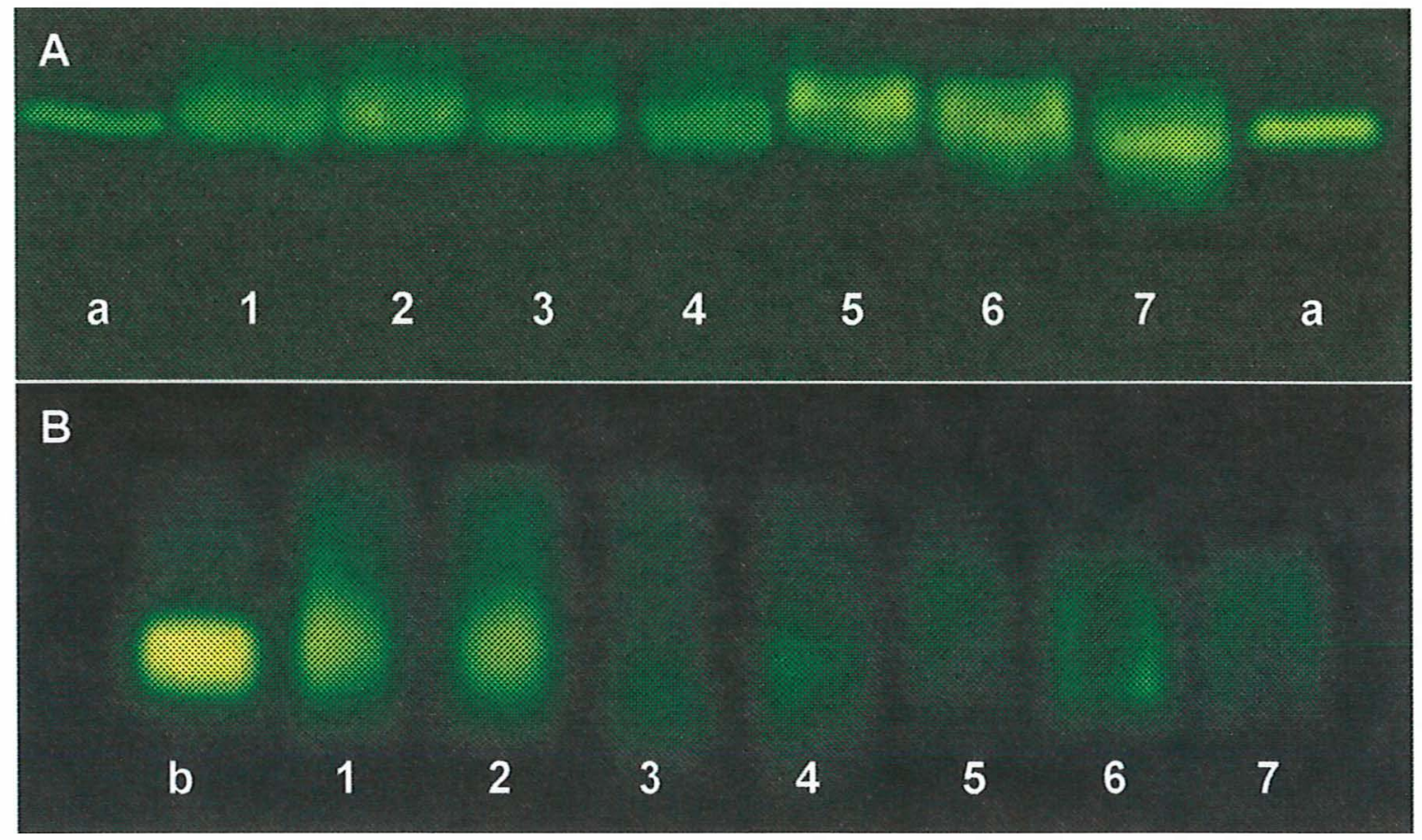

Figura 6. Atividade de CAT em PAGE não-desnaturante, de plântulas submetidas a tratamentos com (A) $2 \mathrm{mM} \mathrm{e} \mathrm{(B)} 5 \mathrm{mM}$ de $\mathrm{CdCl}_{2}$, por (1) $0 \mathrm{~h}$ (controle) e (2) $12 \mathrm{~h}$, (3) 36 h, (4) 60 h, (5) 72 h, (6) 84 h e (7) 96 h de exposição; (a) e (b) padrões de CAT bovina. 


\subsubsection{A tividade da SOD e m PA GE}

A atividade total das isoformas de SOD não mostrou variações nas concentrações de $2 \mathrm{mM}$ e $5 \mathrm{mM}$ de $\mathrm{CdCl}_{2}$ ao longo de $96 \mathrm{~h}$ de tratamento em relação ao controle (Fig. 7). Foram constatadas a presença de sete isoformas de SOD nas concentrações de $0 \mathrm{mM}$ e $2 \mathrm{mM}$ e seis isoformas visíveis na concentração de $5 \mathrm{mM}$ (Fig. 8).

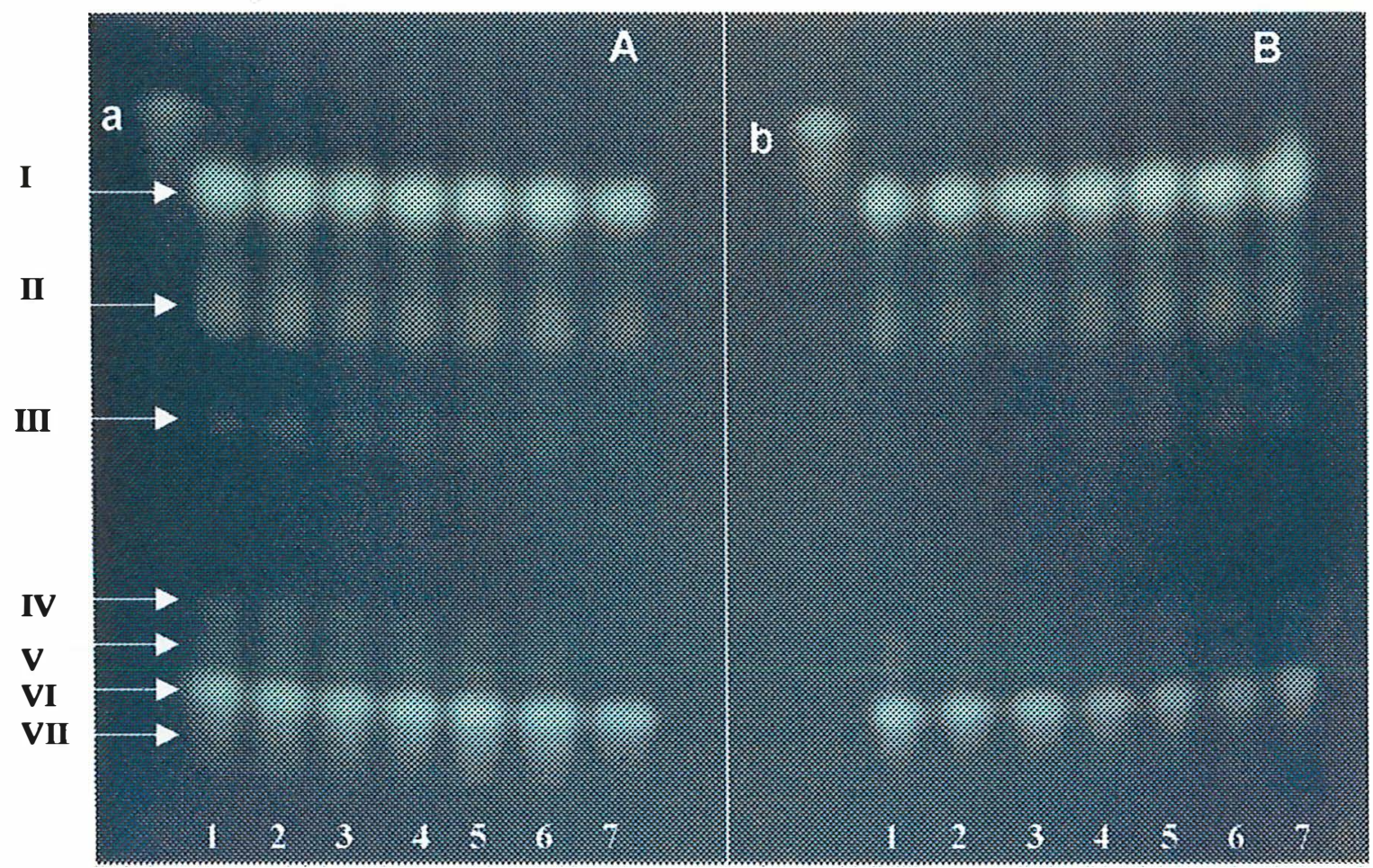

Figura 7. Atividade de SOD determinada em PAGE não-desnaturante em folhas de plântulas de cana-de-açúcar, submetidas à tratamentos com (A) $0 \mathrm{mM}$ (controle) e (B) 2 $\mathrm{mM}$ de $\mathrm{CdCl}_{2}$; (1) $0 \mathrm{~h}$, (2) $12 \mathrm{~h}$, (3) $36 \mathrm{~h}$, (4) $60 \mathrm{~h}$, (5) $72 \mathrm{~h}$, (6) $84 \mathrm{~h}$ e (7) $96 \mathrm{~h}$ de tratamento; (a) e (b) padrões de SOD de figado bovino; As setas I, II, III, IV, V, VI e VII representam as isoformas de SOD. 


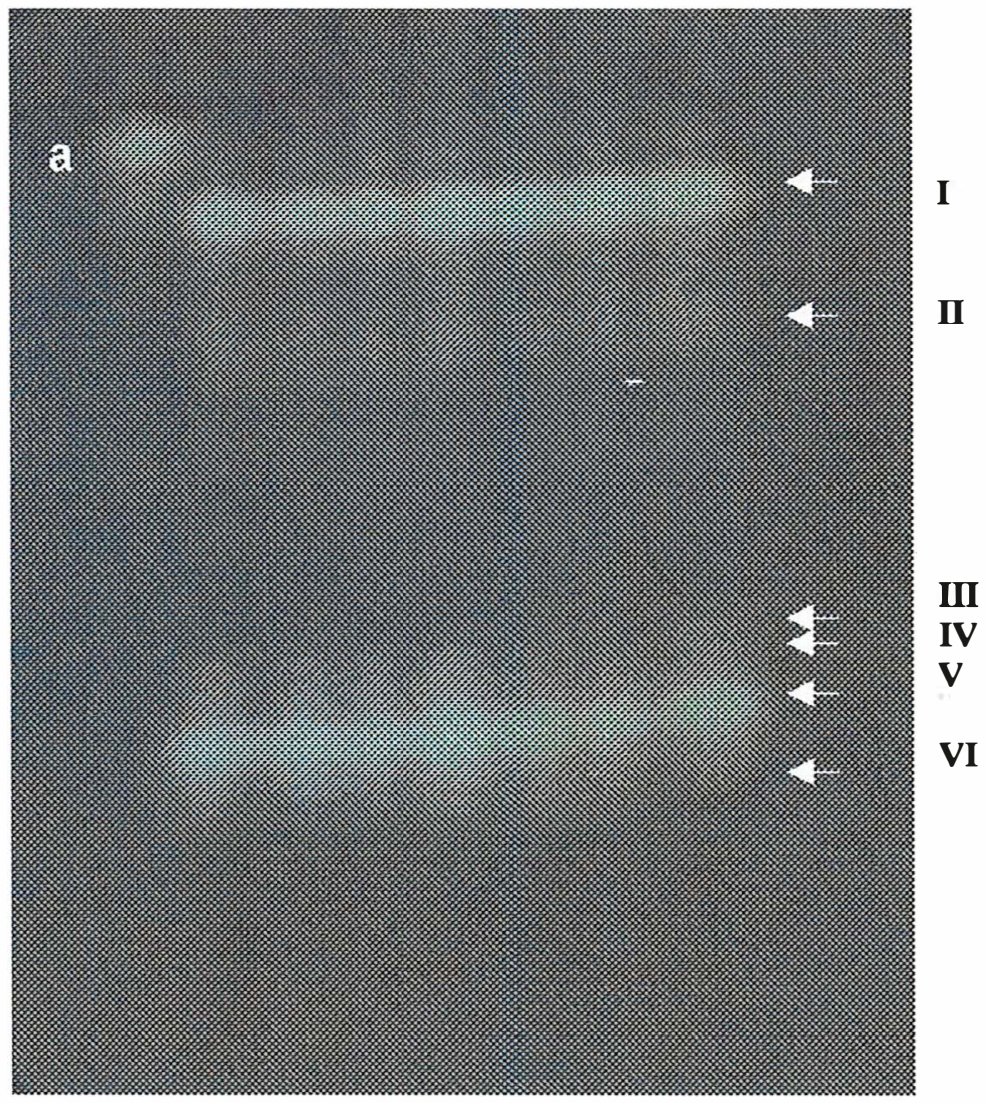

Figura 8. Atividade de SOD determinada em PAGE não-desnaturante em folhas de plântulas de cana-de açúcar,submetidas à $5 \mathrm{mM}$ de $\mathrm{CdCl}_{2}$; (1) 0 h (controle) e (2) 12 h, (3) 36 h, (4) 60 h, (5) 72 h, (6) 84 h e (7) 96 h de tratamento; (a) padrão de SOD de figado bovino; As setas I, II, II, IV, V e VI representam as isoformas de SOD. 


\subsubsection{Atividade da GR por espectrofotometria}

A atividade da GR de folhas apresentou variações significativas durante o período de tratamento, nas concentrações de $2 \mathrm{mM}$ e $5 \mathrm{mM}$. Houve um aumento da atividade da enzima a partir de $60 \mathrm{~h}$, sendo mantido um padrão superior até $96 \mathrm{~h}$ em ambas concentrações em relação ao controle. A concentração de $5 \mathrm{mM}$ apresentou um aumento maior em relação a concentração de 2 mM. (Fig. 9).

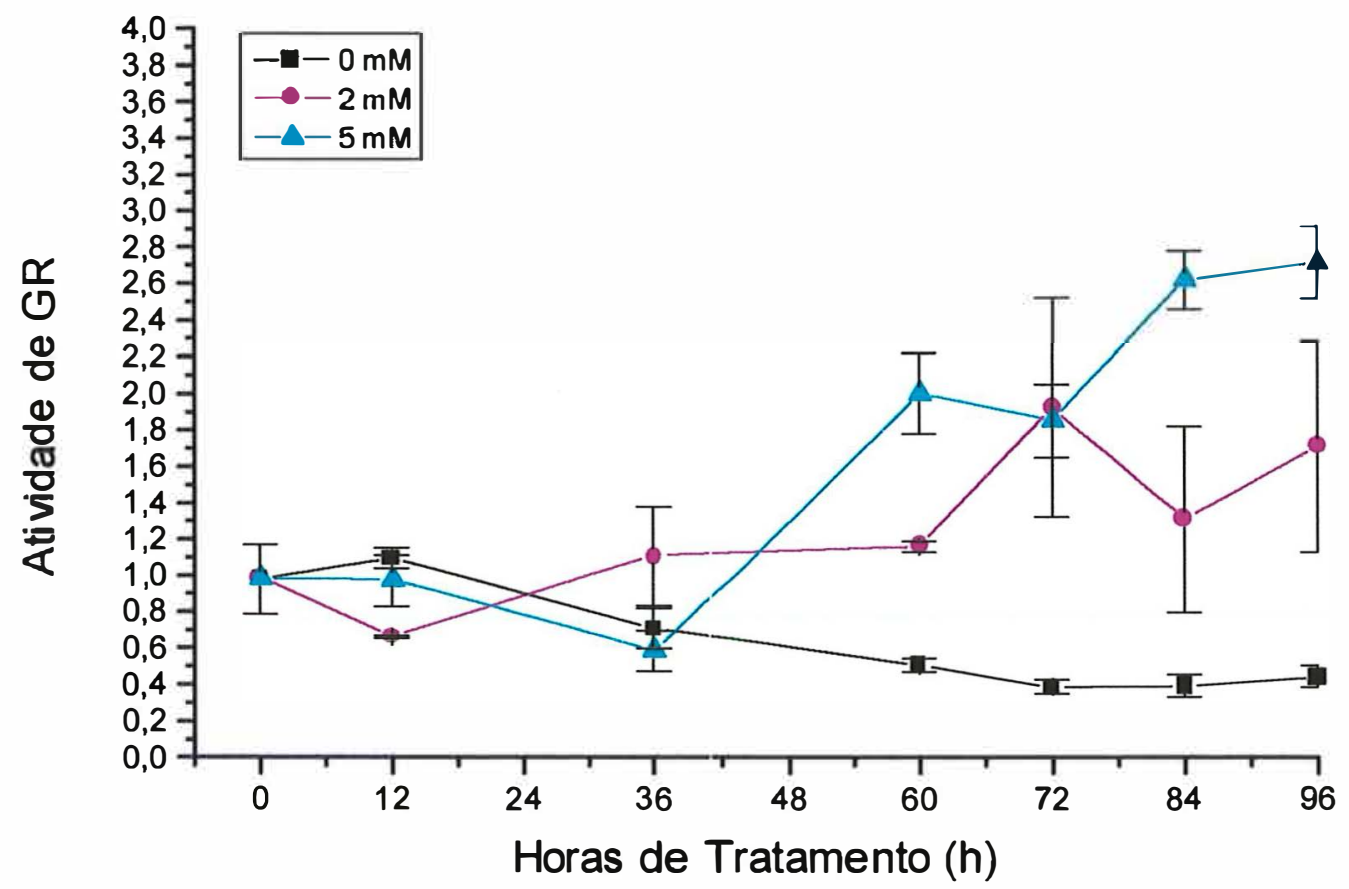

Figura 9. Atividade especifica de GR ( $\mu \mathrm{mol} / \mathrm{min} / \mathrm{mg}$ prot) em folhas de plântulas de cana-de-açúcar submetidas à diferentes concentrações de $\mathrm{CdCl}_{2}$. 


\subsection{Resultados em calos de cana-de-açúcar}

\subsubsection{Crescimento e desenvolvimento}

Os calos expostos aos tratamentos com $\mathrm{CdCl}_{2}$, apresentaram uma inibição no crescimento nas concentrações de 0,5 e 1,0 mM após um período de 15 dias de exposição (Figs. 10 e 11). Nas concentrações de 0,01 mM, 0,02 mM e 0,05 mM houve um crescimento e ganho de massa superiores ao controle, principalmente na concentração de $0,01 \mathrm{mM}$ onde o ganho de massa foi bem superior (Fig. 11).

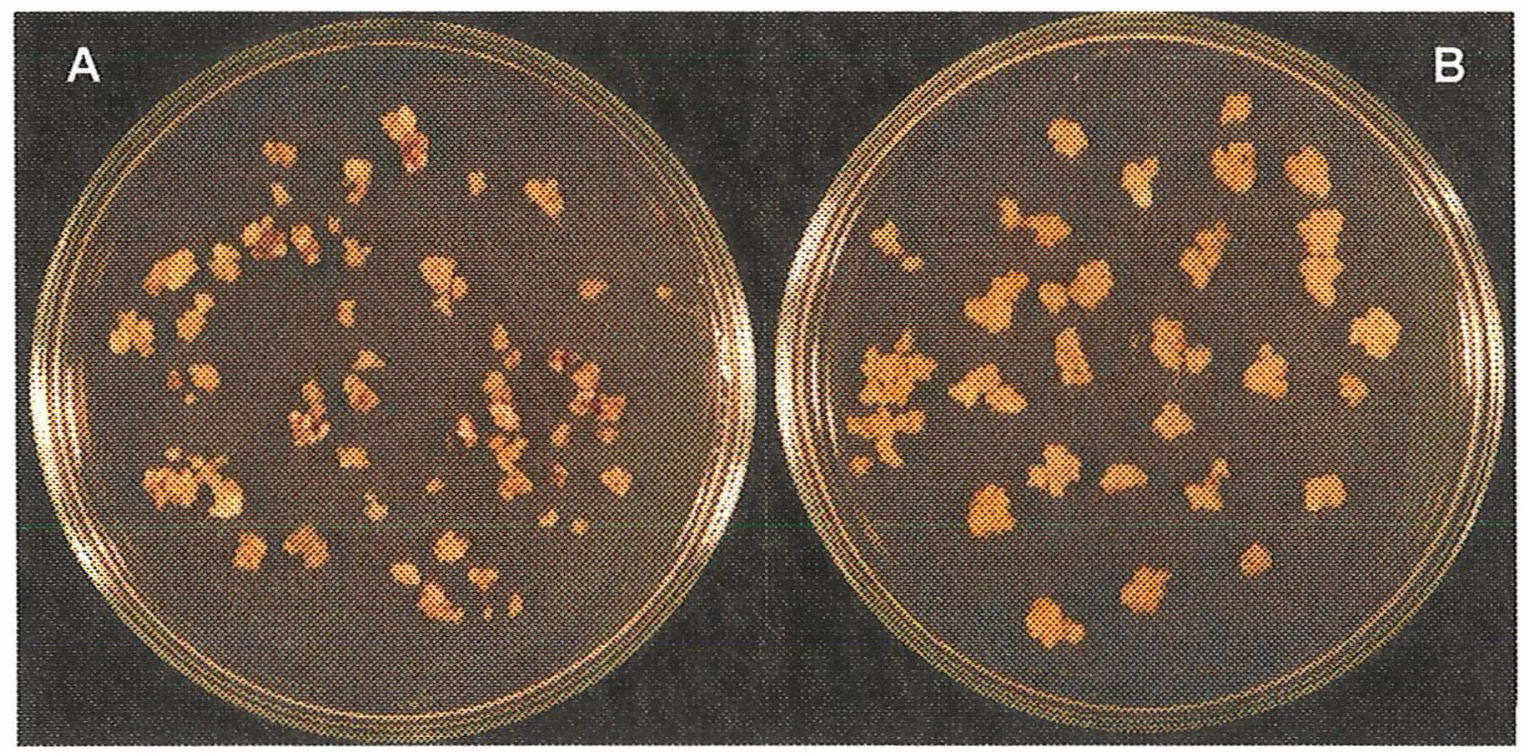

Figura 10. Efeito do Cd no crescimento de calos de cana-de-açúcar que foram crescidos por 15 dias em meio de cultura acrescido de (A) $0 \mathrm{mM}$ (controle) e (B) $1 \mathrm{mM}$ de $\mathrm{CdCl}_{2}$. 


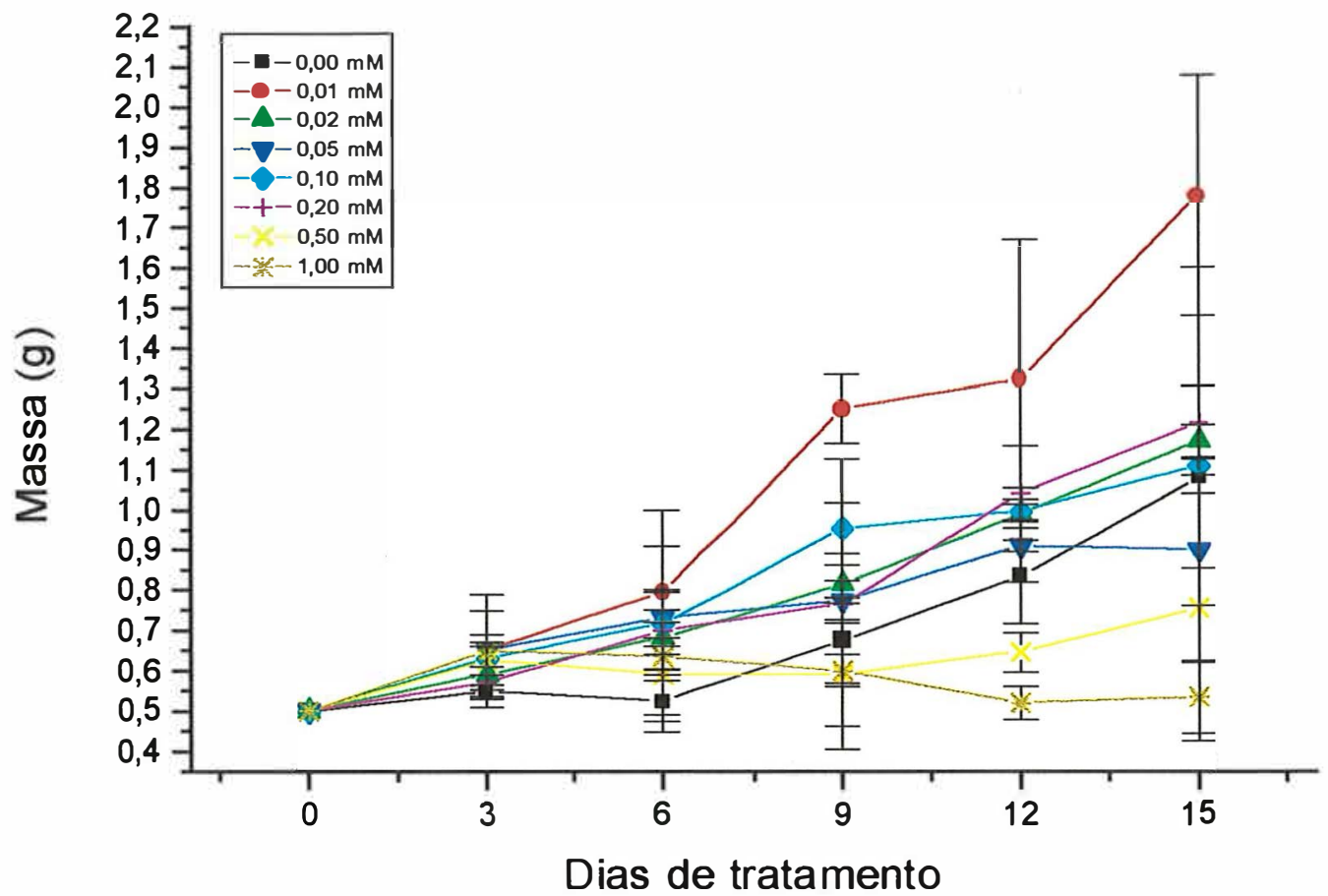

Figura 11. Peso fresco de calos de cana-de-açúcar submetidos a várias concentrações de $\mathrm{CdCl}_{2}$ durante 15 dias.

\subsubsection{Experimento preliminar}

Os resultados deste experimento preliminar mostraram um aumento significativo da atividade da CAT nas concentrações de $0,5 \mathrm{mM}$ e $1,0 \mathrm{Mm}$ (Fig. 12). Nas concentrações mais baixas houveram variações, porém não foram muito diferentes dos padrões de comportamento do controle, embora em algumas concentrações a atividade tenha aumentado ou diminuído ao longo do tempo. Os resultados para 0,1 e 1,0 mM foram confirmados em PAGE não-desnaturante e apresentaram a mesma tendência. Entretanto há a necessidade de se realizar mais repetições deste experimento para confirmar esses resultados. 


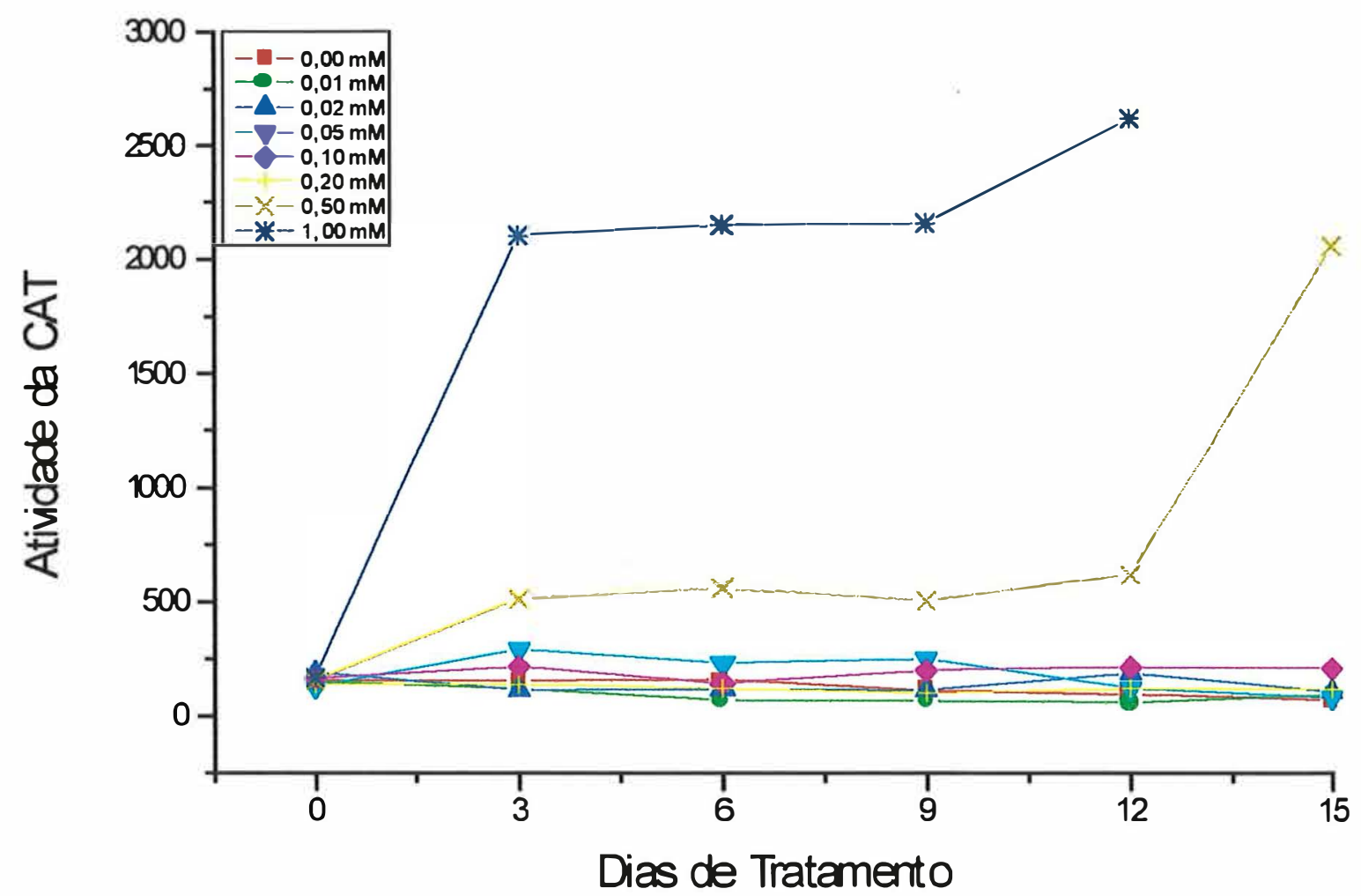

Figura 12. Atividade específica de CAT ( $\mu \mathrm{mol} / \mathrm{min} / \mathrm{mg}$ prot) calos de cana-de-açúcar submetidas à diferentes concentrações de $\mathrm{CdCl}_{2}$.

\subsubsection{Atividade de CAT em PAGE}

A atividade da CAT em calos de cana-de-açúcar submetidos a tratamento com $\mathrm{CdCl}_{2}$, não mostrou alterações na concentração de $0,1 \mathrm{mM}$ em relação ao controle, exceto por uma pequena diminuição nos horários de 24 a $36 \mathrm{~h}$. nas três isoformas encontradas. Entretanto, de maneira geral durante o período de 15 dias a atividade se manteve nos níveis do controle (Fig. 13). Na concentração de 1,0 mM houve um aumento significativo a partir de $24 \mathrm{~h}$ em duas das três isoformas encontradas. Uma das isoformas diminuiu a partir de $96 \mathrm{~h} \mathrm{(Fig.13).}$ 


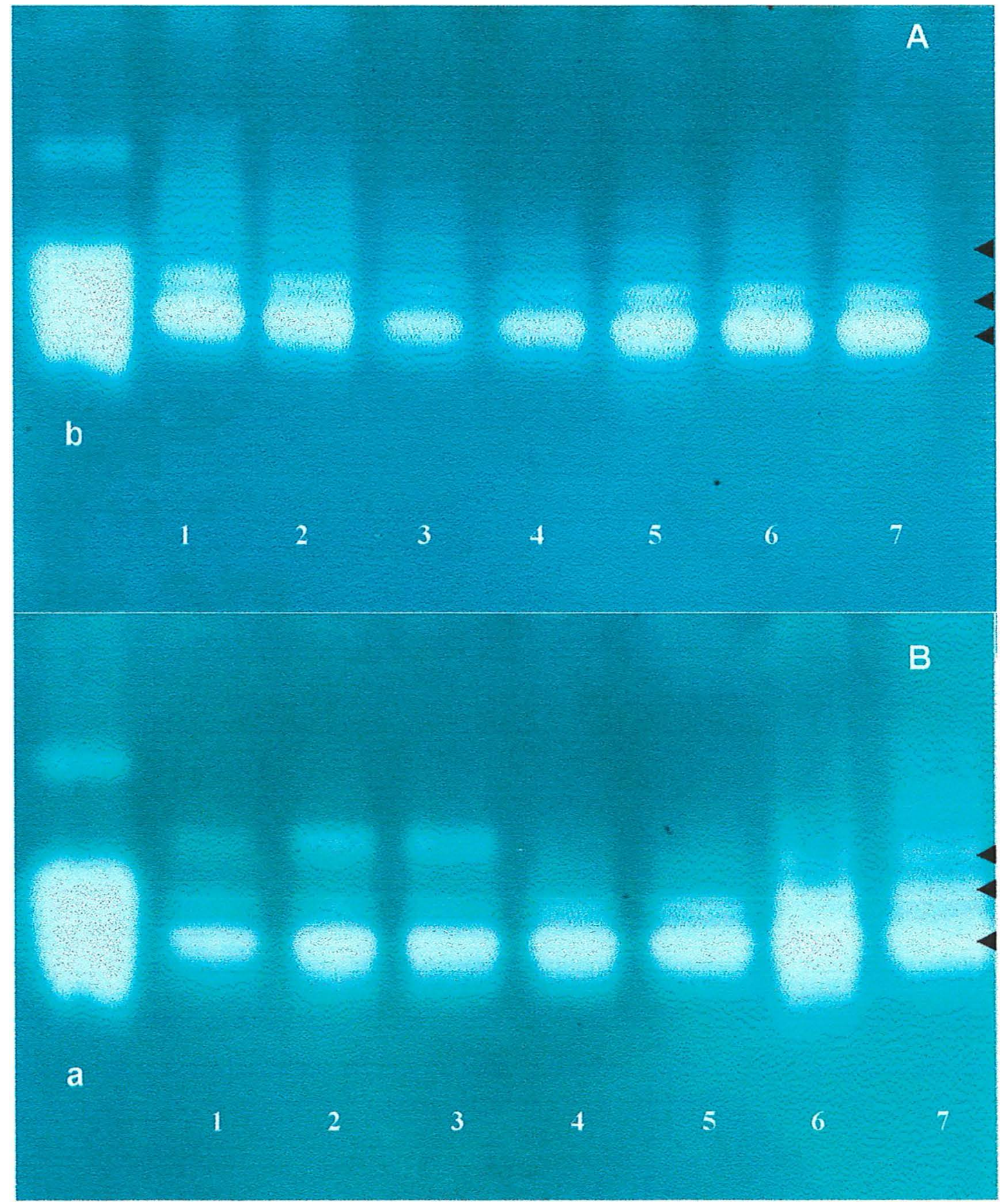

Figura 13. Atividade de CAT determinada em PAGE não desnaturante em calos de cana-de-açúcar submetidos à tratamentos com (A) $0,1 \mathrm{mM}$ e (B) $1,0 \mathrm{mM}$ de $\mathrm{CdCl}_{2}$; (1) Oh (controle) e (2) $12 \mathrm{~h}$, (3) $24 \mathrm{~h}$, (4) $36 \mathrm{~h}$, (5) 4 dias, (6) 9 dias, (7) 14 dias de tratamento; (a) e (b) padrões de CAT bovina; As setas representam isoformas de CAT. 


\subsubsection{Atividade da SOD em PAGE}

Os resultados em PAGE em calos de cana-de-açúcar submetidos a tratamento com $\mathrm{CdCl}_{2}$, mostraram que não houve uma variação na atividade total de isoformas de $\mathrm{SOD}$, nas concentrações de 0,1 mM e 1,0 mM em relação ao controle (Fig. 14). Também pode ser observada a presença de 4 isoformas visíveis.
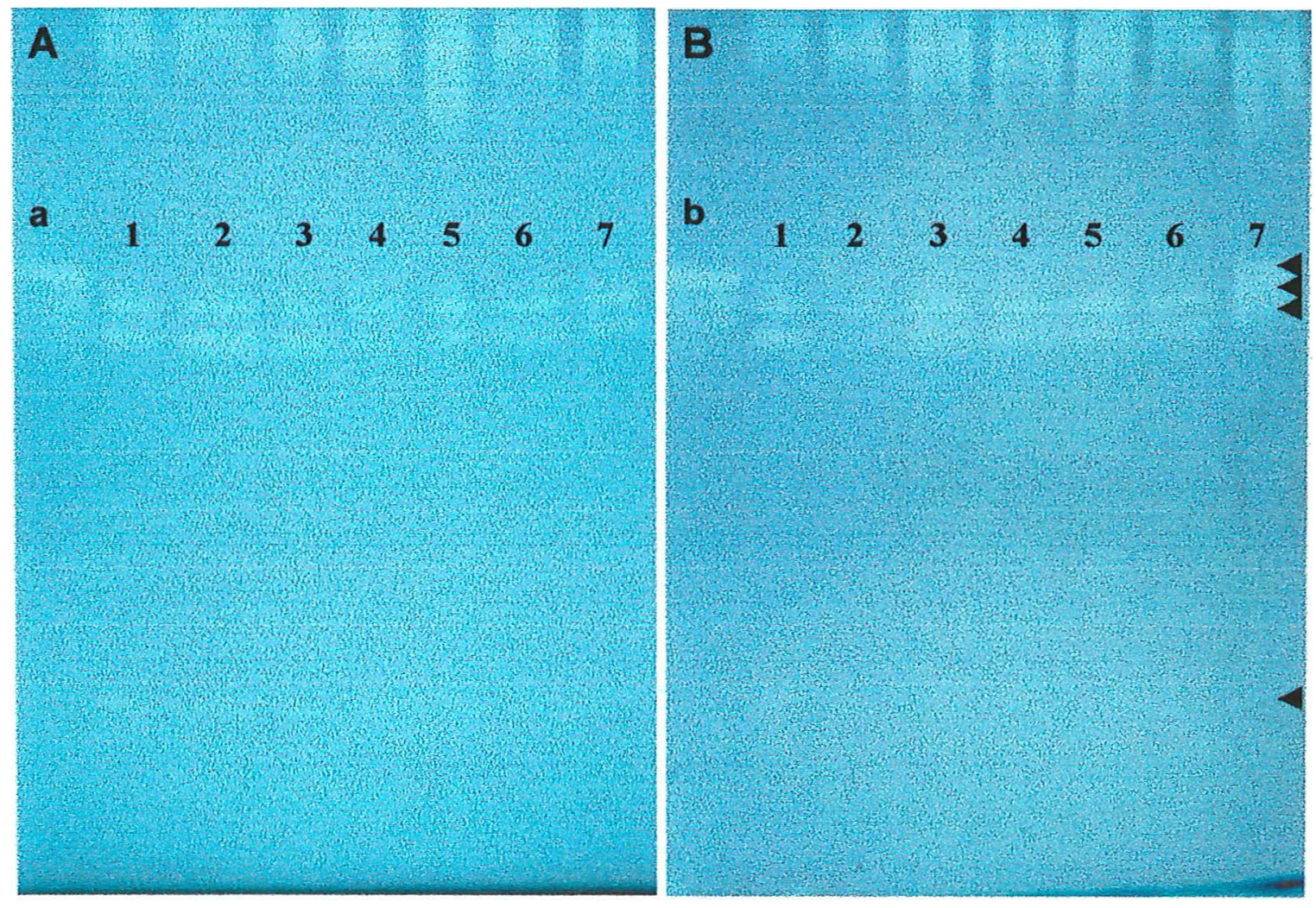

Figura 14. Atividade de SOD determinada em PAGE não-desnaturante, em calos de cana-de-açúcar submetidos a tratamentos com (A) $0,1 \mathrm{mM}$ e (B) $1,0 \mathrm{mM}$ de $\mathrm{CdCl}_{2}$; (1) $0 \mathrm{~h}$, (controle) e (2) $12 \mathrm{~h}$, (3) $24 \mathrm{~h}$, (4) $36 \mathrm{~h}$, (5) 4 dias, (6) 9 dias e (7) 14 dias de tratamento; (a) e (b) padrões de SOD de figado bovino; As setas representam as isoformas de SOD. 


\subsubsection{Cromatografia em camada delgada}

A cromatografia em camada delgada mostrou uma diminuição dos aminoácidos solúveis à partir do $12^{\circ}$ dia de exposição ao $\mathrm{CdCl}_{2}$, nas concentrações de 0,5 e 1,0 mM (Fig. 15).
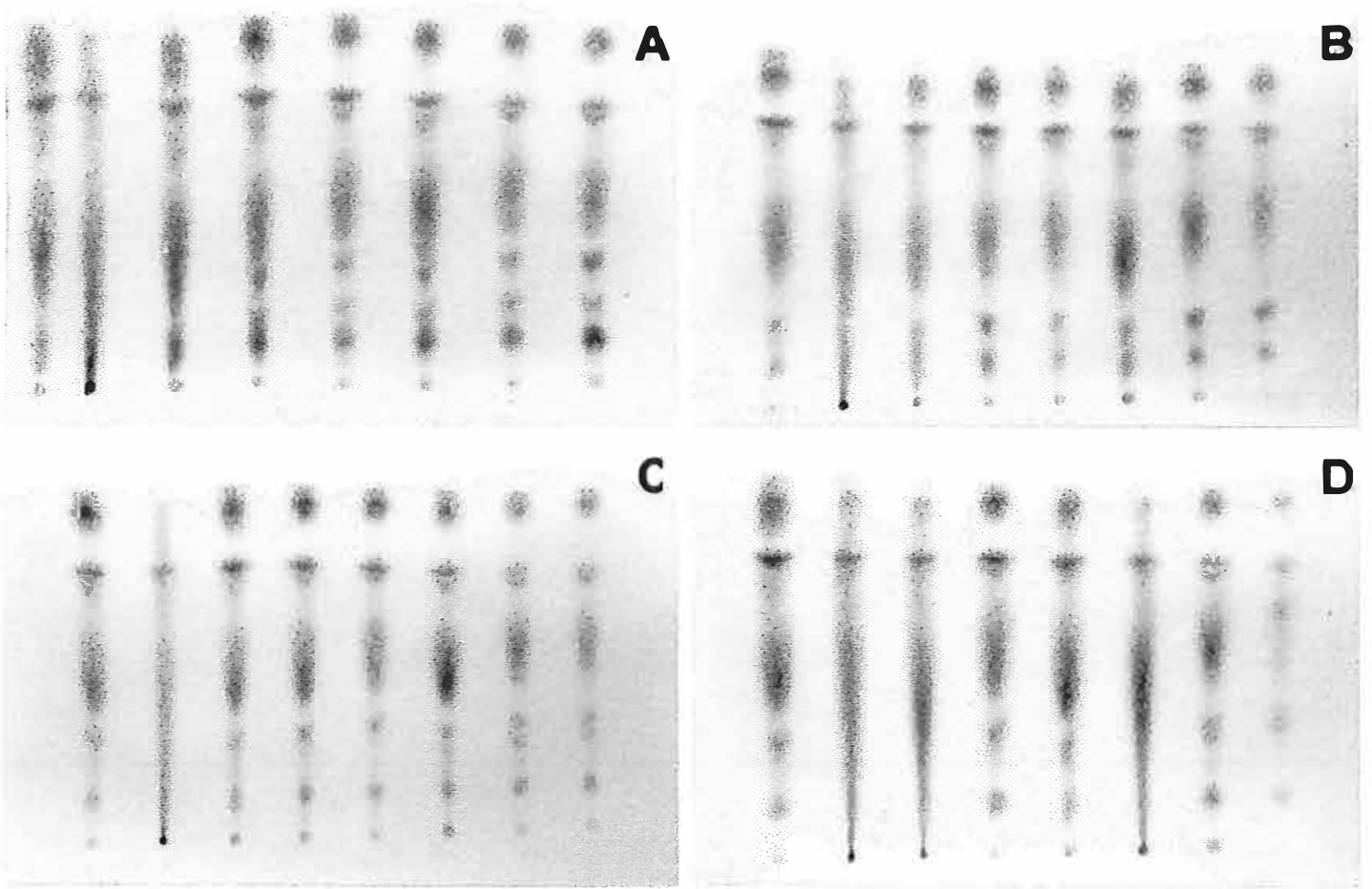

E
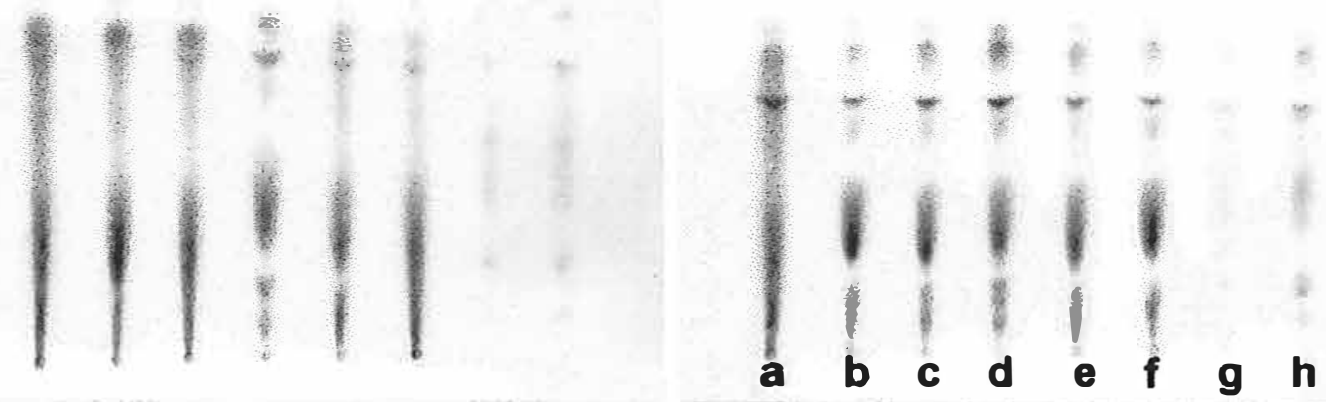

Figura 15. Cromatografia de camada delgada para aminoácidos solúveis de calos de cana-de-açúcar expostas à (a) $0 \mathrm{mM}$, (b) $0,01 \mathrm{mM}$, (c) $0,02 \mathrm{mM}$, (d) $0,05 \mathrm{mM}$, (e) 0,1 mM, (f) 0,2 mM, (g) 0,5 $\mathrm{mM}$ e (h) $1,0 \mathrm{mM}$ de $\mathrm{CdCl}_{2}$, após (A) 3 dias, (B) 6 dias, (C) 9 dias, (D) 12 dias e (F) 18 dias de tratamento. 


\subsection{Caracterização das isoformas de SOD}

A caracterização mostrou a presença de duas isoformas de $\mathrm{Cu} / \mathrm{Zn}-\mathrm{SOD}$ em folhas e de uma isoforma de Mn-SOD presente apenas em calos (Fig. 16). Como pode ser observado em (A), (B) e (C) (Fig. 15), aparecem bandas nessas fatias que foram incubadas em água, solução de $\mathrm{H}_{2} \mathrm{O}_{2}$ e $\mathrm{KCN}$ respectivamente, indicando que a enzima é resistente a esses compostos. Essa é uma característica da Mn-SOD. Já em folhas, duas bandas aparecem apenas em (D), sendo ausentes nas fatias encubadas em $\mathrm{H}_{2} \mathrm{O}_{2}$ e KCN e indicando a presença de enzimas susceptíveis a esses compostos. Essa é uma característica da $\mathrm{Cu} / \mathrm{Zn}-\mathrm{SOD}$.
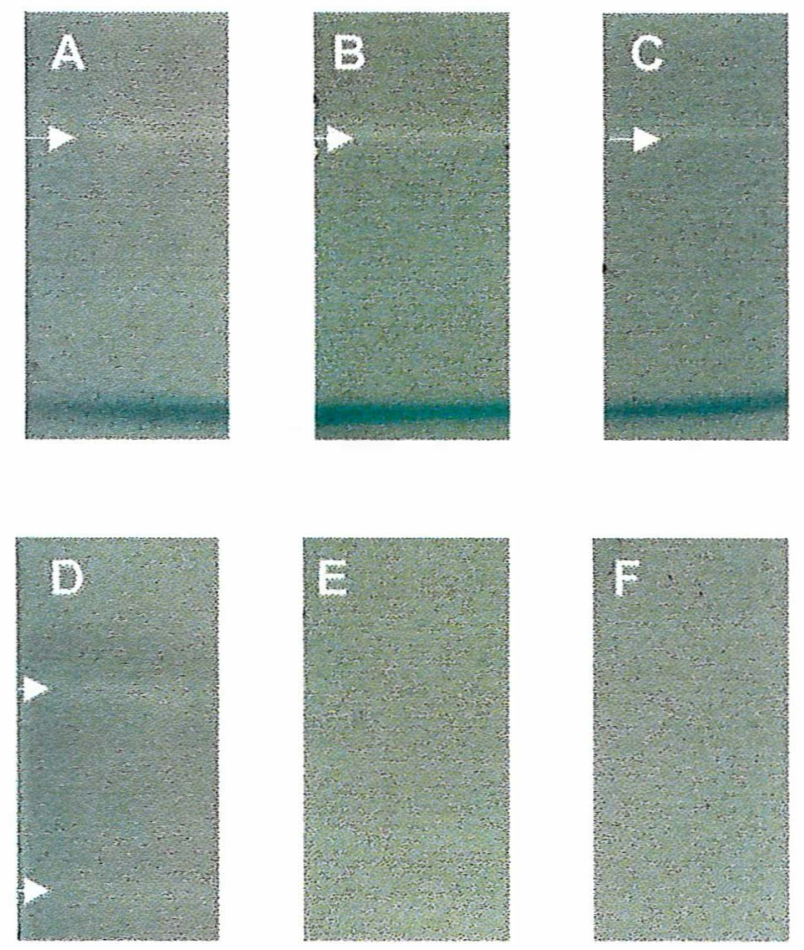

Figura. 16. Isoformas de $\operatorname{SOD}$ em (A, B e C) calos e (D, E, F) plântulas de cana-de-açúcar determinada em PAGE não-desnaturante; (A e D) encubação em água d.d., (B e E) em $\mathrm{H}_{2} \mathrm{O}_{2}$ e $(\mathrm{C}$ e F) em $\mathrm{KCN}$ antes da revelação; As setas em (A), (B) e (C) indicam uma Mn-SOD e em (D) duas Cu/Zn-SOD. 


\section{DISCUSSÃO}

Efeitos drásticos induzidos pela toxicidade do Cd têm sido relatados em organismos vivos (Vitória et al., 2000).

Em plantas, a toxicidade desse metal pode promover diversas alterações no metabolismo, as quais são principalmente resultado da ação de EAOs cuja geração é intensificada sob condições de estresse (Smirnoff, 1993; Prasad, 1995).

A senescência, clorose e coloração marrom avermelhada observada nas folhas podem ser efeitos induzidos pelo $\mathrm{Cd}$. Particularmente os sintomas de clorose podem ser causados por uma carência de Fe devido a competição entre o $\mathrm{Fe}$ e o $\mathrm{Cd}$ por sítios de absorção na membrana plasmática (Foy et al., 1978; Siedlecka e Krupa, 1999). Esses efeitos também foram observados em Alyssum argenteum e Alyssum maritimum (Schickler e Caspi, 1999).

As alterações no crescimento, como constatado na parte aérea em cana-deaçúcar expostas à concentração de $1,0 \mathrm{mM}$ de $\mathrm{Cd}$, são relatadas como característica em plantas submetidas ao estresse por metais pesados, incluindo o $\mathrm{Cd}$ (Lamoreaux \& Chaney, 1977; Barcelo \& Poschenreider, 1990). Esse efeito inibitório também foi observado em várias outras espécies de plantas como arroz (Moya et al., 1993), feijão (Siedlecka \& Krupa, 1996), trigo (Ouzounidou et al., 1997), soja (El Shintinawy, 1999), Silene vulgaris (Sneller et al., 1999), cevada (Boussama et al., 1999) e rabanete (Vitória et al., 2000).

Plantas possuem diversos mecanismos para prevenir ou aliviar os danos causados por EAOs. Esses mecanismos incluem enzimas antioxidantes como SOD, CAT e GR (Alscher \& Hess, 1993; Rao et al., 1996). 
Estudos têm relatado o efeito do Cd na atividade de enzimas antioxidantes em plantas. Diversas isoenzimas de SOD, CAT e GR são encontradas em plantas e seus conteúdos relativos são alterados durante o estresse. A atividade de diferentes enzimas ocorre simultaneamente.

As SODs são enzimas que contém metais e catalisam a dismutação do radical superóxido em $\mathrm{O}_{2}$ e $\mathrm{H}_{2} \mathrm{O}_{2}$ (Matson, 1998), regulando assim, os níveis de $\mathrm{O}_{2}{ }^{\circ-}$ e $\mathrm{H}_{2} \mathrm{O}_{2}$ que são substratos da reação que origina os radicais $\mathrm{OH}^{\bullet}$, representando por isso, o papel central no mecanismo de defesa antioxidante (Alscher et al., 1998). Em plantas existem três formas desta enzima, as quais são classificadas segundo o íon metálico em seu sítio ativo: formas cobre/zinco ( $\mathrm{Cu} / \mathrm{Zn}-\mathrm{SOD}$ ), manganês $(\mathrm{Mn}-\mathrm{SOD})$ e ferro (FeSOD) (Bowler et al., 1994; Chen \& Liu, 1996).

A atividade da SOD, bem como a expressão dos genes que codificam suas isoformas tem mostrado ser alterada sob diversas condições de estresse (Willekens et al., 1995). Esta alteração no padrão de atividade dessa enzima é bastante variável e pode ser dependente da espécie, tecido, fases de desenvolvimento da planta além das próprias particularidades das isoformas (Azevedo et al., 1998).

O padrão de atividade da SOD em cana-de-açúcar não sofreu alterações significativas em plântulas e calos nas concentrações de $\mathrm{CdCl}_{2}$ utilizadas, indicando que provavelmente não houve intensificação na geração de radicais $\mathrm{O}_{2}{ }^{\bullet-}$, ou se houve, a quantidade e nível de atividade das SODs já encontravam-se altos o suficiente para combater os radicais gerados por indução pelo $\mathrm{Cd}$. Foram encontradas até sete isoformas em calos e seis em plântulas. Esse resultado é compatível com resultados já obtidos onde foram encontradas até dez isoformas, sendo que em milho foi relatada a presença de sete isoformas (Giannopolitis \& Ries, 1977). Resultados similares foram mostrados em Lupinus luteus (Gowzdz et al., 1997) e Helianthus annus (Gallego et al., 1999) também em altas concentrações. Foi observada variação específica apenas para uma das isoformas somente na concentração de $5 \mathrm{mM}$. para as demais não houveram variações entre os tratamentos e em relação ao controle suportando a hipótese proposta. 
A CAT é encontrada no citoplasma, mitocôndrias e peroxissomos de células de animais, vegetais e microrganismos aeróbicos, atuando como reguladoras dos níveis de $\mathrm{H}_{2} \mathrm{O}_{2}$, os quais são decompostos em $\mathrm{H}_{2} \mathrm{O}$ e $\mathrm{O}_{2}$ (Scandalios, 1990). São abundantes em glioxissomas de tecidos que armazenam lipídeos, onde decompõem 0 $\mathrm{H}_{2} \mathrm{O}_{2}$ formado durante a $\beta$-oxidação de ácidos graxos (Holtman et al., 1994; Voet \& Voet, 1995), e em peroxissomas de folhas verdes, onde o $\mathrm{H}_{2} \mathrm{O}_{2}$ é produzido durante a fotorrespiração pela conversão do glicolato em glioxilato (Willekens et al., 1997).

Três isoenzimas geneticamente distintas foram caracterizadas em plantas de milho (Scandalios, 1994) e Nicotiana plumbaginifolia (Willekens et al., 1994b), enquanto duas foram identificadas em cevada (Skadsen, 1995). Em Arabidopsis, uma família de multi-genes codifica subunidades individuais que se associam para formar até seis isoformas (Frugoli et al., 1996).

Em folhas de cana-de-açúcar, a diminuição da atividade de CAT na concentração maior ( $5 \mathrm{mM}$ ) está de acordo com os resultados obtidos em feijão (Chaoui, 1997), ervilha (Dalurzo et al., 1997), Lupinus luteus (Gowdz et al., 1997) e girassol (Galego et al., 1999). Na concentração menor $(2 \mathrm{mM})$ a atividade de CAT não sofreu alterações em relação ao controle. Essa diminuição da CAT nas condições experimentais descritas, pode ser devido a uma diminuição na fotossíntese levando a uma menor concentração de $\mathrm{H}_{2} \mathrm{O}_{2}$ nos peroxissomos. A CAT é diretamente regulada pelos níveis de $\mathrm{H}_{2} \mathrm{O}_{2}$ (Polidoros \& Scandálios, 1999). A inalterada da atividade na concentração menor, sugere que pelo menos no período analisado não houveram alterações significativas no processo de geração de $\mathrm{H}_{2} \mathrm{O}_{2}$.

Esses resultados também podem implicar em uma resposta dose dependente e que em altas doses a capacidade das enzimas antioxidantes é diminuída (Gowdz et al., 1997). Em contrapartida resultados obtidos em rabanete mostraram um aumento da CAT (Vitória et al., 2000).

Embora não se tenha quantificado a partição de Cd nos diferentes tecidos, é relatado na literatura que o Cd poder ficar retido de $34 \%$ a $97 \%$ na raiz (Jarvis, 1976). Assim o $\mathrm{Cd}$ também pode ter ficado retido na raiz e a quantidade translocada à parte aérea não ser suficiente para causar uma resposta a nível enzimático. Ainda pode ter 
ocorrido uma barreira para absorção do Cd imposta pelos toletes, os quais também podem ter retido de alguma forma o metal, justificando talvez o efeito tardio do $\mathrm{Cd}$ nas plântulas.

Esses resultados acima citados foram obtidos por espectrofotometria e confirmados em PAGE não-desnaturante.

Em calos o aumento da CAT na concentração de $1,0 \mathrm{mM}$ pode ser associado a uma intensificação dos níveis de $\mathrm{H}_{2} \mathrm{O}_{2}$ a serem convertidos por essa enzima. Nesse tecido a eficiência do ciclo da glutationa-ascorbato pode ter sido menor, e segundo Creissen et al. (1993), essa via é principalmente ativa em cloroplastos. Também pode ter ocorrido uma provável depleção de GSH para síntese de PCs, tomando a célula mais susceptível ao estresse oxidativo sob exposição ao Cd (Jackson et al., 1992; Meuwly \& Rauser, 1992), ou ainda a geração de $\mathrm{H}_{2} \mathrm{O}_{2}$ em outros sítios como os glioxissomos. Assim é sugerido que o $\mathrm{H}_{2} \mathrm{O}_{2}$ gerado deve ser metabolizado principalmente pela CAT, justificando seu aumento.

Os calos foram mais susceptíveis quando comparados às plântulas considerando as doses de $\mathrm{Cd}$ que induziram efeitos na atividade de CAT. De fato o ambiente celular se torna mais oxidante durante o crescimento de calos do que no crescimento normal de plântulas (Dey \& Kar, 1995).

Diversos papéis metabólicos, regulatórios e antioxidativos da GSH, resultam de sua oxidação a GSSG. Para a maioria dessas funções a GSH deve estar em sua forma reduzida. Essa redução é conduzida pela flavoproteína glutationa redutase (GR) em uma reação de oxidação-redução NADPH-dependente da GSSG para GSH (Creissen et al., 1993).

Em plantas, a maior atividade de GR é encontrada em cloroplastos. Em folhas de ervilhas os cloroplastos e mitocôndrias apresentaram $77 \%$ e $3 \%$, respectivamente, do total de atividade da GR, com o restante sendo citosólico (Edwards et al., 1990).

A GSH tem uma afinidade relativamente alta para ligação ao Cd fazendo deste composto um quelante potencial no citosol (Perrim \& Watt, 1971). Evidências sugerem que GSH constitui uma primeira e rápida resposta de defesa contra exposição 
ao Cd e que a tolerância para sustentar a exposição depende da síntese de PCs em plantas (Singhal et al., 1987). Grill et al. (1989) mostrou que as PCs são sintetizadas a partir de GSH. Assim, manter os níveis altos de GSH constitui uma estratégia importante para a síntese de PCs, sendo que para isso, um aumento na atividade da GR se torna necessário.

Resultados similares foram encontrados em folhas de feijão (Chaoui et al., 1997) e girassol (Gallego et al., 1996) submetidos ao Cd.

$\mathrm{O}$ aumento da atividade da GR em cana-de-açúcar nas concentrações de $2 \mathrm{mM}$ e $5 \mathrm{mM}$, pode ter ocorrido para manter altos níveis de GSH nas células para a ligação aos íons de $\mathrm{Cd}$ e (ou) para a síntese de PCs. Entretanto, para a confirmação dessa hipótese é necessário a identifícação da presença de PCs e de complexos GSH-Cd ${ }^{2+}$. Além disso, o tripeptídeo GSH é um dos principais antioxidantes solúveis em plantas (Alscher, 1989) e também pode estar atuando diretamente no $\mathrm{H}_{2} \mathrm{O}_{2}$.

Em relação ao padrão de aminoácidos obtido em calos, a diminuição destes a partir de 12 dias de exposição nas concentrações de 0,5 e 1,0 mM, indicam uma queda no metabolismo, podendo ser início de um processo necrótico, sendo sugerido um efeito secundário do Cd. 


\section{CONCLUSÕES}

1. Considerando as altas concentrações de Cd utilizadas para afetar o desenvolvimento seja de calos ou plantas, em comparação com o relatado na literatura, a cana-deaçúcar é altamente resistente ao metal.

2. Baixas concentrações de Cd estimulam o crescimento de calos de cana-de-açúcar.

3. Em plântulas o mecanismo central mobilizado para minimizar os danos causados pelo Cd e para conter o estresse oxidativo foi a indução do aumento na atividade de GR, provavelmente, para aumentar a síntese de glutationa e consequentemente de fitoquelatinas.

4. Em calos a indução do aumento da atividade de CAT constitui um importante mecanismo de minimização de danos.

5. A cana de açúcar pode constituir um bom modelo para estudos de fitorremediação. 


\section{REFERÊNCIAS BIBLIOGRÁFICAS}

ABLER, M.L.; SCANDALIOS, J.G. Regulation of the cyclic repression of the Cat3 catalase gene in maize leaves and roots occurs via the dark light transition. Maydica, v.39, n.2, p.83-88, 1994.

ALCHE, J.D.; CORPAS, F.J.; RODRIGUEZ-GARCIA, M.I.; DEL RIO, L.A. Identification and immunolocalization of superoxide dismutase isoenzymes of olive pollen. Physiologia Plantarum, v.104, n.4, p.772-776, 1998.

AL-LAHHAM, A.; ROHDE, V.; HEIM, P.; LEUCHTER, R.; VEECK, J.; WUNDERLICH, C.; WOLF, K.; ZIMMERMANN, M. Phytochelatin syntesis: A second role for the glutathione synthetase gene of Schizosaccharomyces pombe. Yeast, v.15, n.5, p.385-396, 1999.

ALLEN, R.D. Dissection of oxidative stress tolerance using trangenic plants. Plant Physiology, v.107, n.4, p.1049-1054, 1995.

ALLOWAY, B.J. The origin of heavy metals in soils. Blackie Academic Professional, London. ISBN 0-7514-0198-6, 1995, p.39-57.

ALSCHER, R.G.; HESS, J.L. Antioxidants in higher plants, CRC Press, Boca Raton, USA, 1993.

ALSCHER, R.G. Biosynthesis and antioxidant function of glutathione in plants. Physiologia Plantarum, v.77, n. 3, p.457-464, 1989.

ANDERSON, M.D.; PRASAD, T.K.; STEWART, C.R. Changes in isozymes profiles of catalase, peroxidase and glutatione reductase during aclimation to chilling in mesocotyls of maize seedlings. Plant Physiology, v.109, n.4, p.1247-1257, 1995.

AONO, M.; KUBO, A.; SAJI, H.; NATORI, T.; TANAKA, K.; KONDO, N. Resistance 
to active oxygen-toxicity of transgenic Nicotiana tabacum that expresses the gene for glutathione-reductase from Escherichia coli. Plant and Cell Physiology, v.32, n.5, p.691-697, 1991.

ARINES, J.; QUINTELA, M.; VILARINO, A.; PALMA, J.M. Protein-patterns and superoxide-dismutase activity in nonmy corrhizal and arbuscular mycorrhizal Pisumsativum L. plants. Plant and Soil, v.166, n.1, p.37-45, 1994.

ASADA, K. Production and action of active oxygen species in photosynthetic Tissue. In: FOYER, C.H.; MULLINEAUX, P.M. (Ed.) Causes of photooxidative stress and amelioration of defence systems in plants. CRC Press, Boca Raton, FL, 1994. p.77-104.

ASADA, K.; TAKAHASHI, M. Productiom and scavenging of active oxygen in photosyntesis. In: KYLE, D.J.; OSMOND, C.B.; ARNTZEN, C.J., (Ed.) Photoinhibition. Elsevier Science Publishers, 1987. p.227-287.

AZEVEDO, R.A.; ALAS, R.M.; SMITH, R.J.; LEA, P.J. Response of antioxidant enzymes to transfer from elevated carbon dioxide to air and ozone fumigationn, in the leaves and roots of wild-tipe and a catalase-deficient mutant of barley. Physiologia Plantarum, v.104, n.2, p.280-292, 1998.

BADENHORST, P.W.; AMORY, A.M.; HUCKETT, B.I. Light regulation of native and Echerichia coli glutathione-reductase in trangenic tobacco. Journal of Plant Physiology, v.152, n.4-5, p.502-509, 1998.

BARCELÓ, J.; POSCHENRIEDER, C. Plant water relations as affected by heavy metals: a review. Journal of Plant Nutrition, v.13, n.1, p.1-37, 1990.

BARCELÓ, J.; VAZQUEZ, M.D.; POSCHENRIEDER, C. Structural and ultrastructural disorders in cadmium treated bush bean (Phaseolus vulgharis L.). New Phytologist, v.108, n.1, p.37-49, 1988.

BHATTACHARJEE, S. Membrane lipid peroxidation, free rtadical scavengers and ethylene evolution in Amaranthus as affected by lead and cadmium. Biologia Plantarum, v.40, n.1, p.131-135, 1998.

BAZZAZ, F.A.; CARLSON, R.W.; ROLFE, G.L. The effect of reavy metals on plants: Inhibition of gas exchange in sunflower by $\mathrm{Pb}, \mathrm{Cd}$ and $\mathrm{Ti}$. Environmental 
Pollution, v.7, n.4, p.241-246, 1974 b.

BIELAWSKI, W.; JOY, K.W. Properties of glutathione reductase from chloroplasts and roots of pea. Phytochemistry, v.25, n.10, p.2261-2265, 1986a.

BLACK, H. Absorbing possibilities: Phytoremediation. Environmental Health Perspectives, v.103, n.12, p.1106-1108, 1995.

BOLDT, R.; SCANDALIOS, J.G. Influence of UV-light on expression of the Cat 2 and Cat3 catalase genes in maize. Free Radical Biology and Medicine, v.23, n.3, p.505-514, 1997.

BOO, Y.C.; JUNG, J. Water deficit- induced oxidative stress and antioxidative defenses in rice plants. Journal of Plant Physiology, v.155, n.2, p.255-261, 1999.

BOUSSAMA, N.; OUARITI, O.; SUZUKI, A.; GHORBAL, M.H. Cd-stress on nitrogen assimilation. Journal of Plant Physiology, v.155, n.3, p.310-317, 1999.

BOWLER, C.; VANCAMP, W.; VANMONTAGU, M.; INZE, D. Superoxidedismutase in plants. Critical Reviews in Plant Sciences, v.13, n.3, p.199-218, 1994.

BOWLER, C.; VAN MONTAGU M.; INZE, D. Superoxide dismutase and stress tolerance. Annual Review of Plant Physiology and Plant Molecular Biology, v.43, p.83-116. 1992.

BREJ, T. Heavy metal tolerance in Agropiron repens (L.) P. Bauv. Populations from the Legnica copper smelter area, Lower Silesia. Acta Societatis Botanicorum Poloniae, v.67, n.3-4, p.325-333, 1998.

BRUMMER, W. Heavy metals species, mobility availability in soils. In BERNHARD, M.; BRINCKMAN, F. E.; SADLER, P.J. Ed. The importance of chemical speciation in environmental processes. Springer-Verlag, Berlin, 1986. p.169192.

CAMPBELL, P.G.C.; LEWIS, A.G.; CHAPMAN, P.M.; CROWDER, A.A.; FLETCHER W.K.; IMBER, C.; LUOMA, S.N.; STOKES, P.M.; WINFREY, M. Biologically available metals in sediments. National Research Council Canadá. $\mathrm{n}^{\circ}$ 27694 Assc.Comm. Sci. Criteria for Env. Qual., 1988. 298p.

CATALDO, D.A.; GARLAND, T.R.; WILDUNG, R.E. Cadmium uptake kinetics in 
intact soybean plants. Plant Physiology, v.73, n.3, p.844-848, 1983.

CHAOUI, A.; MAZHOUDI, S.; GHORGBAL, M.H.; EL FERJANI, E. Cadmium and zinc indution of lipid peroxidation and effects on antioxidants enzyme activities in bean (Phaseolus vulgaris L.). Plant Science, v.127, n.2, p.139-147,1997.

CHAUDRI, A.M.; MCGRATH, S.P.; GILLER, K.E.; RIETZ, E.; SAUERBECK, D.R. Enumeration of indigenous rhizobium-leguminosarum biovar trifolii in soils previously treated with metal-contaminated sewage-sludge. Soil Biology and Biochemistry, v.25, n.3, p.301-309, 1993.

CHEN, J.J.; ZHOU, J.M.; GOLDSBROUGH, P.B. Characterization of phytochelatin synthase from tomato. Physiologia Plantarum, v.101, n.1, p.165-172, 1997.

CHEN, H.Y.; LIU, W.Y. The molecular evolution of superoxide dismutase based on its distribution and structure. Progress in Biochemistry and Biophysics, v.23, n.5, p.408-413, 1996.

CHEN, Y.M.; LUCAS, P.W.; WELLBURN, A.R. Relationship between foliar injury and changes in antioxidant levels in red and Norway spruce exposed to acidic mists. Environmental Pollution, v.69, n.1, p.1-15, 1991.

CHIA, L.S.; MAYFIELD, C.I.; THOMPSON, J.E. Simulated acid rain induceslipid peroxidation and membrane damage in foliage. Plant Cell and Environment, v.7, n.5, p.333-338, 1984.

CHIMENT, J.J.; ALSCHER, R.G.; HUGHES, P.R. Glutathione as an indicator of $\mathrm{SO}_{2}-$ induced stress in soybean. Environmental Experimental Botany, v.26, n.2, p.147$152,1986$.

CHRISTOV. K.; BAKARDJEVA, N.T. Effect of calcium and zinc on subcellular distribution, activity and thermosensitivity of superoxide dismutase in Mnium affine. Biologia Plantarum, v.42, n.1, p.57-63, 1999.

CLEMENS, S.; KIM, E.J.; NEUMANN, D.; SCHROEDER, J.I. Tolerance to toxic metals by a gene family of phytochelatins synthases from plants and yeast. EMBO Journal, v.18, n.12, p.3325-3333, 1999.

COBETT, C.S. A family of phytochelatins synthase genes from plants, fungal and annimal species. Trends in Plant Sciences, v.4, p.335-337, 1999. 
CONKLIN, P.L.; LAST, R.L. Differential accumulation of antioxidant mRNAs in Arabidopsis thaliana exposed to ozone. Plant Physiology, v.109, n.1, p.203-212, 1995.

CORPAS, F.J.; SANDALIO, L.M.; DEL RIO, L.A.; TRELEASE, R.N. Copper-zinc superoxide dismutase is a constituent enzyme of the matrix of peroxisomes in the cotyledons of oilseed plants. New Phytologist, v.138, n.2, p.307-314, 1998.

CORPAS, F.J.; SANDALIO, L.M.; PALMA, J.M.; LEIDI, E.O.; HERNANDEZ, J.A.; SEVILLA, F.; DEL RIO, L.A. Subcellular-distribution of superoxide-dismutase in leaves of ureide-producing leguminous plants. Physiologia Plantarum, v.82, n. 2, p.285-291, 1991.

COSTA, G.; MOREL, J.L. Cadmium uptake by Lupinus albus (L.): cadmium excretion, a possible mechanism of cadmium tolerance. Journal of Plant Nutrition, v.16, n.10, p.1921-1929, 1993.

CREISSEN, G.P.; EDWARDS, E.A.; MULLINEAUX, P.M. Glutatione reductase and ascorbate peroxidase. In: FOYER, C.H.; MULLINEAUX, P.M. (Ed.) Causes of Photooxidative Stress and Amelioration of Defense Systems in Plants. CRC Press Boca Raton, FL. ISBN 0-8493-5443-9, 1994. p 343-364.

CREISSEN, G.P.; REYNOLDS, H.; XUE, Y.B.; MULLINEAUX, P.M. Simultaneous targeting of pea glutathione-reductase and of a bacterial fusion protein to cloroplasts and mitochondria in trangenic tobacco. Plant Journal, v.8, 2, p.167-175, 1995.

CREISSEN, G.P.; BROADBENT, P.; KULAR, B.; REYNOLDS, H.; WELLBURN, A.R.; MULLINEAUX, P.M. Manipulation of glutathione-reductase in transgenic plants-implications for plants responses to environmental-stress. Proceedings of the Royal Society of Edinburgh, Section B - Biological Sciences, v.102, p.167175, 1994.

CREISSEN, G.P.; MULLINEAUX, P.M. Cloning and characterization of glutathionereductase cDNAs and identification of 2 genes encoding the tobacco enzyme. Planta, v.197, n.2, p.422-425, 1995. 
CREISSEN, G.; EDWARDS, E.A.; ENARD, C.; WELBURN, A.; MULLINEAUX, P. Molecular characterization of glutathione-reductase cDNAs from pea (Pisum sativum L.). Plant Journal, v.2, n.1, p.129, 1992.

CUTLER, J.M.; RAINS, D.W. Characterization of cadmium uptake by plant tissue. Plant Physiology, v.54, n.1, p.67-71, 1974.

DALURZO, H.C.; SANDALIO, L.M.; GOMEZ, M.; DEL RIO, L.A. Cadmium infiltration of detached pea leaves. Effect on its activated oxygen metabolism. Phyton-Annales Rei Botanicae, v.37, n.3, p.59-64, 1997.

DE, A.K. Cadmium, the polluter around us. Sci. Rep. v.29, p.19-21, 1992.

DEY, S.K.; KAR, M. Antioxidant efficiency during callus initiation from mature rice. embryo. Plant and Cell Physiology, v.36, n.4, p.543-549, 1995.

DHINDSA, R.S.; PLUMB-DHINDSA, P.; THORPE, T.A. Leaf senescence: correlated with increased levels of membrane permeability and lipid peroxidation, and decreased levels of superoxide dismutase and catalase. Journal of Experimental Botany, v.32, n.126, p.93-101, 1981.

DI CAGNO, R.; GUIDI, L. STEFANI, A.; SOLDATINI, G.F. Effects of cadmiun on growth of Hellianthus annus seedlings: physiological aspects. New Phytologist, v.144, n.1, p.65-71, 1999.

DI TOPPI, L.S.; GABBRIELLI, R. Response to cadmium in higher plants. Environmental and Experimental Botany, v.4 1, n.2, p.105-130, 1999.

DUDKA, S.; MLLER, W.P. Accumulation of potentially toxic elements in plants and transfer to human food chain. Journal of Environmental Science and Health part B-Pesticides Food Contaminants and Agricultural Wastes, v.34, n.4, p.681-708, 1999.

EDWARDS, E.A.; RAWSTHORNE, S.; MULLINEAUX, P.M. Subcellular distribution of multiple forms of glutathione reductase in leaves of pea (Pisum sativum L.). Planta, v.180, n.2, p.278-284, 1990.

EL ENANY, A.E. Glutathione metabolism in soybean callus-culture as affected by salinity. Biologia Plantarum, v.39, n.1, p.35-39, 1997. 
EL-SHINTINAWY, F. Glutathione counteracts the inhibitory effect induced by cadmiun on Photosynthetic process in soybean. Photosynthetica, v.36, n.1-2, p.171-179, 1999.

FERNANDES, J.C.; HENRIQUES, F.S. Biochemical, physiological, and structural effects of excess copper in plants. Botanical Review, v.57, n.3, p.246-273, 1991.

FLORIJN, P.J.; VAN BEUSICHEM, M.L. Uptake and distribution of cadmium in maize inbred lines. Plant and Soil, v.150, n.1, p.25-32, 1993a.

FLORIJN, P.J.; VAN BEUSICHEM, M.L. Phytochelatins concentrations and binding state of $\mathrm{Cd}$ in roots of maize genotypes differing in shoot/root partitioning. Journal of Plant Physiology, v.142, n.1, p.537-542, 1993b.

FOY, C.D.; CHANEY, R.L.; WHITE, M.C. The Physiology of metal toxicity in Plants. Annual Review of Plant Physiology, v.29, p.511-566, 1978.

FOYER, C.H.; LOPEZ-DELGADO, H.; DAT, J.F.; SCOTT, I.M. Hidrogen peroxideand glutathione-associated mechanism of acclimatory stress tolerance and signalling. Physiologia Plantarum, v.100, n.2, p.241-254, 1997.

FOYER, C.H.; LELANDAIS, M.; KUNERT, K.J. Photoxidative stress in plants. Physiologia Plantarum, v.92, n.4, p.696-717, 1994.

FOYER, C.H.; DUJARDYN, M.; LEMOINE, Y. Responses of photosyntesis and the xantophyll cycle and ascorbate-glutathione cycles to changes in irradiance, photoinhiobition and recovery. Plant Physiology and Biochemistry, v.27, n.5, p.751-760, 1989.

FRUGOLI, J.A; MCPEEK, M.A.; THOMAS, T.L.; MCCLUNG, C.R. Intron loss and gain during evolution of the catalase family in Angiosperms. Genetics, v.149, n.1, p.355-365, 1998.

FRUGOLI, J.A.; ZONGH, H.H.; NUCCIO, M.L.; MCCOURT, P.; MCPEEK, M.A.; THOMAS, T.L.; MCCLUNG, C.R. Catalase is encoded by a multigene family in Arabidopsis thaliana (L.) Heynh. Plant Physiology, v.112, n.1, p.327-336, 1996.

FUHRER, J. Ethylene biosintesis and cadmium toxicity in leaf tissue of beans Phaseolus vulgaris L. Plant Physiology, v.70, n.1, p.162-167, 1982. 
GABE, U.; RODELLA, A.A. Trace elements in brazilian agricultural limestones and mineral fertilizers. Communications in Soil Science and Plant Analysis, v.30, n.5-6, p.605-620, 1999.

GABBRIELLI, R.; PANDOLFINI, T.; VERGNANO, O.; PALANDRI, M.R. Comparison of two serpentine species with different nickel tolerance strategies. Plant and Soil, v.122, n.2, p.271-277, 1990.

GALLEGO, S.M.; BENAVÍDES, M.P.; TOMARO, M.L. Effect of reavy metal ion excess on sunflower leaves: evidence for involvment of oxidative stress. Plant Science, v.121, n.2, p.151-159, 1996.

GALEGO, S.M.; BENAVIDES, M.P.; TOMARO, M.L. Oxidative damage caused by cadmium choride in sunflower (Helianthus annuus L.) plants. PhytonInternational Journal of Experimental Botany, v.58, n. 1-2, p.41-52, 1996 b.

GALLEGO, S.M.; BENAVIDES, M.P. ; TOMARO, M.L. Effect of cadmium ions on antioxidant defense system in sunflower cotyledons. Biologia Plantarum, v.42, n.1, p.49-55, 1999.

GALLI, U.; SCHUEPP, H.; BRUNOLD, C. Thiols in cadmium and copper-treated maize (Zea mays L.). Planta, v.198, n.1, p.139-143, 1996.

GIANNOOPOLITS, C.N.; RIES, S.K. Superoxide dismutases. Occurrence in higher plants. Plant Physiology, v.59, p.309-314, 1977.

GARCIA-PLAZAOLA, J.I.; ARTETXE, U.; DUNABEITIA, M.K.; BECERRIL, J.M. Role of photoprotective systems of holm-oak (Quercus ilex) in the adaptation to winter conditions. Journal of Plant Physiology, v.155, n.4-5, p.625-630, 1999.

GREER, S.; PERHAN, R.N. Glutathione-reductase from Echerichia coli: Cloning and sequence analysis of the gene and relationship to other flavoprotein disulphyde oxireductases. Biochemistry, v.25, n.9, p.2736-2742, 1986.

GREGER, M.; JOHANSSON, M.; STHIL, A.; HAMZA, K. Foliar uptake of Cd by pea (Pisum sativum) and sugar beet (Beta vulgaris). Physiologia Plantarum, v.88, n.4, p.563-570, 1993.

GRILL, D.; ESTERBAUER, H.; LÕSCH, U. Effect of sulphur dioxide on glutathione in leaves of plants. Environmental. Pollution, v.19, n.3, p.187-194, 1979. 
GRILL, E.; WINNACKER, E.L.; ZENK, M.H. Phytochelatins - the principal heavy- metal complexing peptides of higher plants. Science, v.230, n.4726, p.674-676, 1985.

GRILL, E.; GEKELER, W.; WINNACKER, E.L.; ZENK, M.H. Homo-phytochelatins are heavy metal-binding peptides of homo-glutathione containing Fabales. FEBS Letters, v.205, n.1, p.47-50, 1986.

GRILL, E.; WINNACKER, E.L.; ZENK, M.H. Phytochelatins a class of heavy metal binding proteins from plants are functionally analagous to metallothioneins. Proceedings of the National Academy of Sciences of the U.S.A., v.84, n.2, p.439-443, 1987.

GRILL, E.; THUMANN, J.; WINNACKER, E.L.; ZENK, M.H. Phytochelatins, the heavy metals binding peptides of plants are synthetised from glutathione by a especific gammaglutamylcysteine dipeptide transpeptidase (phytochelatin syntase) Proceedings of the National Academy of Sciences of the U.S.A., v.86, n.18, p.6838-6842, 1989.

GROTEN, J.P.; VANBLADEREM, P.J. Cadmium bioavailability and healt risk in food. Trends in Food Science \& Technology, v.5, n.2, p.50-55, 1994.

GULLNER, G.; UOTILA, M. Responses of glutathione S-tansferase to cadmium and mercury exposure in pedunculate oak (Quercus robur) leaf discs. Botanica Acta, v.11, n.1, p.62-65, 1998.

GUO, Y.; MARSCHNER, H. Uptake, distribution, and binding of cadmium and nickel in different plant species. Journal of Plant Nutrition, v.18, p.2691-2706, 1995.

GUPTA, S.C.; GOLDSBROUGH, P.B. Phytochelatin accumulation and cadmium tolerance in selected tomato cell lines. Plant Physiology, v.97, n.1, p.306-312, 1991.

GWOZDZ, E.A.; PRZYMUSINSKI, R.; RUCINSKA, R.; DECKERT, J. Plant Cell responses to heavy metals: molecular and physiological aspects. Acta Physiologiae Plantarum, v.19, n.4, p.459-465, 1997.

HA, S.B.; SMITH, A.P.; HOWDEN, R.; DIETRICCH, W.M.; BUGG, S.; O'CONNEL, M.J.; GOLDSBROUGH, P.B.; COBBETT, C.S. Phytochelatin synthase genes from Arabdopsis and Schizosaccharomyces pombe. Plant Cell, v.11, n.6, p.1153-1163, 1999. 
HALliwell, B.; GUTTERIDGE, J.M.C. Free Radicals in Biology and Medicine. Clarendon Press, Oxford, 1989, p.188-266.

HANSON, A.D.; HITZ, W.D. Metabolic responses of mesophytes to plant water deficits. Annual Review of Plant Physiology, v.33, p.163-203, 1982.

HARDIMAN, R.T.; JACOBY, B. Absorption and translocation of Cd in bush bean (Phaseolus vulgaris). Physiologia Plantarum, v.61, n.4, p.670-674, 1984.

HASHIRI, F. Cadmium uptake by plants. Journal of Environmental Quality, v.2, p.93-95, 1973.

HEISS, S.; SHAFER, H.J.; HAAG-KERWER, A.; RAUSCH, T. Cloning sulfur assimilation genes of Brassica juncea L.: cadmium differentially affects the expression of a putative low-affinity sulfate transporter and isoforms of ATP sulfurylase and APS reductase. Plant Molecular Biology, v.39, n.4, p.847-857, 1999.

HERMAN, B.; BICZAK, R.; GURGUL, E. Effect of 1,10-phenanthroline on peroxidase and catalase activity and chlorophyll, sugar and ascorbic acid contents. Biologia Plantarum, v.41, n.4, p.607-611, 1998.

HINKLE, P.M.; KINSELLA, P.A.; OSTERHOUDTH, K.C. Cadmium uptake and toxicity via voltage-sensitive calcium chanels. The Journal of Biological Chemistry, v.262, n.34, p.16333-16337, 1987.

HOAGLAND, D.R.; ARNON, D.I. The water culture method for growing plants without soil. California Agriculture Experimental Station. University of California Berkeley, Circ. 347, 1953.

HOLTMAN, W.L.; HEISTEK, J.C.; MATTER, K.A.; BAKHUIZEN, R.; DOUMA, A.C. $\beta$-Oxidation of fatty acids is linked to the glyoxylate cycle in the aleurone but not in the embryo of germinating barley. Plant Science, v.94, n.1, p.43-53, 1994.

HOMMA, Y. ; HIRATA, H. Kinetics of cadmium and zinc absorption by rice seedling roots. Soil Science and Plant Nutition, v.30, n.4, p.527-532, 1984.

HOWDEN, R.; GOLDSBROUGH, P.B.; ANDERSEN, C.R.; COBBETT, C.S. Cadmium-sensitive, cad I mutants of arabidopsism thaliana are phytochelatin deficient. Plant Physiology, v.107, n.4, p.1059-1066, 1995a. 
HOWDEN, R.; ANDERSEN, C.R.; GOLDSBROUGH, P.B.; COBBETT, C.S. A cadmium-sensitive, glutathione-deficient mutant of Arabidopsis-thaliana. Plant Physiology,v.107, n.4, p.1067-1073, 1995 b.

IRELAND, C.R.; BAKER, N.R.; LONG, S.P. The role of carbon dioxide and oxigen in determining chloropyll fluorescence quenching during leaf development. Planta, v.165, n.4, p.477-485, 1985.

JALIL, A.; SELLES, F.; CLARKE, J.M. Growth and cadmium accumulation in two durum weath cultivars. Communications in Soil Science and Plant Analysis, v.25, n.15-16, p.2597-2611, 1994a.

JALIL, A.; SELLES, F.; CLARKE, J.M. Effect of cadmium of growth and the uptake of cadmium and others elements by durum weath. Journal of Plant Nutrition, v.17, n.11, p.1839-1858, 1994 b.

JARVIS, S.C.; JONES, L.H.P.; HOPPER, M.J. Cadmium uptake from solution by plants and its transport from root to shoot. Plant and Soil, v.44, n.1, p.179-191, 1976.

JIMENEZ, A.; HERNANDEZ, J.A.; DEL RIO, L.A.; SEVILLA, F. Ascorbateglutathione cycle in mitochondria and peroxisomes of pea leaves: Changes induced by leaf senescence. Phyton-Annales Rei Botanicae, v.37, n.3, p.101-107, 1997.

KABATA-PENDIAS, A.; PENDIAS, H. Trace elements in soil and plants, CRC Press, Boca Raton, FL. ISBN 0-8493-6643-7, n.2,1992. p.131-142.

KAMINAKA, H.; MORITAS, S.; NAKAJIMA, M.; MASUMURA, T.; TANAKA, K. Gene cloning and expression of cytosolic g lutathione reductase in rice (Oryza sativa L.). Plant and Cell Physiology, v.39, n.12, p.1269-1280, 1998.

KAMINAKA, H.; MORITA, S.; YOKOI, H.; MASUMURA, T.; TANAKA, K. Molecular cloning and characterization of a cDNA for plastidic copper/zincsuperoxide dismutase in rice (Oryza sativa L). Plant and Cell Physiology, v.38, n.1, p.65-69, 1997.

KANGASJARVI, J.; TALVINEN, J.; UTRIAINEN, M.; KARJALAINEN, R. Plant defence systems induced by ozone . Plant Cell and Environment, v.17, n.7, p.783794, 1994. 
KLAPHECK, S.; FLIEGNER, W.; ZIMMER, I. Hydroxymethyl-phytochelatins [( $\gamma-$ glutamylcysteine $)_{\mathrm{n}}$-serine] are metal-induced peptides of the Poaceae. Plant Physiology, v.104, n.4, p.1325-1332, 1994.

KATO, J.; YAMAHARA, T.; TANAKA, K.; TAKIO, S.; SATOH, T. Characterization of catalase from green algae Chlamydomonas reinhardtii. Journal of Plant Physiology, v.151, n.3, p.262-268, 1997.

KEN, C.F.; SHAW, J.F.; WU, J.L.; LIN, C.T. Molecular cloning of a cDNA coding for copper/zinc superoxide dismutase from zebrafish and its expression in Escherichia coli. Journal of Agricultural and Food Chemistry, v.46, n.7, p.2863-2867, 1998.

KERDNAIMONGKOL, K.; WOODSON, W.R. Inhibition of catalase by antisense RNA increases susceptibility to oxidative stress and chilling injury in transgenic tomato plants. Jounal of the American Society for Horticultural Science, v.124, n.4, p.330-336, 1999.

KESSELER, A.; BRAND, M.D. The mechanism of the stimulation of state 4 respiration by cadmium in potato tuber (Solanum tuberosum) mitochondria. Plant Physiology and Biochesmistry, v.33, n.4, p.519-528, 1995.

KHAN, D.H.; FRANKLAND, B. Effects of cadmium and lead on radish plants with particular reference to movement of metal through soil profile and plant. Plant and Soil, v.70, n.3, p.335-345, 1983.

KIM, Y.K.; KWON, S.I.; AN, C.S. Isolation and characterization of cytosolic copper/zinc superoxide dismutase from Capsicum annuum L. Molecules and Cells, v.7, n.5, p.668-673, 1997.

KNEER, R.; ZENK, M.H. Phytochelatins protect plant enzymes from heavy metal poisoning. Phytochemistry, v.31, n.8, p.2663-2667, 1992.

KOTRBA, P.; MACEK, T.; RUML, T. Heavy metal-binding peptides and proteins in plants. A review. Collection of Czechoslovak Chemical Communications, v.64, n.7, p.1057-1086, 1999.

KOVACS, M.; PODANI, J. Bioindication: A short review on the use of plants as indicators of heavy metals. Acta Biologica Hungarica, v.37, p.19-29, 1986. 
KRAUS, T.E.; EVANS, R.C.; FLETCHER, R.A.; PAUL, S.K.P. Paclobutrazol enhances tolerances to increased levels of UV-B radiation in soybean (Glycine max) seedlings. Canadian Journal Botany, v.73, n.6, p.797-806, 1995.

KRAUSE, G.H.; KODSTER, S.; WONG, S.C. Photoinhibition of photosyntesis under anaerobic conditions studied with leaves and chloroplasts of Spinacia oleracea L.. Planta, v.165, n.3, p.430-438, 1985.

KRUPA, Z. Cadmium-induced changes in the composition and structure of the lightharvesting chorophyll $\mathrm{a} / \mathrm{b}$ protein complex II in radish cotyledons. Physiologia Plantaru m, v.73, n.4, p.518-524, 1988.

KUBO, A.; AONO, M.; NAKAJIMA, N.; SAJI, H.; TANAKA, K.; KONDO, N. Differential responses in activity of antioxidants enzymes to different environmental stresses in Arabidopsis thaliana. Journal of Plant Research, v.112, n.1 107, p.279290, 1999.

KUBO, A.; SANO, T.; SAJI, H.; TANAKA, K.; KONDO, N.; TANAKA, K. Primary structure and properties of glutathione-reductase from Arabdopsis thaliana. Plant and Cell Physiology, v.34, n.8, p.1259-1266, 1993.

KUREPA, J.; HEROUART, D.; VANMONTAGU, M.; INZE, D. Differential expression of $\mathrm{CuZn}$ - and Fe-superoxide dismutase genes of tobacco during development, oxidative stress, and hormonal treatments. Plant and Cell Physiology, v.38, n.4, p.463-470, 1997.

LALL, N.; NIKOLOVA, R.V.; BOSA, A. Changes in isozyme patterns of superóxide dismutase, peróxide and catalase in leaves of Impatiens flanaganiae in response to $\mathrm{Fe}, \mathrm{Mn}, \mathrm{Zn}$, and $\mathrm{Cu}$ deficiencies. Phyton-International Journal of Experimental Botany, v.63, n.1-2, p.147-153, 1998.

LAEMMLI,U.K. Cleavage of structural proteins during the assembly of the head of bacteriophage T4. Nature, v.227, p.680-685, 1970.

LAMOREAUX, R.J.; CHANEY, W.R. Growth and water movement in silver maple seedlings affected by cadmuin. Journal of Environmental Quality, v.6, n.2, p.201-206,1977. 
LAMOREAUX, R.J.; CHANEY, WR. The effect of cadmium on net phothosynthesis transpiration, dark respiration' rate and activities of several enzymes in soybean seedlings. Physiologia Plantarum, v.43, n.3, p.231-236, 1978.

LAMY, I.; BOURGEOIS, S.; BERMOND, A. Soil cadmium mobility as a consequence of sewage sludge disposal. Journal of Environmental Quality, v.22, n.4, p.731737, 1993.

LARSON, R.A. The antioxidants of higher plants. Phytochemistry, v.27, n.4, p.969978, 1988.

LEDERER, B.; KNORZER, O.C.; BOGER, P. Differential gene expression in plants stressed by the peroxidizing herbicide oxyfluorfen. Zeitschrift Fur Naturforschung C-A Journal of Biosciences, v.54, n.9-10, p.764-770, 1999.

LEE, K.C.; CUNNINGHAM, B.A.; PULSEN, B.M.; LIANG, B.H.; MOORE, R.B. Effects of cadmium on respiration rate and activities of several enzymes in soybean seedlings. Physiologia Plantarum, v.36, n.1, p.4-6, 1976.

LEE, H.; JO, J.; SON, D. Molecular cloning na characterization of the gene encoding glutathione rreductase in Brassica campestris. Biochimica et Biophysica Acta Gene Structure and Expression, v.1395, n.3, p.309-314, 1998.

LEE, J.; DAWES, I.W.; ROE, J.H. Isolation, expression and regulation of the pgrl(+) gene encoding glutathione reductase absolutely required for the growth of Scchizosaccaromyces pombe. Journal of Biological Chemistry, v.272, n.37, p.23042-23049, 1997.

LEE, S.; LEUSTEK, T. The affect of cadmium on sulfate assimilation enzymes in Brassica juncea. Plant Science, v.141, p.201-207, 1999.

LEIPNER, J.; FRACHEBOUD, Y.; STAMP, P. Effect of growing season on the photosynthetic apparatus and leaf antioxidative defenses in two maize genotypes of different chilling tolerance. Environmental ond Experimental Botany, v.42, n.2, p.129-139, 1999.

LEOPOLD, I.; GUNTHER, D.; SCHIMIDT, J.; NEUMANN, D. Phytochelatins and heavy metal tolerance. Phytochemistry, v.50, n.8, p.1323-1328, 1999. 
LESHAN, Y.Y. Plant senescence processes and free radicals. Free Radical Biological Medicine, v.5, p.39-49, 1988.

LUBBEN, S.; SAUERBECK, D. Transfer factors and transfer coefficients for heavy metal transfer from soil to plants. In: SAUERBECK, D.; LUBBEN, S. (Ed.) Auswirkinng von Siedlungsabfallen auf Boden, Bodenorganismen und Pflanzen. Berichte aus der Okologischen Forschung, v.6. Forschungszentrum Julich Gmbh., Julich, Germany, 1991.

LUNA, C.M.; GONZALEZ, C. A.; TRIPPI, V.S. Oxidative damage caused by an excess of copper in oat leaves. Plant and Cell Physiology, v.35, n.1, p.11-15, 1994.

MADAMANCHI, N.R.; ANDERSON, J.V.; ALSCHER, R.G.; CRAMER, C.L.; HESS, J.L. Purification of multiple forms of glutathione-reductase from pea (Pisum sativum L.) seedliongs and enzyme levels in ozone fumigated pea leaves. Plant Physiology, v.100, n.1, p.138-145, 1992.

MALAN, C.; GREYLING, M.M.; GRESSE, J.L. Correlation between CuZn superoxide dismutase and glutathione reductase and environmental and xenobiotic stress tolerance in maize inbreds. Plant Science, v.69, n.2, p.157-166, 1990.

MARRS, K.A. The functions and regulation of glutathione S-transferase in plants. Annual Review of Plant Physiology and Molecular Biology, v.47, p.127-158, 1996.

MATTSON, M.P. Answering the old age question. Chemistry \& Industry, v.20, p.843-848, 1998.

MATTIAZO-PREZOTTO, M.E. Comportamento de cobre, cádmio, cromio, níquel e zinco adicionados a solos de clima tropical em diferentes valores de $\mathrm{pH}$. Piracicaba, 1994. 197p. Tese (Livre-Docência) - Escola Superior de Agricultura "Luiz de Queiroz", Universidade de Sào Paulo.

MAZZA, C.A.; BATTISTA, D.; ZIMA, A.M.; SZWARCBERG-BRACCHITTA, M.; GIORDANO, C.V.; ACEVEDO, A.; SCOPEL, A.L.; BALLARE, C.L. The effects of solar ultraviolet $B$ radiation on the growth and yeld of barley are accompained by increased DNA damage and antioxidant responses Plant Cell and Environment, 
v.22, n.1, p.61-70, 1999.

MCBRIDE, M.B. Toxic metal accumulation from agricultural use of sludge: Are USEPA protective? Journal of Environmental Quality, v.24, n.1, p.5 -18, 1995.

MCCORD, J.M.; FRIDOVICH Superoxide dismutases: na enzimatic function for erythrocuprein (hemocuprein). Journal of Biology Chemistry, v.244, p.6049-6055, 1969.

MCGRATH, S.P. Long-term studies of metal transfers following applications of sewage sludge. In: COUGHTREY, P.J., MARTIN, M.H. ; UNSWORTH, M.H. (Ed.) Pollutant transport and fate in ecosystems. Oxford: Blackwell Scientific, 1987, p. 301-317.

MCMAHON, P.J.; ANDERSON, J.W. Preferencial allocation of sulphur into gammaglutamylcysteinyl peptides in wheat plants grow at low sulphur nutrition in the presence od cadmium. Physiologia Plantarum, v.104, n.3, p.440-448, 1998.

MEHRA, R.K.; WINGE, D.R. Metal ion resistance in fungi: Molecular mechanisms and their regulated expression. Journal of Cellular Biochemistry, v.45, n.1, p.3040, 1991.

MELO, W.J.; MARQUES, M.O.; SILVA, F.C.; BOARETTO, A.E. Uso de resíduos sólidos urbanos na agricultura e impactos ambientais. /Apresentado ao XXVI Congresso Brasileiro de Ciência do Solo, Rio de Janeiro, 20-26 de Julho de 1997. $28 \mathrm{p}$.

MEHLHORN, H.; SEUFERT, G.; SCHMIDT, T.A.; KUNERT, K.J. Effects of $\mathrm{SO}_{2}$ and $\mathrm{O}_{3}$ on production of antioxidants in conifers. Plant Physiology, v.82, n.1, p.336338,1986 .

MERRINGTON, G.; AllOWAY, B.J. The flux of $\mathrm{Cd}, \mathrm{Cu}, \mathrm{Pb}$ and $\mathrm{Zn}$ in mining polluted soils. Water Air and Soil Pollution, v.73, n.1-4, p.333-344, 1994.

MIAO, Z.H.; GAYNOR, J.J. Molecular-cloning, characterization and expression of Mn-superoxide dismutase from the rubber tree (Hevea-Brasiliensis). Plant Molecular Biology, v.23, n.2, p.267-277, 1993.

MISHRA, R.K.; SINGHAL, G.S. Function of photosynthetic apparatus of intact wheat leaves and hight light and heat stress and its relationship with peroxidation of 
tylacoid lipids. Plant Physiology, v.98, n.1, p.1-6, 1992.

MISZALSK, Z.; SLESAK, I.; NIEWIADOMSKA, E.; BACZEK-KWINTA, R.; LUTTGE, U.; RATAJCZAK, R. Subcellular localization and stress responses of superoxide dismutase isoforms from leaves in the C3-CAM intermediate halophyte Mesembryanthemum crystallinum L.. Plant Cell and Environment, v.21, n.2, p.169-179, 1998.

MOHAN. B.S.; HOSETTI, B.B. Potential phytotoxicity of lead and cadmium to Lemna minor grown in sewage stabilization ponds. Environmental Pollution, v.98, n.2, p.233-238, 1997.

MORTVEDT, J.J. Heavy metal contaminants in inorganic and organic fertilizers. Fertilizer Research, v.43, n.1-3, p.55-61, 1996.

MOYA, J.L.; ROS, R.; PICAZO, I. Influence of cadmium and nickel on growth, net photosynthesis and carbohydrate distribbution in rice plants. Photosynthesis Research, v.36, n.2, p.75-80, 1993.

MULLINS, G.L.; SOMMERS, L.E. Cadmium and zinc influx characteristics by intact com (Zea mays L.) seedlings. Plant and Soil, v.96, n.2, p.153-164, 1986.

MURAI, R.; MURAI, K. Different transcriptional regulation of cytosolic and plastidic $\mathrm{Cu} / \mathrm{Zn}$-superoxide dismutase genes in Solidago altissima (Asteraceae). Plant Science, v.120, n.1, p.71-79, 1996.

MURASHIGE, T.; SKOOG, F. A revised medium for rapid growth and bio assays with tobacco tissue cultures. Physiol Plantarum, v.15, n.3, p.473, 1962 .

MURASUGI, A.; WADA, C.; HAYASHI, Y. Occurrence of acid-labile in cadmiumbinding peptide 1 from fission yeast. Jou rnal of Biochemistry, v.93, n.2, p.661664, 1983.

NASCIMENTO, C.W.A.; PEREIRA, J.B.M. Uptake and distribution of cadmium and micronutrients by bean cultivars exposed to cadmium levels. Pesquisa Agropecuária Brasileira, v.32, n.12, p.1303-1308, 1997.

NELLESSEN, J.E.; FLETCHER, J.S. Assessment of published literature on the uptake, accumulation and translocation of heavy metals by vascular plants. Chemosphere, v.27, n.9, p.1669-1680, 1993. 
NIYOGI, K.K. Photoprotection revisited: Genetic and Molecular Approaches. Annual Review of Plant Physiology and Plant Molecular Biology, v.50, p.333-359, 1999.

NOCTOR, G.; FOYER, C.H. Ascorbate and glutathione: keeping active oxygen under control. Annual Review of Plant Physiology and Molecular Biology, v.49, p.249-279, 1998.

OBATA, H.; KAWAMURA, S.; SENOO, K.; TANAKA, A. Changes in the level of protein and activity of $\mathrm{Cu} / \mathrm{Zn}$-superoxide dismutase in zinc deficient rice plant, Oryza sativa L. Soil Science and Plant Nutrition, v.45, n.4, p.891-896, 1999.

OGAWA, K.; KANEMATSU, S.; ASADA, K. Intra- and extra-cellular localization of "cytosolic" $\mathrm{Cu}, \mathrm{Zn}$-Superoxide Dismutase in spinach lesf and hypocotyl. Plant and Cell Physiology, v.37, n.6, p.790-799, 1996.

ORNES, W.H.; SAJWAN, K.S. Cadmium accumutation and bioavailability in coonsail (Ceratophyllum demersum L.) plants. Water Air and Soil Pollution, v.69, n.3-4, p.291-300, 1993.

OUZOUNIDOU, G.; MOUSTAKAS, M.; ELEFTHERIOU, E.P. Physiological and ultrastructural effects of cadmium on wheat (Triticum aestivum $\mathrm{L}$ ) leaves. Archives of Environmental Contamination and Toxicology, v., n.2, p.154-160, 1997.

PAGE, A.L.; BINGHAN, F.T.; NELSON, C. Cadmium absorption and growth of various plant species as influencied by solution cadmium concentration. Journal of Environmental Quality, v.1, p.288-292, 1972.

PATRA, J.; PANDA, B.B. A comparison of biochemical responses to oxidative and metal stress in seedlings of barley (Hordeum vulgare L.). Envirommental Pollution, v.101, n.1, p.99-105, 1998.

PETTERSON, O. Differences in cadmium uptake between plant species and cultivars. Swed. J. Agric. Res., v.7, p.21-24, 1977.

PETIT, C.M.; VAN DE GEIJN In vivo measurements of cadmium $\left({ }^{115 \mathrm{~m} C d}\right)$ transport and accumulationin stems of intact tomato plants (Lycopersicon esculentum Mill.). Planta, v.138, n.2, p.137-143, 1978.

POLIDOROS, A.N.; SCANDALIOS, J.G. Role of hidrogen peroxide and different classes of antioxidants in the regulation of catalase and glutathione S-transferase 
gene expression in maize (Zea mays L.). Physiologia Plantarum, v.106, p.112$120,1999$.

POLIDOROS, A.N.; SCANDALIOS, J.G. Circadian expression of the maize catalase Cat3 gene is highly conserved among diverse maize genotypes with structurally different promoters. Genetics, v.149, n.1, p.405-415, 1998.

POSCHENRIEDER, C.; GUNSE, B.; BARCELO, J. Influence of cadmium of water relations, stomatal resistance, and abscisic acid content in expanding bean leaves. Plant Physiology, v.90, p.1365-1371, 1989.

PRASAD, M.N.V. Cadmiun toxicity and tolerance in vascular plants. Environmental Experimental Botany, v.35, n.4, p.525-545, 1995.

RAMALHO, J.C.; CAMPOS, P.S.; TEIXEIRA, M.; NUNES, M.A. Nitrogen dependent changes in antioxidant system and in fatty acid composition of cloroplast membranes from Coffea arabica L. plants submitted to high irradiance. Plant Science, v.135, n.2, p.115-124, 1998.

RAO, M.V.; PALYATH, G.; ORMROD, D. P. Ultraviolet - B and ozone induced biochemical changes in antioxidant enzimes of Arabidops thaliana. Plant Physiology, v.110, p.125-136, 1996.

RASCIO, N.; DALLAVECCHIA, F.D.; FERRETI, M.; MERKO, L.; GHISI, R. Some effects of cadmium on maize plants. Archives of Environmental Contamination and Toxicology, v.25, n.2, p.244-249, 1993.

RAUSER, W.E. Changes in glutathione contens of maize seedlings exposed to cadmium. Plant Science., v.51, n.2-3, p.171-175, 1987.

RAUSER, W.E. Phitochelatins and related pepitides. Structure. Biosynthesis and funcion. Plant Physiology, v.109, n.4, p.1141-1149, 1995.

REBAFKA, F.P., SHULZ, R.; MARSCHNER, H. Investigations of nickel availability in soils containing high geogenic nickel contents. Angewandte Botanik, v.64, n.34, p.317-328, 1990.

RENNENBERG, H. Glutathione metabolism and possible biological roles in higher plants. Phytochemistry, v.21, p.2771-2781, 1982. 
ROBERTS, A.H.C.; LONGHURST, R.D.; BROWN, M.W. Cadmium status of soils, plants and grazing animals in New Zeland. New Zeland Journal of Agricultural Research, v.37, n.1, p.119-129, 1994.

ROBINSON, J.M. Does oxygen photoreduction occur in vivo? Physiologia Plantarum, v.72, n.3, p.666-680, 1988.

RODRIGUEZ-ROSALES, M.P.; KERKEB, L.; BUENO, P.; DONAIRE, J.P. Changes induced by $\mathrm{NaCl}$ in lipid content and composition, lipoxygenase, plasma membrane $\mathrm{H}^{+}$-ATPase and antioxidant enzyme activity of tomato (Lycopersicon esculentum. Mill) calli. Plant Science, v.143, n.2, p.143-150, 1999.

ROY, A.K.; SHARMA, A.; TALUKADER, G. Some aspects of aluminium toxicity in plants. Botanical Review, v.54, n.2, p.145-178, 1988.

ROY, S.; HÃNNINEN, O. Pentachlorophenol: uptake/ elimination kinetics and metabolism in an aquatic plant, Eichhornia crassipes. Environmental Toxicology and Chemistry, v.13, n.5, p.763-773, 1994.

RUEGSEGGER, A.; SCHMUTZ, D.; BRUNOLD, C. Effect of cadmium on $\gamma$ glutamylcysteine synthesis in maize seedlings. Plant Physiology, v.99, n.2, p.428$433,1992$.

SAKAMOTO, A.; OKUMURA, T.; OHSUGA, H.; TANAKA, K. Genomic structure of the gene for copper/zinc-superoxide dismutase in rice. FEBS Letters, v.301, n.2, p.185-189, 1992.

SALT, D.E.; BLAYLOCK, M.; KUMAR, N.P.B.A.; DUSENKOV, V.; ENSLEY, B.D.; CHET, I.; RASKIN, I. Phytorremediation: a novel strategy for the removal of toxic metals from the environment using plants. Bio-Thechnology, v.13, n.5, p.468-474, 1995.

SALT, D.E.; RAUSER, W.E. MgATP-dependent transport of phytochelatins across the tonoplast of oat roots. Plant Physiology, v.107, n.4, p.1293-1301, 1995.

SALT, D.E.; WAGNER, G.J. Cadmium transport across tonoplast of vesicles from oat roots. Journal of Biological Chemistry, v.268, n.17, p.12297-12302, 1993.

SANDMANN, G.; BÕGER, P. Copper-mediated lipid peroxidation processes in photosynthetic membranes. Plant Physiology, v.66, p.797-800, 1980. 
SANDMANN, G.; BOGER, P. The enzimological function of heavy metals and their role in electron transfer processes in plants. In: LAUCHLI, A. ; BIELESKI, R.L (Ed.) Encyclopedia of Plant Physiology. vol 15B: Inorganic Plant Nutrition,. Springer-Verlag, Berlin, 1983. pp.563-596

SANTOS, R.; BOCQUET. S.; PUPPO, A.; TOUATI, D. Characterization of an atypical superoxide dismutase from Sinorhizobium meliloti. Journal of Bacteriology, v.181, n.15, p.4509-4516, 1999.

SATOFUKA, H.; AMANO, S.; ATOMI, H.; TAKAGI, M.; HIRATA, K.; IMANAKA, T. Rapid method for dectection and detoxification of heavy metal ions in water environments using phytochelatin. Journal of Bioscience and Bioengineering, v.88, n.3, p.287-292, 1999.

SCANDALIOS, J.G. Regulation and properties of plant catalases. In: FOYER, C. H. AND MULIUNEAUX, P.M. (Ed.) Causes of Photoxidative Stress and Amelioration of Defense Systems in Plants. CRC Press, Boca Raton, FL. ISBN 08493-5443-9, 1994. pp. 275-315.

SCANDAlios, J.G. Oxygen stress and superoxide dismutases. Plant Physiology, v.101, p.7-12, 1993.

SCANDALIOS, J.G. Response of plant antioxidant defense genes to environmental stress. Advances in Genetics, v.28, n., p.1-41, 1990.

SCHICKLER, H.; CASPI, H. Response of antioxidative enzymes to nickel and cadmium stress in hyperaccumulator plants of the genus Alyssum. Physiologia Plantarum, v.105, n.1, p.39-44, 1999.

SCHLEGEL, H.; GODBOLD, D.L.; HUTTERMANN, A. Whole plant aspects of heavy metal induced changes in $\mathrm{CO} 2$ uptake and water relations of spruce (Picea abies) seedlings. Physiologia Plantarum, v.69, n.2, p.265-270, 1987.

SCRUTTON, N.S.; BERRY, A.; PERHAN, R.N. Redesign of the coenzyme specificity of a dehyrogenase by protein engineering. Nature, v.343, n.6253, p.38, 1990.

SEHMER, L.; DIZENGREMEL, P. Contribution to subcellular localization of superoxide dismutase isoforms of spruce needles and oak leaves. Journal of Plant Physiology, v.53, n.5-6, p.545-551, 1998. 
SHARMA, Y.K.; DAVIS, K.R. Ozone induced expression of stress related genes in Arabidopsis thaliana. Plant Physiology, v. 105, n.11, p.1089-1096, 1994.

SHEORAN, I.S.; SINGAL, H.R.; SING, R. Effect of cadmium and nickel on in vivo carbon dioxid exchange rate of pigeon pea (Cajanus cajan). Photosynthesis Research, V.23, N.3, P.345-351, 1990.

SINGHAL, R.K.; ANDERSON, M.E.; MEISTER, A. Glutathione, a first line of defence against cadmium toxicity. FASEB Journal, v.1, p.220-223, 1987.

SKADSEN, R.W.; SCHUZELEFERT, P.; HERBST, J.M. Molecular cloning, characterization and expression analysis of two catalase isozyme genes in barley. Plant Molecular Biology, v.29, n.5, p. 1005-1014, 1995.

SMEYERS-VERBEKE, J.; DE GRAEVE, M.; FRANCOIS, M.; DE JAEGERE, R.; MASSART, D.L. Cd uptake by intact wheat plants. Plant Cell and Environment, v.1, p.291-296, 1978,

SMIRNOFF, N. The Role of Active oxygen in the response of plants to water deficit and desication. New Phytologist, v.125, n.1, p.27-58, 1993.

SMIRNOFF, N.; CUMBES, Q.J. Hydroxyl radical scavenging activity of compatible solute. Phytochemistry, v.28, n.4, p.1057-1060, 1989.

SMITH, I.K.; VIERHELLER, T.L.; THORNE, C.A. Assay of glutathione reductase incrude tissue-homogenates, using 5.5' DITHIOBIS (2-nitrobenzoic acid). Annalitical Biochemistry, v.125, n.2, p.27-58, 1988.

SNELLER, F.E.C.; NOORDOVER, E.C.M.; TEN BOOKUM, W.M.; SCHAT, H.; BEDAUX, J.J.M.; VERKLEIJ, J.A.C. Quantitative relationship between phytochelatin accumulation and growth inhibition during prolonged exposure to cadmium in Silene vulgaris. Ecotoxicology, v.8, n.3, p.167-175, 1999.

SOMASHEKARAIAH, B.V.; PADMAJA, K.; PRASAD, A.R.K. Phytotoxicity of cadmium ions on germinating seedlings of mung bean (Phaseolus vulgaris) involvment of lipide peroxides in chlorophyll degradation. Physiologia Plantarum, v.85, n.l, p.85-89, 1992.

STEFFENS, J.C. The heavy metals-binding peptides of plants. Annual Review of Plant Physiology and Plant Molecular B iology, v.41, p.553-575, 1990. 
STOBART, A.K.; GRIFFITHS, W.T.; AMEENBUCHARI, J.A.; SHERWOOD, R.P. The effect of $\mathrm{Cd}^{2+}$ on the biosynthesis of chlorophyll in leaves of barley. Physiologia Plantarum, v.63, n.3, p.293-298, 1985.

STREB, P.; FEIERABEND, J. Significance of antioxidants and electron sinks for the cold-hardening-induced resistance of winter rye leaves to photooxidative stress. Plant Cell and Enviromment, v.22, n.10, p.1225-1237, 1999.

STRELLER,S.; WINGSLE, G. Pinus-sylvestris 1 needles contain extracellular $\mathrm{Cu} / \mathrm{Zn}$ superoxide-dismutase. Planta, v.192, n.2, p.195-201, 1994.

STROINSKI, A.; KOZLOWSKA, M. Cadmium-induced oxidative stress in potato tuber. Acta Societatis Botanicorum Poloniae, v.66, n.2, p.189-195, 1997.

TALANOVA, V.V.; TITOV, A.F.; BOEVA, N.P. Effects of cadmium and lead ions on growth and proline na abscisic acid contents in cucumber seedlings. Russian Journal of Plant Physiology, v.46, n.1, p.141-143, 1999.

TAMADDON, F.; HOGLAND, W. Review of cadmium in plastic wast in Sweden Waste Manage Research, v.11, n.4, p.287-295, 1993.

TANAKA, K; TAKIO, S; YAMAMOTO, I; SATOH, T Characterization of a cDNA encoding CuZn-superoxide dismutase from the liverwort Marchantia paleacea var. diptera. Plant and Cell Physiology, v.39, n.2, p.235-240, 1998.

TUTIC, M.; LU, X.; SCHIRMER, R.H.; WERNER, D. Cloning and sequencing of mammalian glutathione reductase cDNA. Europen Journal Biochemistry, v.188, n.3, p.523-528, 1990.

THYGESEN, P.W.; WHELAN, J.; MORELL, M.K.; DAY, D.A. The isolation and characterisation of a gene encoding superoxide dismutase from Bradyrhizobium sp (Parasponia) strain ANU289. Biochemistry and Molecular Biology International, v.37, n.3, p.401-412, 1995.

TYYSTJARVI, E.; RIIKONEN, M.; ARISI, A.C.M.; KETTUNEN, R.; JOUANIN, L.; FOYER, C.H. Photoinhibition of photosystem II in tobacco plants overexpressing glutathione reductase and poplars overexpressing superoxide dismutase. Physiologia Plantarum, v.105, n.3, p.409-416, 1999. 
VAN ASSCHE, F.; CLIJSTERS, H. Effects of metals on enzyme activity in plants. Plant Cell and Environment, v.13, p.195-206, 1990.

VAN CAMP, W.; HEROUART, D.; WILLEKENS, H.; TAKAHASHI, H.; SAITO, K.; VANMONTAGU, M.; INZE, D. Tissue-Specific activity of two manganese superoxide dismutase promoters in transgenic tobacco. Plant Physiology, v.112, n.2, p.525-535, 1996.

VITORIA, A.P.; SMITH, R.J.; LEA, P.J.; AZEVEDO, R.A. Antioxidant enzymes responses to cadmium in radish tissues. Phytochemistry, 2000 (submetido).

VOET, D.; VOET, J.G. Biochemistry, $2^{\mathrm{a}}$ ed. New York; Chichester; Brisbane; Toronto; Singapore: Wiley, 1995. 1361p.

VOGELI-LANGE, R.; WAGNER, G.J. Relationship between cadmium, glutathione and cadmium-binding peptides (phytochelatins) in leaves of intact tobacco seedlings. Plant Science, v.114, n.0, p.11-18, 1996.

WAGNER, G.J. Accumutation of cadmium in crop plants and its consequences to human health. Advances in Agronomy, v.51, p.173-212, 1993.

WILLEKENS, H.; VAN CAMP; W.; VAN MONTAGU, M.; INZÉ, D.; LANGEBARTELS, C.B.; SANDERMANN, H. Ozone, sulphur dioxide, and ultraviolet have similar Effects on mRNA accumulation of antioxidant genes in Nicotiana plumbaginfolia L. Plant Physiology, v.106, p.1007-1014,1994.

WILLEKENS, H.; LANGEBARTELS, C.B.; TIRE, C.; VAN MONTAGU, M.; INZÉ, D.; VAN CAMP, W. Differential expression of catalase genes in Nicotiana plumbaginifolia (L.). Proceedings of the National Academy of Sciences of the United States of America, v.91, n.22, p.10450-10454, 1994a.

WILLEKENS, H.; CHAMNONGPOL, S.; DAVEY, M.; SCHRAUDNER, M.; LANGEBAERTELS, C.; VAN MONTAGU, M.; INZÉ, D.; VAN CAMP, W. Catalase is a sink for $\mathrm{H}_{2} \mathrm{O}_{2}$ and is indispensable for stress defense in $\mathrm{C} 3$ plants. EMBO Journal, v.16, n.16, p.4806-4816, 1997.

WINSTON, G.W. Physicochemical basis for free radical production in cells: production and defenses. In: ALSCHER, R.G.; CUMMING, I.R. (Ed.). Stress responses in plants: adaptation and acclimation mechanisms. New York: 
Wiley-Liss, 1990, p.57-86.

WOOLHOUSE, H.W. Toxicity and tolerance in the responses of plants to metals. In: LANGE, O.L;. NOBEL, P.S.; OSMOND, C.B.; ZIEGLER, H. (Ed.) Encyclopedia of Plant Physiology, v.12 C; Responses to the chemical and biological environment. Springer Verlag, Berlin, 1983. p. 245-300.

XIANG, C.B.; OLIVER, D.J. Glutathione metabolic genes cordinately respond to heavy metals and jasmonic acid in Arabidopsis. Plant Cell, v.10, n.9, p.1539-1550, 1998.

YAMAHARA, T.; SHIONO, T.; SUZUKI, T.; TANAKA, K.; TAKIO, S.; YAMAZAKI, S.; SATOH, T. Isolation of a germin-like protein with manganese superoxide dismutase activity from cells of a moss, Barbula unguiculata. Journal of Biological Chemistry, v.274, n.47, p.33274-33278, 1999.

YANG, X.; BALIGAR, V.C.; MARTENS, D.C.; CLARK, R.B. Influx, transport, and accumulation of cadmium in plant species grown at differnt $\mathrm{Cd} 2+$ activities. Journal of Environmental Science and Health, part- B, v.30, n.4, p.569-583, 1995.

YU, Q.; RENGEL, Z. Drought and salinity differentially influence activities of superoxide dismutases in narrow-leafed lupins. Plant Science, v.142, n.1, p.1-11, 1999.

YU, Q.; OSBORNE, L.D.; RENGEL, Z. Increased tolerance to Mn deficiency in transgenic tobacco overproducing superoxide dismutase. Annals of Botany, v.84, n.4, p.543-547, 1999.

ZHANG, J.X.; CHAY, T.Y.; BURKAKD, G. Research advancves on the mecanisms of heavy metal tolerance in plants. Acta Botanica Sinica, v.41, n.5, p.453-457, 1999. 